\title{
Youth and Digital Citizenship+ (Plus): Understanding Skills for a Digital World
}

\section{Citation}

Cortesi, Sandra, Alexa Hasse, Andres Lombana-Bermudez, Sonia Kim, and Urs Gasser. "Youth and Digital Citizenship+ (Plus): Understanding Skills for a Digital World." Berkman Klein Center for Internet \& Society (2020).

\section{Permanent link}

http://nrs.harvard.edu/urn-3:HUL.InstRepos:42638976

\section{Terms of Use}

This article was downloaded from Harvard University's DASH repository, and is made available under the terms and conditions applicable to Other Posted Material, as set forth at http:// nrs.harvard.edu/urn-3:HUL.InstRepos:dash.current.terms-of-use\#LAA

\section{Share Your Story}

The Harvard community has made this article openly available.

Please share how this access benefits you. Submit a story. 


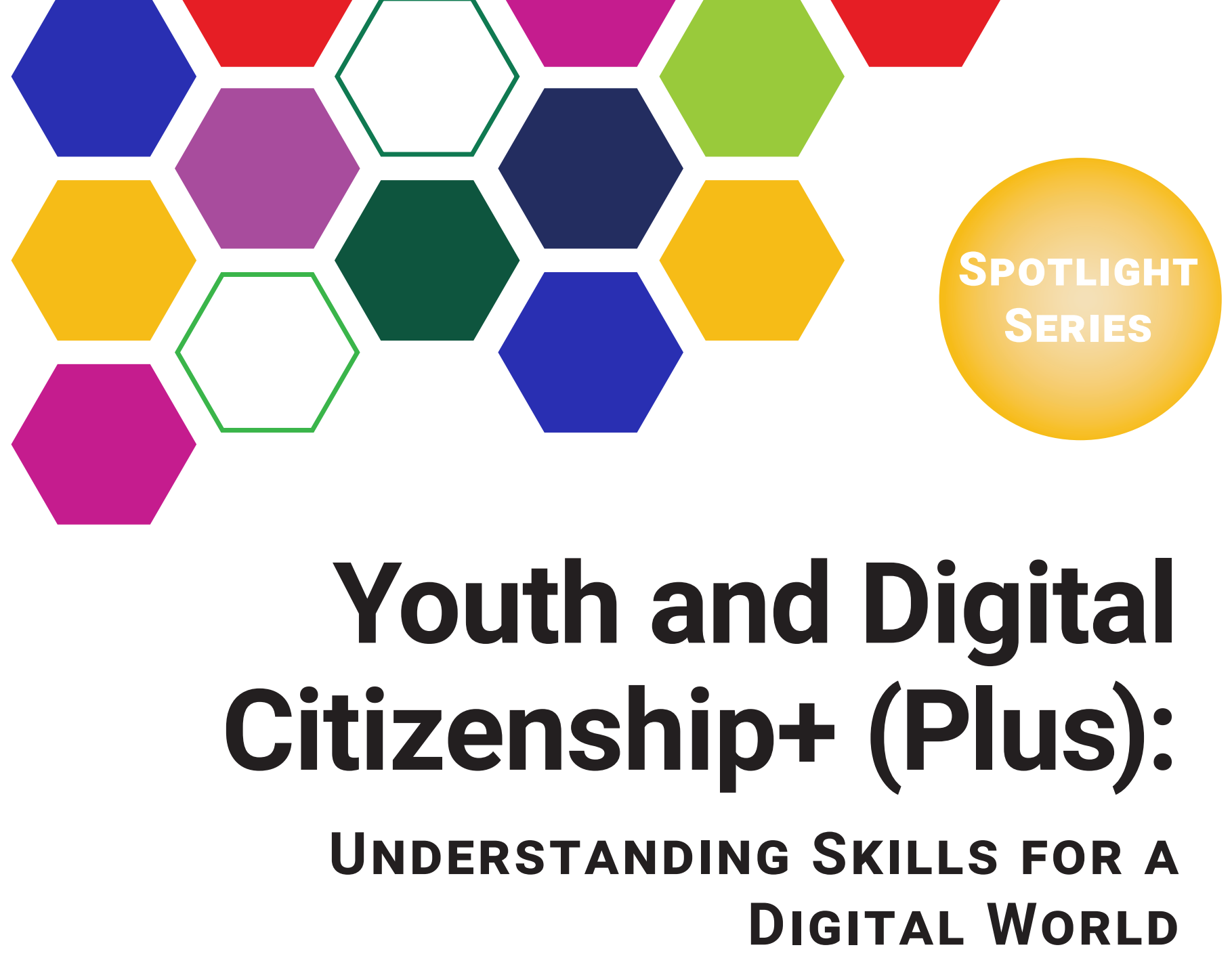

Sandra Cortesi Alexa Hasse Andres Lombana-Bermudez Sonia Kim Urs Gasser

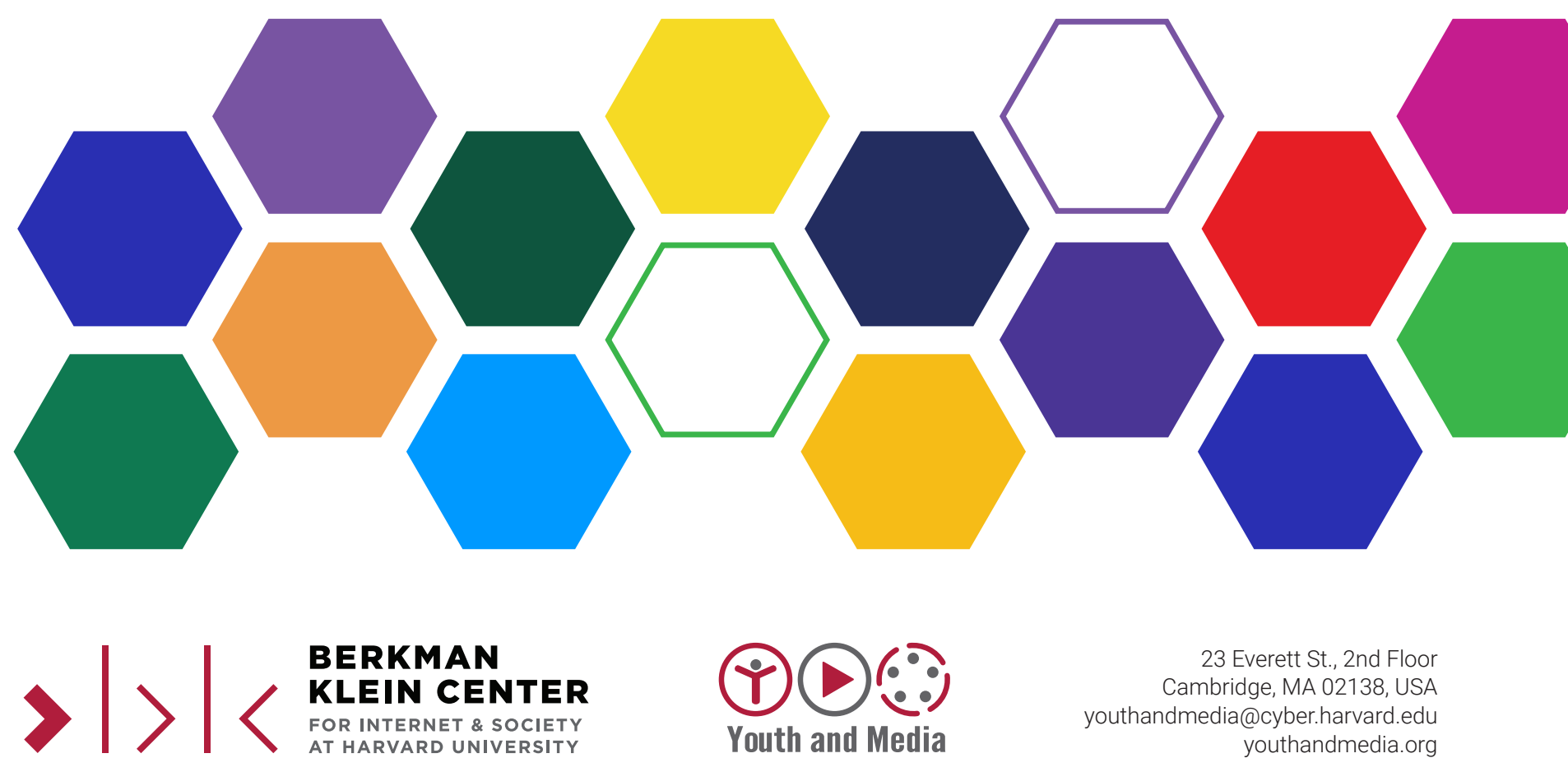




\section{SUGGESTED CITATIONS}

\section{APA}

Cortesi, S., Hasse, A., Lombana-Bermudez, A., Kim, S., \& Gasser, U. (2020). Youth and digital citizenship+ (plus): Understanding skills for a digital world. Youth and Media, Berkman Klein Center for Internet \& Society. Retrieved from https://cyber.harvard.edu/publication/2020/youth-and-digital-citizenship-plus

\section{Chicago (Bibliography)}

Cortesi, Sandra, Alexa Hasse, Andres Lombana-Bermudez, Sonia Kim, and Urs Gasser. "Youth and Digital Citizenship+ (Plus): Understanding Skills for a Digital World," Youth and Media, Berkman Klein Center for Internet \& Society (2020), accessed on [Month Day, Year], https://cyber.harvard.edu/publication/2020/youth-and-digitalcitizenship-plus

\section{Chicago (Footnote)}

Sandra Cortesi, Alexa Hasse, Andres Lombana-Bermudez, Sonia Kim, and Urs Gasser. "Youth and Digital Citizenship+ (Plus): Understanding Skills for a Digital World," Youth and Media, Berkman Klein Center for Internet \& Society (2020), accessed on [Month Day, Year], https://cyber.harvard.edu/publication/2020/youth-and-digitalcitizenship-plus.

\section{MLA}

Cortesi, Sandra, Alexa Hasse, Andres Lombana-Bermudez, Sonia Kim, and Urs Gasser. "Youth and Digital Citizenship+ (Plus): Understanding Skills for a Digital World." Youth and Media, Berkman Klein Center for Internet \& Society, 2020. Web. [Day Mon. Year]. <https://cyber.harvard.edu/publication/2020/youth-and-digitalcitizenship-plus>.

\section{Bluebook}

Sandra Cortesi, Alexa Hasse, Andres Lombana-Bermudez, Sonia Kim, and Urs Gasser. YOUTH AND DIGITAL CITIZENSHIP+ (PLUS): UNDERSTANDING SKILLS FOR A DIGITAL WORLD (2020), available at https://cyber. harvard.edu/publication/2020/youth-and-digital-citizenship-plus

\section{KEYWORDS}

Youth, young people, children, adolescents, teenagers, education, high school, middle school, digital media, new media, Internet, ICT, Web, online, digital citizenship, digital literacy, media literacy, new media literacies, 21 st century skills, digital competence.

\section{PUBLICATION DATE}

March 2020

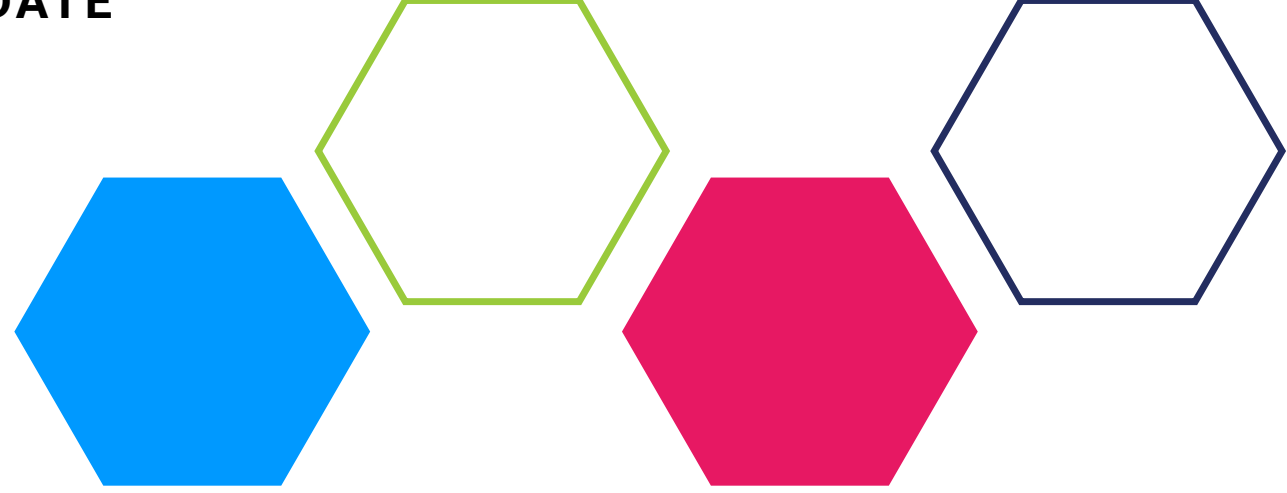




\section{LICENSE}

This work is licensed under a Creative Commons Attribution-ShareAlike 4.0 International (CC BY-SA 4.0) license.

\section{ACKNOWLEDGEMENTS}

We are deeply grateful to all the members of the Berkman Klein Center's Youth and Media team for their support of the project upon which this spotlight is based. We would like to particularly thank visiting researcher Santiago Amador for his visionary thinking at the very beginning of this project and for spearheading - in close collaboration with research assistant Miriam Feldman - the organization of several thoughtful and engaging sessions with Berkman Klein fellows, staff, and summer interns to help construct our team's 17 digital citizenship+ (plus) areas.

We would also like to thank current and former Youth and Media team members, including Michelle Ciccone, Tanvi Kanchinadam, Jackie Kim, Amanda Kraley, Chalene Riser, Nathaniel Talbot, Pedro Maddens Toscano, and Jessi Whitby, as well as former Berkman Klein research assistant Tim Koay and former Berkman Klein project coordinator Amy Zhang for their excellent work in assisting in the review and mapping of the frameworks addressing digital citizenship and similar concepts. We are grateful to Chris Dede, Mariel García-Montes, Renee Hobbs, and Rey Junco for their thoughtful review of draft sections of this publication and their pioneering work in the field. Additionally, we are thankful for Ann Cortissoz's copy editing of this publication.

Thanks also to Sam Daitzman for her artistic vision and development of the visualization mapping 35 frameworks on digital citizenship and related concepts, showcased in part III, section 3 of this paper. Additionally, we would like to thank Rebecca Smith and Claudia Thomas for the inspiration behind the wonderful illustrations integrated in this paper and Alex Edgerly for the creative layout and design of the spotlight.

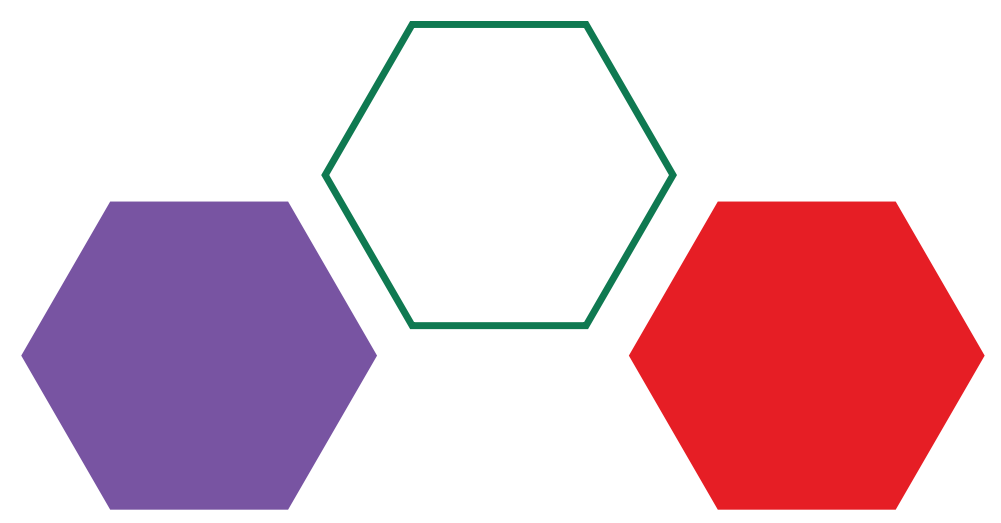




\section{Youth and Digital Citizenship+ (Plus): Understanding Skills for a Digital World}

\section{By Sandra Cortesi, Alexa Hasse, Andres Lombana-Bermudez, Sonia Kim, \& Urs Gasser.}

Digital citizenship has become a topic of growing importance among academics and policymakers alike, at the center of debate and theorization around the skills youth need to navigate and actively participate in our digital world. On a global level, a variety of stakeholders - including government, international organizations, nongovernmental organizations, and academia - have adopted the term to develop and shape formal and informal learning programs that aim to help youth address the challenges and embrace the opportunities the digital environment may present. Yet, there is little consensus as to the broad areas (e.g., safety and well-being, civic and political engagement, identity exploration), and skills within them, digital citizenship should encompass. In this spotlight, Youth and Media explores the concept of digital citizenship, providing an overview of the current dialogue surrounding the term, with a focus on several key questions. Why does digital citizenship matter? Why has the concept become central in discussions about youth (ages 12-18), education, and learning in the 21 st century? In a world where the online and offline are increasingly blending, to what extent should we emphasize the role of the "digital" in "digital citizenship"? To what degree do youth feel connected to the term "citizen?" How is the concept of digital citizenship similar to or different from other concepts, such as digital literacy or 21 st century skills? How should we approach these concepts to more effectively foster the skills youth need to thrive in today's society? And to what extent have we as decision-makers, academics, and educators been successful at incorporating youth voices in the development, implementation, and evaluation of digital citizenship initiatives?

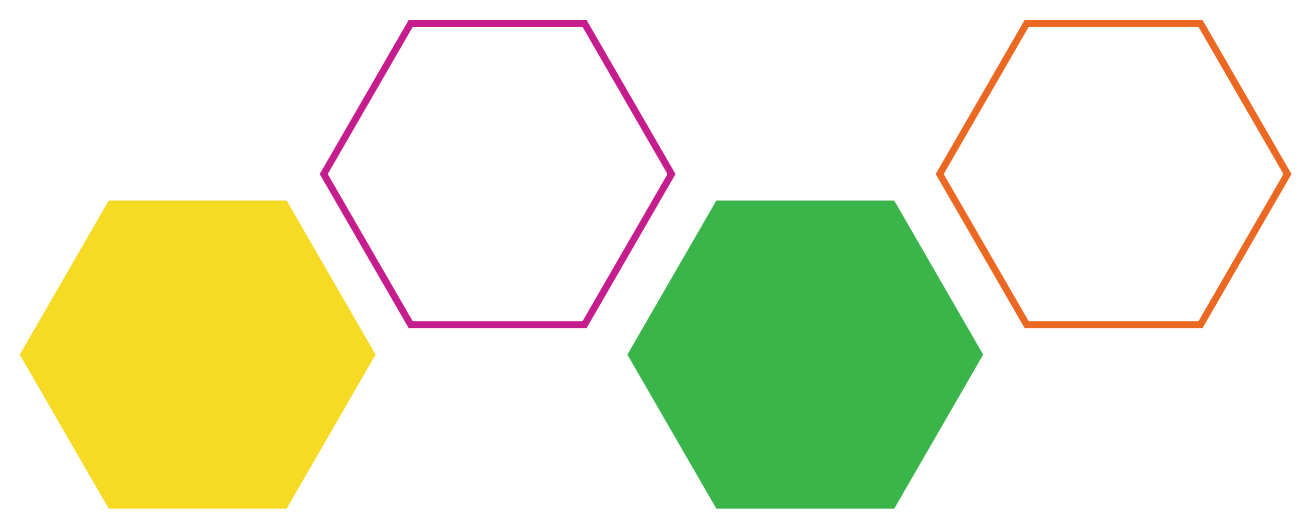




\section{TABLE OF CONTENTS}

0. READER'S GUIDE: CONTEXT AND PURPOSE

I. A CLOSER LOOK AT DIGITAL CITIZENSHIP 9

1. Introduction 9

2. Exploring the Early Landscape of Digital Citizenship 10

3. Digital Citizenship in the Classroom 13

4. Some Complicating Elements $\quad 15$

5. Bound to the Term "Digital Citizenship" 16

6. Why "Digital Citizenship+ (Plus)" 17

II. OTHER CONCEPTS $\quad 19$

$\begin{array}{ll}\text { 1. Digital Literacy } & 19\end{array}$

2. Media Literacy and New Media Literacies 22

3. 21st Century Skills 23

4. Digital Competence $\quad 24$

\section{MAPPING OF DIGITAL CITIZENSHIP FRAMEWORKS 26}

1. The Mapping Process and Creation of Digital Citizenship+ (Plus) 26

2. The 17 Areas That Currently Constitute Digital Citizenship+ (Plus) 28

The Areas Applied in a School Context 31

The Areas in Sets of Educational Tools 32

A Possible Grouping 33

3. A Visualization of Our Findings Within the 35 Frameworks 34 


\section{CONSIDERATIONS}

1. Understanding of the Lens and Connected Terms

2. Recognizing the Interconnectedness of Areas

3. Being Mindful of Context

4. Choosing a More Balanced Approach

5. Involving Youth

6. Assessing Framework Efficacy

V. LOOKING AHEAD: UNDEREXPLORED AREAS

1. Data

2. Computational Thinking

3. Artificial Intelligence

VI. SUPPLEMENTARY MATERIALS

1. Demographic Factors and Differing Experiences 


\section{O. READER'S GUIDE: CONTEXT AND PURPOSE}

Over the last five years, the Youth and Media (YaM) team at the Berkman Klein Center for Internet \& Society at Harvard University has engaged in and supported numerous efforts related to youth (ages 12-18) ${ }^{1}$, digital technologies, and learning. Some of these efforts included traditional research, while others were more focused on education and community building. ${ }^{2}$

Throughout the years, but recently with more frequency, individuals from various sectors (government, international organizations, nongovernmental organizations (NGOs), and academia) have come to us with questions such as "How do you define media literacy and how do you think it's different from information or news literacy?," "Is there a difference between 'digital citizenship' and 'digital literacy?," "Do these two concepts address the same skills?," and "Is the focus of digital citizenship civics, safety, or something else?" Concurrently, YaM has been developing a significant number of educational resources empowering young people in the digital world. We wanted to better understand if these educational resources are in fact addressing the topics most relevant to youth or whether there are gaps that we need to close. Taken together, these conceptual and practical questions motivated us to pause and take stock of the status of the vibrant and at times fragmented debate about digital citizenship, literacies, skills, competencies and related terms and concepts, with the goal to come up with a clearer understanding of the current landscape and translate the findings from such a stock-taking into a set of actionable take-aways that would inform our collective work in this thematic area.

This spotlight captures what we have learned in this review and contains six key parts that highlight the evolving discourse around what we capture under the umbrella term "digital citizenship" (more on terminology momentarily) and considerations related to the development and deployment of this concept. We hope this snapshot is helpful to a diverse group of readers including policymakers, educators, parents or caregivers, or people involved in the development of a digital citizenship framework or any related concept.

In part I, we explain why we use "digital citizenship" as an anchoring concept. We first offer readers a brief overview of the youth and media discussion trajectory. We then explore various ways digital citizenship has been conceptualized by scholars in the field and applied in formal educational settings around the world. Next, we examine the benefits and drawbacks of this term from an objective and subjective lens. From this discussion, we propose the modified term "digital citizenship+ (plus)" (which we expand as a framework in part III of this spotlight) and our rationale behind it.

' People use a variety of terms to refer to youth, such as: "youth," "young people," "minors," "children," "younger children and older children," "preadolescents," "adolescents," "teens," "teenagers," "younger teenagers and older teenagers," and "older youth." We have adopted the convention of referring to all legal minors (generally, individuals under the age of 18 in U.S. law) as "youth." We choose to follow the institutional category of minors because of its common social and legal aspects (e.g., legal adulthood - when parents lose parenting rights and responsibilities regarding the person concerned, most common voting age). For more information, please see Youth and Digital Media: From Credibility to Information Quality. 
In part II, we turn our attention to concepts related to digital citizenship that address young people's skill development in the context of digital media. Much like digital citizenship, each of these concepts digital literacy, media literacy, new media literacies, 21st century skills, and digital competence are typically associated with frameworks and accompanying learning materials that aim to help individuals address the challenges and embrace the opportunities associated with our digital world. We envision that this section will provide readers with an understanding of some of the general ideas included in each of these concepts, while also acknowledging that the overall landscape of these concepts is quite complex. Many of the frameworks within a given concept diverge in terms of the skills they address. There is also a great deal of overlap among skills when looking across these concepts.

While we have decided to introduce and use the term "digital citizenship+ (plus)," we want to be mindful of how others in government, international organizations, NGOs, and academia have created and applied their own frameworks around digital citizenship and its related skills. In part III, we describe the process by which we mapped a set of $\mathbf{3 5}$ frameworks (illustrated in a visualization) that address digital citizenship or other concepts, such as media literacy or online safety. We then showcase the results from this mapping exercise the 17 areas of life in our digital citizenship+ (plus) framework, which we propose future frameworks on digital citizenship, and similar concepts, should address. Additionally, we suggest a possible way to group these 17 areas, as well as how these areas might be applied in practice, particularly within the educational space.

In part IV, we offer several observations and considerations, based on the mapping process described in part III, that may be helpful in the development and deployment of frameworks addressing digital citizenship or a related concept. These considerations concern 1) the specific term(s) one uses to describe how an individual masters an area of life related to the digital world (e.g., skills, literacies, abilities, etc.) and how the term(s) relates to the overall goal of the framework; 2) the interconnected nature of areas of life related to the digital environment; 3) the importance of contextual factors of relevance - such as age, ethnicity, race, gender and sexual identity, religion, national origin, location, skill and educational level, and/or socioeconomic status - in how frameworks are conceptualized and applied; 4) the value of approaching digital citizenship in a balanced manner that accounts for both the challenges and the opportunities youth encounter online; 5) the inclusion of youth in developing frameworks and examples of forms this participation may take; and 6) the importance of actionable efficacy data.

In part $\mathbf{V}$, we narrow our focus in on three specific areas of life that we noticed were rarely explicitly included in the frameworks we explored in our mapping exercise detailed in part III: data, computational thinking, and artificial intelligence. In this part $V$, we explore formal and informal educational initiatives around each of these three areas in the hopes of fostering additional dialogue around how the areas can be further incorporated into digital citizenship efforts.

Finally, in part VI, we feature two supplementary reading materials. First, we discuss how young people's access to and experiences with using digital technologies vary by demographic factors including gender, socioeconomic status, and race. Then - connecting gender with reflections around the underexplored areas of life detailed in part Vwe present a brief overview of the gender gap in computer science. More specifically, we explore the computer science gender landscape both in and outside of the U.S. and describe some of the driving social and cultural forces that have contributed to the gender imbalance in this field, with a focus on the U.S. The section concludes by presenting formal and informal educational initiatives around the world that are working to address the gender gap in computer science. 


\section{A CLOSER LOOK AT DIGITAL CITIZENSHIP}

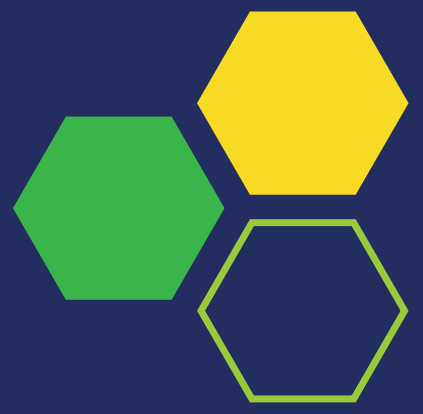

Many different terms and concepts are used to describe, frame, and categorize the various skills that help youth make better use of digital technologies. For the purpose of this report, we decided to focus on the concept of digital citizenship. We wrote this part I to share the factors that have shaped this decision and the elements that continue to influence our thinking in this space. To provide context, section 1 begins with a brief overview of the youth and media discussion trajectory. In section 2, we present different theoretical conceptions of digital citizenship, starting with early definitions of the concept. In section 3, we discuss how digital citizenship has been applied in the formal educational context in regions around the world. In section 4, we hope to convey why, given the adult-normative discourse around youth and citizenship, among other factors, we struggle with the term "digital citizenship." In section 5, we describe why, in light of developments within formal and informal learning spaces, we have chosen to focus on digital citizenship. Finally, in section 6 , we introduce our rationale for constructively tweaking "digital citizenship" and reframing the concept as "digital citizenship+ (plus)."

\section{INTRODUCTION}

For many of today's youth, the use of digital technologies has increasingly become a routine part of their daily lives. The growing prevalence, use, and agency of digital technologies has changed how young people socialize, communicate, play, and learn. These technologies have opened up a variety of ways for youth to participate (e.g., through video remixes or memes), create and innovate, and interact with those from different cultures and communities.

Initially, much of the public conversation around youth and digital technologies centered on assessing and understanding the risks and potential harms digital technologies may pose (e.g., Barbosa, 2014; Byrne, Kardefelt-Winther, Livingstone, \& Stoilova, 2016; Gasser, Cortesi, \& Gerlach, 2012; Hinduja \& Patchin, 2009; Jones, Mitchell, \& Finkelhor, 2013; Lenhart, Madden, Smith, Purcell, \& Zickuhr, 2011; Levy et al., 2012; Livingstone, Haddon, Görzig, \& Ólafsson, 2011; O’Neill, Staksrud, \& McLaughlin, 2013; Palfrey, boyd, \& Sacco, 2010; Ybarra, boyd, Korchmaros, \& Oppenheim, 2012).

This stance was later supplemented by a dialogue around the potential opportunities associated with young people's use of digital media (e.g., Banaji \& Buckingham, 2013; Benkler, 2006; boyd, 2014; Brennan \& Resnick, 2013; Cobo et al., 2018; Gasser, Cortesi, Malik, \& Lee, 2012; Gray, 2009; Ito et al., 2008; Ito et al., 2010; James, 2014; Jenkins, 2019; Jenkins, Clinton, Purushotma, Robison, \& Weigel, 2006; Jenkins, Ford, \& Green, 2013; Jenkins, Ito, \& boyd, 2015; Livingstone, Mascheroni, \& Staksrud, 2015; Palfrey \& Gasser, 2008; Rideout, 2015). 
During approximately the last seven years, the predominantly risk-oriented policy conversation has turned into an increasingly holistic debate about the challenges and opportunities of digital technologies for youth and their interests (Gasser \& Cortesi, 2017; Kleine, Hollow, \& Poveda, 2014; Livingstone \& Bulger, 2013; Palfrey \& Gasser, 2016; Third, Bellerose, Dawkins, Keltie, \& Pihl, 2014; Third, Bellerose, Diniz De Oliveira, Lala, \& Theakstone, 2017; United Nations Children's Fund [UNICEF], 2017). This evolving dialogue aims to consider the Internet access conditions youth face, their level of agency when using digital technologies, their degree of experience using these technologies, their rights and responsibilities, the types of activities youth engage in, and how they do so in creative, meaningful, ethical, responsible, and participatory ways.

In parallel with the study of challenges and opportunities youth have been and still are encountering in the digital environment, different stakeholders - including those in government, international organizations, NGOs, and academia have looked more closely at the skills that help youth make better use of digital technologies. Concepts such as digital citizenship, digital literacy, and new media literacies have been used to group these skills, as well as organize them under educational programs that can be implemented in formal, informal, and connected learning environments.

\section{EXPLORING THE EARLY LANDSCAPE OF DIGITAL CITIZENSHIP}

In our rapidly evolving digital world, the notion of what it means to be a "citizen" and a "digital citizen" have become topics of increasing importance among both academics and policymakers. Despite the growing discussion around digital citizenship in research and governance, there is little consensus as to how this concept is defined. In this part I, section 2, we aim to showcase various ways "digital citizenship" has been conceptualized, starting with early definitions of the concept. These conceptions range from those that focus on the technological facets to those that explore the opportunities digital technologies may offer in supporting new forms of citizenship (Gleason \& von Gillern, 2018).

Against the backdrop of the growing use of the Internet and digital technologies in the late 20th and early 21 st centuries, an initial conception of digital citizenship was put forth in 2004 by educational technology consultant Mike Ribble. Digital citizenship was defined as "the norms of behavior with regard to technology use" (e.g., how to safeguard one's physical health in the context of technology use (e.g., mitigating eyestrain), how to protect the integrity of one's information and digital devices, and how to buy and/or sell goods online) (Ribble, Bailey, \& Ross, 2004, p. 7). Later, in 2007, Ribble and co-author Gerald Bailey released Digital Citizenship in Schools, providing a set of professional development resources geared towards teachers, school staff, and administrators to help them better understand digital citizenship and how to incorporate this concept in a school or district. The book also offers lesson plans to guide teachers in implementing digital citizenship within the classroom. That same year, the International Society for Technology in Education (ISTE) - a nonprofit dedicated to educators interested in integrating technology in education - incorporated the term "digital citizenship" in the refresh of their 1998 National Educational Technology Standards

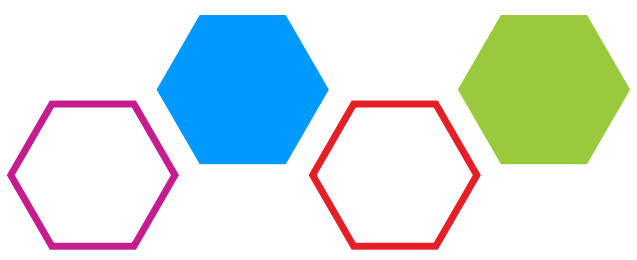


(NETS) for Students. The 2007 digital citizenship standard called upon students to "understand human, cultural, and societal issues related to technology and practice legal and ethical behavior" in the digital environment (ISTE, 2007, p. 2). This normative view of digital citizenship focuses on helping young people understand the values and norms around responsible and appropriate use of digital technologies. ${ }^{4}$ According to this perspective, put forth by Ribble and ISTE, educators cultivate youth's digital citizenship by, for example, teaching young people how to understand and apply legal concepts to the content they share, manage their online security, and assess the credibility of information online.

A different early model of digital citizenship defines the concept within the context of economic and political participation in society. According to Mossberger, Tolbert, and McNeal (2007), digital citizens are those "who use the Internet regularly and effectively - that is, on a daily basis" (p. 1). "Effective" Internet use not only implies daily Internet use, but the technical competence to use digital technologies (e.g., knowing how to use computer hardware and software) and possessing the skills to find, understand, evaluate, and use information in the digital environment. In turn, regular and effective Internet use helps an individual participate in society, economically and politically. More specifically, digital citizens use the Internet "at work for economic gain" and "for political information to fulfill their civic duty" (Mossberger et al., 2007, p. 2). In this context, Mossberger and colleagues' (2007) research, drawing upon nationally representative surveys of adults in the U.S., examined the association between their definition of effective Internet use and factors such as wages and income, civic engagement (i.e., political knowledge, interest, and online discussion), and political participation (i.e., voting). While Mossberger et al. (2007) focus their research on the adult population, they note the importance of preparing youth to become digital citizens through 1) access to digital technologies, and 2) public school education that helps promote both the technical skills to use digital technologies and the ability to find and critically engage with information online.

Another approach to digital citizenship examines how - primarily in response to social and economic shifts ${ }^{5}$ largely occurring in industrialized democracies and the growing use of digital technologies - young people today are engaging with civics and politics in ways different from the notion of citizenship characteristic of previous generations (Bennett, 2008; Dalton, 2008; Kahne, Lee, \& Feezell, 2012). According to this perspective, what is often viewed as a lack of civic and political engagement among youth might instead be due to a shift in the type of citizenship youth are embracing, from "dutiful" to "actualizing"6 (Bennett, 1998, 2007, 2008, 2012; Bennett, Wells, \& Rank, 2009). In the "dutiful" model, citizenship is based on traditional concepts of citizenship that emphasize civic and political activities such as voting and staying informed about public events through traditional mass media (e.g., newspapers, television) (Bennett, 2008). The literature, in and beyond the U.S., indicates broad patterns of decline in traditional forms of civic and political engagement among young adults, ${ }^{7}$ including voting (Fieldhouse, Tranmer, \& Russell, 2007; File, 2014) and trust in elected officials (Gramlich, 2019). By contrast, in the "actualizing" model, activities associated with traditional citizenship are not as meaningful as those that more closely align with individuals' values and interests, such as advocating for issues like gender equality, environmental conservation, or other causes individuals are passionate about (Bennett, 1998, 2007, 2008). In this model, civic and political activities are often carried out in the context of peer-to-peer relationships and

\footnotetext{
${ }^{3}$ The 2007 refresh of the 1998 NETS for Students marked a shift from a focus on learning how to use technology to leveraging technology to learn (ISTE, n.d.).

${ }^{4}$ Ribble and ISTE have since updated their conceptions of digital citizenship. See Ribble and Park (2019) and (ISTE, n.d.); both of these updated frameworks have been mapped in our visualization (see part III, section 3). For the purposes of this part I, section 2, however, the focus is on early definitions of digital citizenship.

${ }^{5}$ To learn more about such shifts in the context of civic and political participation please see, for instance, Bennett (1998), Giddens (1991), and Inglehart (1997).

${ }^{6}$ As Bennett, Freelon, and Wells (2010) note, it's important to keep in mind that certain individuals or demographic groups are not likely to engage exclusively in activities associated with "actualizing citizenship," versus "dutiful citizenship," or vice versa. Instead, these models are meant to showcase overall trends in civic and political engagement.

${ }^{7}$ File (2014) and Fieldhouse et al. (2007) define young adults as those ages 18-24, while Gramlich (2019) as those ages 18-29.
} 
coordinated via digital technologies ${ }^{8}$ (Bennett, 2007, 2008). Although Bennett does not view actualizing citizenship as originating from the growing use of digital technologies, the digital landscape represents an important space in expressing this form of citizenship (Kligler-Vilenchik, 2017).

As Bennett et al. (2010) observe, the growing prevalence of participatory practices online often within a "participatory culture" - appears to represent one contributing factor to emerging forms of civic and political engagement among youth. According to Jenkins and colleagues (2006, p. 3), a participatory culture is a culture "with relatively low barriers to artistic expression and civic engagement," characterized by support for sharing one's creations with others, often in the context of informal mentorships. In the digital landscape, engagement in a participatory culture may take the form of: 1) expressions (creating content, such as fan fiction), 2) affiliations (being part of online communities, such as forums or social networking platforms), 3) collaborative problem-solving (working with others to create new knowledge, like through Wikipedia), and 4) circulations (impacting the way that media content flows by, for instance, podcasting) (Jenkins et al., 2006). For youth with access to digital technologies and the requisite skills to use them, participatory cultures thus create opportunities to connect with interest-driven communities, cooperate on peer-based production projects, and share information, among other productive activities (Benkler, 2006; Jenkins, 2006; Jenkins et al., 2006; Ito et al., 2010). These forms of engagement in the digital world can open opportunities for creativity, learning, self-expression, and civic engagement (Jenkins et al., 2006).

In the context of civic engagement, many youth today are expressing their voice around civic issues by creating and circulating media such as memes, blogs, or videos (Jenkins, Shresthova, GamberThompson, Kligler-Vilenchik, \& Zimmerman, 2016). As Cohen and Kahne (2012) explain, "the participatory skills, norms, and networks that develop when social media is used to socialize with friends or to engage with those who share one's interests can and are being transferred to the political realm" (p. 3). Building off of Jenkins et al.'s (2006) concept of participatory culture, "participatory politics" can be defined as "interactive, peer-based acts through which individuals and groups seek to exert both voice and influence on issues of public concern" (Cohen \& Kahne, 2012, p. vi). These acts may take the form of, for example, using Twitter to rally individuals around a cause someone cares about or sharing political news on social media (Cohen \& Kahne, 2012; Kahne, Hodgin, \& Eidman-Aadahl, 2016). Recent research helps shed light on such practices among youth. On a global scale, a study of 9-to-17-year-olds across 10 countries - Albania, Argentina, Brazil, Bulgaria, Ghana, Italy, Montenegro, the Philippines, South Africa, and Uruguay - indicated that $13 \%$ were involved in an online protest or campaign, and 19\% talked about social or political issues with others online (Global Kids Online, 2019). Additionally, several studies in and outside of the U.S. show that online participatory practices among youth are associated with offline political participation like voting (Cohen \& Kahne, 2012) and activities such as volunteering and raising money for a charitable cause (Xenos, Vromen, \& Loader, 2014).

The three conceptions of digital citizenship (Gleason \& von Gillern, 2016) reviewed in this part I, section 2 represent a piece of the rich contributions to the digital citizenship landscape. Our notion of digital citizenship - what we term "digital citizenship+ (plus)" (see this part I, section 6) - draws inspiration from the wide-ranging body of literature on digital citizenship and other concepts (e.g., digital literacy, digital competence, 21st century skills, media literacy, new media literacies ${ }^{9}$ ), while integrating our extensive research and educational work on youth and digital media.

\footnotetext{
${ }^{8}$ Digital technologies represent a key arena where forms of actualizing citizenship are enacted, but are not the sole arena (Bennett et al., 2009). Offline examples of actualizing citizenship might include, for instance, boycotting specific products for environmental reasons or signing a petition around veterans' issues (Shehata, Ekström, \& Olsson, 2016).

${ }^{9}$ See part II for a high-level overview of these concepts.
} 


\section{DIGITAL CITIZENSHIP IN THE CLASSROOM}

This part I, section 3 discusses how digital citizenship has been incorporated in the classroom over the past decade or so. However, it's important to note that, in parallel, schools around the world may also have been teaching digital skills, but incorporating these skills under a different concept (e.g., digital literacy, media literacy).

In the mid to late 2000s, as the Internet and digital technologies started to become more common, the primary focus in education in the context of the digital environment (beyond technical skills such as learning to type and using certain software) centered around Internet safety. These efforts arose in response to public concern around the possible risks youth encounter online, particularly around cyberbullying, Internet addiction, and online predators (Jones, 2010; Palfrey \& Gasser, 2008). During that time, schools in the U.S., for example, increasingly incorporated some form of Internet safety education (ISE) into the curricula - a survey of youth Internet users in 2010 revealed that nearly half (45\%) indicate receiving ISE in school, an increase of 15\% from 2005 (Mitchell, Jones, Finkelhor, \& Wolak, 2013).

Starting around the early to mid 2010s, in many regions of the world, however, policymakers' understanding of the role digital technologies play in education shifted from a focus on online protection towards a more balanced approach that helps support youth participate online in critical, effective, and responsible ways (United Nations Educational, Scientific and Cultural Organization [UNESCO], 2016). For instance, in the U.K., policymakers observed that the potential risks stemming from online content can be managed if policies address not only safety and basic digital literacy skills but also the skills needed to ethically and critically use digital technologies (Byron, 2008). As UNESCO (2016) points out, in Europe, such a shift is evidenced in the conversion of the Safer Internet Programme into the Better Internet for Kids Programme (European Commission, 2012). In the U.S., we see a move towards more balanced policies through, for instance, Washington state's bill around incorporating digital citizenship, Internet safety, and media literacy in the school curriculum, ${ }^{10}$ which has acted as a model bill for other states in the U.S. (Media Literacy Now, 2016). Moving beyond a sole focus on the risks the digital environment may present, the state's Digital Citizenship Advisory Committee (Small, 2016) explains:

Students must understand how to use personal technology in ways that augment their learning experience, leading to analysis, evaluation, reflection, and enhanced skills of expression. Our students can be expected to continue actively engaging and expressing their voices in this digital landscape; we must therefore endeavor to provide the education that will empower them to become media literate and digitally responsible global citizens. (p. 4)

What does digital citizenship education look like in the classroom today? While there is currently little research addressing how digital citizenship is incorporated in schools, preliminary data in and outside of the U.S. helps shed light on this important topic.

In the U.S., Common Sense's recent nationally representative survey of 1,208 kindergarten through 12 th grade ${ }^{11}$ teachers found that approximately $60 \%$ of teachers nationwide utilize a digital citizenship resource or curriculum with their students. In the survey, digital citizenship was defined as "thinking critically, behaving safely, and participating responsibly in the digital world" (Vega \& Robb, 2019, p. 7). The survey revealed that almost half (48\%) of high school teachers used some form of digital citizenship curricula or resource, versus 57\% of middle school teachers. Across all grade levels, among those teachers who used a digital citizenship resource or curriculum, a large majority (91\%) indicated that it was at least "moderately" effective in "helping students make smart, safe, or ethical decisions online" (Vega \& Robb, 2019, p. 11). The

\footnotetext{
${ }^{10}$ To learn more about Washington state's digital citizenship, Internet safety, and media literacy legislation, please see this part I, section 5.

${ }^{11}$ N.B: To view kindergarten through 12th grade corresponding ages based on the U.S. educational system please see Appendix D, "Table 2. K-12 Grades And Approximate Corresponding Ages In U.S. Education," from Gasser et al. (2012).
} 
survey also assessed whether teachers taught any of the following six digital citizenship competencies, as defined by Common Sense: 1) "privacy and safety," 2) "digital footprint and identity," 3) "relationships and communication," 4) "media balance and well-being," 5) "news and media literacy," and 6) "digital drama, cyberbullying, and hate speech"12 (Vega \& Robb, 2019, p. 9). Overall, a majority of secondary school teachers (76\%) taught at least one competency.

Across all grade levels, among those teachers who incorporate digital citizenship competencies in the classroom, which competencies do they teach most often? "Digital drama, cyberbullying, and hate speech" represented the most frequently taught competency (46\%), followed closely by "privacy and safety" (43\%). For teachers who taught any of the six competencies, the survey revealed that about $60 \%$ did so on a monthly basis, or more frequently. And though "relationships and communication" and "news and media literacy" represented the third and fourth most commonly taught competencies (both taught by $38 \%$ of teachers), they were incorporated in the classroom more frequently by those who taught them. Approximately seven out of 10 who taught "relationships and communication" and/or "news and media literacy" did so at least monthly. In contrast, about six out of ten teachers who taught "digital drama, cyberbullying, and hate speech" and/ or "privacy and safety" did so at least monthly. Vega and Robb (2019) note that this finding indicates that "relationships and communication" and "news and media literacy" may represent areas that students find particularly engaging.

What does digital citizenship education look like in classrooms in other parts of the world? In the AsiaPacific region, UNESCO (2016) undertook a review of Member States' national digital citizenship policies for pre-primary, primary, and secondary schools as part of their "Fostering Digital Citizenship through Safe, Effective and Responsible Use of ICT ${ }^{13 "}$ project.
Digital citizenship was defined as

being able to find, access, use and create information effectively; engage with other users and with content in an active, critical, sensitive and ethical manner; and navigate the online and ICT environment safely and responsibly, while being aware of one's own rights (UNESCO, 2016, p. 15).

The survey revealed that, among the 22 Members States that participated, ${ }^{14}$ a vast majority (80\%) have national programs, policies, and resources for secondary schools that aim to cultivate basic skills related to digital technologies. Fewer Member States (55\%), however, have implemented policies for secondary schools geared towards promoting skills around more participatory and creative ways of engaging with the digital world, such as creating, collaborating, and communicating with others online. And only about half of Member States have implemented policies around promoting the responsible and safe use of digital technologies. The review also examined the extent to which Member States' policies are balanced in terms of promoting opportunities while reducing risks that may come with digital technologies. The report defined "opportunityoriented policies" as policies that "promote ICT access and use, and the creation of ICT-enabled outputs" (UNESCO, 2016, p. 41). Specific aspects of online opportunities that the survey focused on included coding, creating and collaborating with others, and producing videos and images online. "Risk-oriented policies" were those that "seek to ensure students have the necessary skills to protect their privacy and ... ensure cyber security" (p. 41). For secondary school students, results indicated that most Member States place a greater emphasis on policies addressing opportunities, versus risks. This finding was particularly evident in countries such as Japan, China, Niue, Uzbekistan, and the Cook Islands. By contrast, Afghanistan, Samoa, and Australia tended to have more safety-focused policies. Despite this varied policy landscape, the survey demonstrated that Member States' policy readiness to encourage

\footnotetext{
${ }^{12}$ To view the definitions of these six competencies, please see page nine of Vega and Robb (2019).

13 "ICT" is an acronym for "information and communications technology."

${ }^{14}$ To view the list of participating Member States, please see page 71 of UNESCO (2016).
}




youth to harness digital opportunities had a strong, positive association with their readiness to mitigate online risks (UNESCO, 2016). This finding, which held across all grade levels, suggests that, on the whole, Member States tend to have policies that balance the opportunities and risks associated with the digital world. Based on overall findings from the review, the report put forth several policy recommendations, such as developing policies that increase opportunities for youth to engage with digital technologies in creative and participatory ways. The report also recommends that Member States design policies tailored to their local context, and aligned with the experiences and needs of students in these contexts.

Other stakeholders around the world have also put forth recommendations and guidelines with respect to digital citizenship education. In Europe, for example, the Council of Europe's Committee of Ministers recently adopted a set of guidelines for its 47 member States that encourage States to design and support digital citizenship education, and policymakers to prioritize it (Council of Europe, 2019b). The guidelines are part of the Council's intergovernmental project, "Digital Citizenship Education," launched in 2016 (Council of Europe, n.d.). According to the Council of Europe, "digital citizenship" is defined as "the capacity to participate actively, continuously and responsibly in communities (local, national, global, online and offline) at all levels (political, economic, social, cultural and intercultural)" (Council of Europe, 2019a, para. 4). The Committee of Ministers' guidelines around approaches to teaching digital citizenship - within both formal and informal learning settings - emphasize the importance of helping learners understand how to use digital technologies to participate in democratic activities, and take part in offline activities that promote democratic citizenship, such as engaging in intercultural dialogue (Council of Europe, 2019a). Additionally, the guidelines recommend the development of learning opportunities that are co-designed with learners themselves, creating pathways for individualized and inclusive learning.

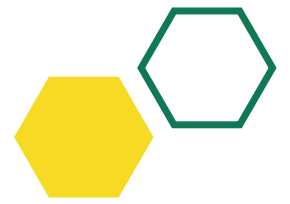

\section{SOME COMPLICATING ELEMENTS}

"Digital citizenship" as a term and concept acknowledging that different notions exist continues to be debated. Even within our YaM team, we appreciate the different notions but also have questions and concerns around the term "digital citizenship" - primarily in the context of youth. There are two complicating elements from our point of view:

1. Digital. First, our own research indicates that - with increased access and potentially more agency and experience related to digital technologies, particularly mobile phones - for many youth, the online and offline worlds are becoming so connected that they are often perceived as just one world. So why not use the term "citizenship" instead of "digital citizenship"? Is the "digital" supposed to highlight the relevance of the online ecosystem? Or is it meant to emphasize the digital tools that are available to exercise one's rights and responsibilities? And if we continue to use the term "digital citizenship," do we then diminish (at least in perception) the fact that the most crucial forms of participation are those in which online activities are translated to offline engagement, and thus fail to address these challenges appropriately?

2. Citizenship. Second, do we, as decision-makers, believe that youth are able to identify as "citizens" and "digital citizens"? This adult-normative perspective of citizenship has been introduced to young people with little explicit youth consultation (Clark \& Marchi, 2017). More specifically, the discourse around youth and citizenship has been shaped by several factors, such as the perception that 1) youth need protection from potential harm in public spaces (e.g., from predatory adults), and that 2) youth themselves are a source of harm, and adults are in need of protection from 
them (even when such youth are not dangerous) (Clark \& Marchi, 2017). As a whole, such a view on youth and citizenship suggests that adults should teach youth how to exercise the rights and responsibilities associated with traditional citizenship, such as political participation (Sherrod, Flanagan, \& Youniss, 2002). According to this perspective, young people "must be socialized into adult norms of political involvement rather than being thinking agents who may express important critiques of citizenship" (Clark \& Marchi, 2017, p. 25). Additionally, this approach presumes that there is the promise of basic rights and an expansion of rights (and responsibilities) for youth in the future. As Clark and Marchi (2017) point out, however, "Unfortunately, this does not pertain to many young people who have experienced marginalization due to disability, race, sexual orientation, lack of access to resources, or their parents' citizenship status" (p. 25).
While we continue to reflect upon these concerns, we also recognize the value of using and more heavily adopting the term "digital citizenship." One, by adding "digital," we believe the concept more strongly showcases the role and agency youth have in fostering their empowerment and visibility. Two, "digital" in combination with "citizenship" makes it more plausible that youth will engage with this concept, even if they are not of the legal voting age, as it appears to be a more flexible and open notion than other forms of citizenship. Three, compared to other concepts, such as digital literacy and new media literacies, digital citizenship generally appears to be more holistic, and thus, in our opinion, a more helpful notion to refer to when debating important areas of life related to the digital landscape, as well as the corresponding skills needed to be successful within those areas.

\section{BOUND TO THE TERM “DIGITAL CITIZENSHIP”}



Independent of the extent to which one prefers the concept of digital citizenship over other concepts, we have chosen to use digital citizenship as a large number of governments, international organizations, NGOs, and academics have adopted it to design, develop, and shape formal and informal learning spaces and programs for youth around areas of life connected to the digital world.

For example, several governmental organizations have started to create their own digital citizenship frameworks around young people's interactions with digital media (often later developing accompanying educational programs and learning materials). Within the frameworks, these stakeholders have put forth a set of skills they believe are important in navigating the digital world. Three examples of such frameworks include:

- Chile's Ministry of Education (MoE): In 2016, Chile's MoElaunchedadigital citizenship program under the Internet Segura ("Secure Internet") campaign. Internet Segura is a part of MoE's broader Enlaces ("Links") program, a national public policy that seeks to provide educational resources and digital infrastructure to public schools in Chile (Blignaut, Hinostroza, Els, \& Brun, 2010). The initiative's digital citizenship framework emphasizes the protection of young people online, addressing concerns around protecting one's privacy and security, and online bullying. Enlaces is developing a "Digital Citizenship Network" of public, private, and civil society stakeholders that seeks to shape public policy by training educators across Chile in teaching digital citizenship (Enlaces, 2017). Additionally, the MoE has released a set of digital citizenship educational resources for children and youth from pre-elementary to secondary school (Enlaces, 2018).

- Washington state Legislature: In 2016, Washington state passed legislation (Substitute Senate Bill 6273) creating a support structure 
for kindergarten through 12th grade teachers to incorporate digital citizenship, media literacy, and Internet safety education in public schools across the state (Media Literacy Now, 2020a). The bill stipulated that the Office of Superintendent of Public Instruction bring together an advisory group to develop recommendations and best practices around digital citizenship, media literacy, and Internet safety instruction (Media Literacy Now, 2020b). In 2017, Washington state implemented several of these recommendations, such as surveying school principals, librarians, and technology directors to better understand how they are incorporating these three concepts in the curriculum, and creating an online repository of recommended educational resources (Washington Office of Superintendent of Public Instruction, n.d.). More recently, in 2019, the legislature approved funding for teacher professional development around these three areas of instruction (Media Literacy Now, 2020b).

- New South Wales' (Australia) Department of Education: Since 2011, public schools across New South Wales (NSW) have integrated digital citizenship in classrooms for kindergarten through 10th grade students (Wittman, 2019). In 2019, NSW's Department of Education, in collaboration with researchers, updated their suite of digital citizenship educational tools, developing an online platform with resources for youth, parents, and educators (Wittman, 2019). On the platform, teachers will find an array of educational activities and games they can integrate into the classroom around topics ranging from access to digital technologies to coding, as well as professional development opportunities. Additionally, the platform showcases how the resources are connected to existing school curricula in New South Wales and Australia (New South Wales Department of Education, n.d.).

Outside of the governmental space, international organizations, NGOs, and those in academia have also developed frameworks around this concept, such as New Zealand's Netsafe (2018) model of digital citizenship; Lisa Jones' and Kimberly Mitchell's (2016) definition of digital citizenship; and DQ Institute's (2019) Digital Intelligence framework.

\section{WHY "DIGITAL CITIZENSHIP+ (PLUS)"}

As this part I, sections 4 and 5 demonstrate, we acknowledge the pros and cons, as well as some of our own difficulties, in using the term "digital citizenship." However, we also recognize the wide adoption of the term among different stakeholders, as well as the different examples of digital citizenship currently being implemented in praxis (see this part I, section 5). Against this backdrop, we have chosen to use the term "digital citizenship+ (plus)" - a modified version of digital citizenship - to signal several key points:
1. The term "digital citizenship+ (plus)" broadens the conversation and questions the scope of the term. We feel that adding a "+ (plus)" encourages further reflection on why the "+ (plus)" is there, what it refers to, and why it is needed in discussions around young people navigating the digital world. This reflection is valuable because it reveals what is still left to be questioned around this widely adopted term. 
2. The term might bring different communities to the same table. There are a variety of terms used to describe the skills individuals need to use technologies in our digital age, including the ones described in part II. Different stakeholders (e.g., government, international organizations, NGOs, academia) use these terms, and their work has tradition and history. Not surprisingly, these different communities can feel strongly about their chosen term(s), and as such, conversations around various terms can often become somewhat siloed. Against this backdrop, we feel that it would be worthwhile to bring different communities together to share their knowledge, ideas, and struggles. A new term might help accomplish this.

3. It keeps the term universal but flexible. Maintaining the term "digital citizenship" may garner additional support across the different communities and cultures that have adopted this term, while the addition of the "+ (plus)" could inspire communities to add skill areas they deem necessary to their own frameworks. Independent of the term that is used, we hope future communities can review our recommendations around the skill areas we present in our own framework and reflect upon the commonalities in our shared mission to promote youth skill development in the context of the digital environment.
4. It is more encompassing of different social, cultural, and regional contexts (see part IV, section 3). Although a shared conceptual understanding and standardized set of skills may facilitate the creation and implementation of educational interventions, it is important to acknowledge that the perceived importance of certain areas of life is likely based on one's context. Having a more open term where skills can be added or prioritized differently based on one's context may acknowledge a shared understanding that youth need to master a variety of important skills while still allowing different communities to select an approach - and group of skills - most appropriate for them. For instance, a community in which youth might not yet have the needed skills to access the Internet will need very different digital citizenship educational interventions compared to a community that wishes to prioritize young people's ability to become entrepreneurs and gain different forms of social, cultural, and economic capital.

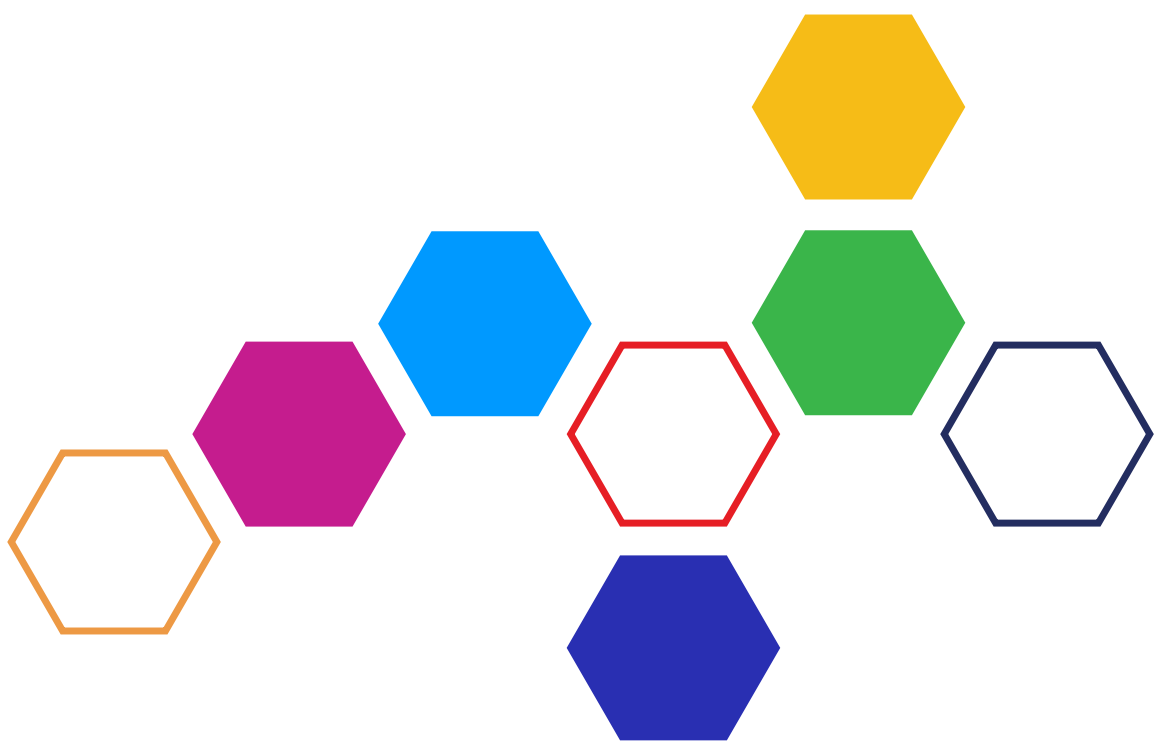




\section{OTHER CONCEPTS}

This part II provides a high-level overview of several concepts connected to digital citizenship that address youth skill development in the context of digital technologies. Like digital citizenship, each of these concepts - digital literacy, media literacy, new media literacies, 21st century skills, and digital competence - aims, at its core, to prepare individuals with the skills needed to navigate the challenges and embrace the opportunities of our evolving digital world. We hope this overview helps situate digital citizenship within a larger ecosystem of similar concepts. While by no means comprehensive, the overview is intended to illustrate relevant literature surrounding each concept - starting with a brief description of the emergence of the concept and then describing related bodies of work.
This part II demonstrates there are similarities and differences both within and across the concepts. For example, within a single concept, differences emerge around the way authors conceptually frame it and the skills they believe it should encompass. Keeping these distinctions in mind, looking across concepts, there is an overlap in the skills included within the frameworks attached to each concept. Thus, what we would like to see as distinct concepts that are neatly operationalized instead becomes concepts with moments of intersection but differences in origin and focus.

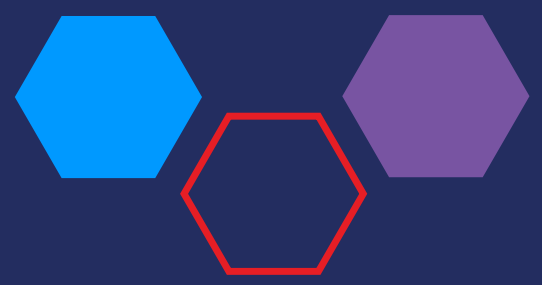

\section{DIGITAL LITERACY}

The American Library Association defines digital literacy as an individual's "ability to use information and communication technologies to find, evaluate, create, and communicate information using both cognitive and technical skills" (2013, p. 2). The emergence of the notion of digital literacy goes back to the debut of the World Wide Web in 1991. Very early conceptualizations of digital literacy in the 1980s (often now referred to as computer literacy) focused primarily on technical skills typically related to using computers and their software as part of career readiness (Bawden, 2008; Martin, 2005). In
1997, Paul Gilster's Digital Literacy suggested this initial scope should be broadened to include an individual's ability to understand and use information from a variety of networked computer sources - in particular, the Internet. The work describes digital literacy generally. Rather than listing specific skills, attitudes, or behaviors, Gilster (1997) emphasized "mastering ideas, not keystrokes" (p. 15) - ideas that capture the importance of knowledge assembly from diverse sources both digital and non-digital and critically differentiating credible online information from misinformation and disinformation. 
From an entirely skill-based perspective, Eshet-Alkalai (2004) conceives of digital literacy as the survival skills needed for functioning in a burgeoning digital world. The scholar notes that digital literacy involves more than the ability to use software or operate digital devices but includes an array of complex cognitive, motor, social, and emotional skills. This skill-based model is made up of several types of literacies, including photo-visual literacy, reproduction literacy, branching literacy, information literacy, and socioemotional literacy (Eshet-Alkalai, 2004). Later, due to the rapid development of multimedia environments and digital gaming, "real-time thinking" was added as a sixth literacy/skill (Eshet, 2012). In a different conceptualization of digital literacy, Martin (2005) defines the concept as the convergence of multiple literacies, including aspects of media literacy, visual literacy, information literacy, and ICT literacy. Refining this model, Martin and Grudziecki (2006) offer three levels of digital literacy: 1) digital competence (e.g., knowledge, skills, and attitudes), 2) the use of digital technologies as applied to specific domains (e.g., one's field of work), and 3) the ability to use digital technologies to promote innovation and creativity. Throughout the framework, the focus is on the importance of situational embedding - that is, using digital technologies according to one's specific context.

Martin and Grudziecki's (2006) three levels of digital literacy may be illustrated, respectively, through the following paradigms: 1) web-focused digital literacy (e.g., Mozilla's (2016) web literacy model); 2) digital literacy that explores how teachers and/or students engage with digital technologies in specific social contexts (e.g., Bhatt, Roock, and Adams' (2015) work on capturing and analyzing data that examines engagement with digital texts in the classroom); and 3) curation practices related to digital literacy (e.g., Mihailidis, 2015). Per the third paradigm, for example, in the context of digital literacy, Mihailidis ${ }^{15}$ (2015) focuses on digital curation and how curation practices may help cultivate digital literacy skills that are creative and user-driven. As one example, Mihailidis (2015) conducted a content analysis of college-aged students' curated stories on Storify ${ }^{16}$ and how their curation practices might impact the development of digital literacy skills. He assessed digital literacy in terms of participants' ability to bring together platforms, content, ideas, and various sources in a clear and balanced manner on the subject at hand (i.e., income inequality) through their digital stories. Results revealed that students were, overall, proficient in assembling and repurposing content while keeping a cohesive and balanced narrative. Data demonstrated variability in the clarity of the stories, which, as Mihailidis notes, may, in part, be due to students' limited formal learning around curation. Indeed, a survey by the New Media Consortium on the landscape of digital literacy in higher education across the U.S. found that the notion of students as digital creators has not yet permeated the classroom (Alexander, Adams Becker, \& Cummins, 2016). More broadly, Mihailidis' (2015) results suggest that digital curation may be an important component of the development of digital literacy. As he explains, the study "supports the need to mobilize the voice and agency of young people through pedagogies that place them as more centered, active, and publicly situated in the process of learning and expression" (Mihailidis, 2015, p. 454).

In another conceptualization, Hargittai views digital literacy as an individual's ability to efficiently and effectively find information online. To assess this form of digital literacy - what Hargittai terms "weboriented digital literacy" - the scholar conducted studies where participants were tasked with finding various types of information online (e.g., Hargittai, $2002,2005,2009)$. These observations of individuals' online browsing behavior focused on the percentage of tasks completed, or "effectiveness," and the amount of time participants spent on the tasks, or "efficiency" (Hargittai, 2005). Additionally, participants were given an assessment of their knowledge around certain Internet- and computer-related terms (e.g.,

\footnotetext{
${ }^{15}$ In addition to digital curation, Mihailidis also explores citizenship practices in the context of media literacy. He proposes several "civic media literacies" that aim to "reframe media literacy interventions towards civic intentionality: a set of design considerations for media literacy initiatives that are based on the value systems of agency, caring, persistence, critical consciousness, and emancipation" (2018, p. 153). To learn more about Mihailidis' work around civics and media literacy, please also see, for example, Gordon and Mihailidis (2016), Mihailidis (2014, 2018, 2019), and Mihailidis and Gerodimos (2016).

${ }^{16}$ Storify is an online platform that allows users to create stories by drawing content from social media platforms (e.g., Twitter, Facebook) and adding text to complement the story (Mihailidis, 2015).
} 
"cookie," "download," "message thread"). Hargittai (2005) found participants' knowledge of such terms served as a proxy of their web-oriented digital literacy. She observed that this assessment of individuals' knowledge of Internet-related terms correlates more with web-oriented digital literacy than traditional digital skill proxies (e.g., Internet self-efficacy, amount of time spent online) (Hargittai, 2005). In a review of knowledge around such terms over time, Hargittai and Hsieh (2012) explain that while some terms are relatively consistent (e.g., browser-related terms such as "bookmark," "favorites," and "reload"), other terms, such as "tagging" and "Wiki," are associated with increased understanding over the years. Hargittai notes that this trend likely reflects the increasing popularity of Wikipedia, activities related to the use of social media platforms, and the evolving nature of digital technologies.

A variation of Hargittai's web-oriented digital literacy can be seen in van Deursen's (2010) framework around digital skills ${ }^{17}$ - more specifically around his definition of operational skills and formal skills. According to van Deursen, digital skills comprise four skill sets: 1) operational skills, which include the technical skills needed to operate computers and the Internet (e.g., knowing how to bookmark a website or download a file); 2) formal skills such as browsing and navigating the Internet (e.g., knowing where to click to go to a different page on the Internet); 3) informational skills, including searching, selecting, and evaluating information online (e.g., knowing the best keywords to use in an online search); and 4) strategic skills, using technologies to achieve one's goals (e.g., comparing prices of products sold online). In his later work, van Deursen added 5) content creation skills needed to create and disseminate content in the digital landscape (e.g., uploading and sharing music and video content), and 6) communication skills to reflect the skills necessary to work with others online (e.g., constructing profiles and identities on social media) (van Deursen, Helsper, \& Eynon, 2014; van Dijk \& van Deursen, 2014).
In Defining Digital Literacy: What Young People Need to Know About Digital Media, David Buckingham (2006) addresses the intersection of digital literacy and media literacy in the context of youth. From the perspective of media literacy education, Buckingham (2003, 2006) positions digital literacy across four facets of media education: 1) representation (understanding how reality is represented in media by, for instance, questioning implicit values and/or biases of online content); 2) language (recognizing how meanings are constructed in the "language" of media by, for example, critically navigating online sites with hyperlinks, graphics, and/or videos); 3) production (comprehending how media are produced by, for instance, asking what technologies are used to generate and distribute material online); and 4) audiences (understanding how media target audiences by being aware of, for example, how social media platforms collect users' information). This notion of digital literacy emphasizes the importance of developing critical approaches to digital media, along with an understanding of digital media's social, economic, and cultural implications.

The role of digital media creation by students as an important part of digital literacy is also addressed by Renee Hobbs. Hobbs (2010) conceptualizes digital and media literacy as the set of emotional, social, and cognitive abilities associated with analyzing, accessing, creating, reflecting, and acting upon media messages in various forms. Against this backdrop, in Create to Learn, Hobbs (2017) helps learners apply this constellation of abilities as they develop multimedia content (e.g., videos, animations, infographics) and cultivate communication and critical thinking skills. Her work has also examined the underlying attitudes that contribute to teachers' interest in integrating digital literacy into the elementary and secondary school curriculum and the pedagogies and instructional practices that support the development of teachers as they learn digital literacy skills (Hobbs \& Coiro, 2019; Hobbs \& Tuzel, 2017).

\footnotetext{
${ }^{17}$ van Deursen, and his collaborator van Dijk, prefer the word "skills" over literacies, as they believe it "suggests a more inter(active) performance in media use than, for example, 'literacy,' which refers to reading and writing text" (van Dijk \& van Deursen, 2014, p. 4). For instance, Internet use extends beyond reading text on a website to interacting with others online, through social media, email, or gaming communities (van Dijk \& van Deursen, 2014).
} 


\section{MEDIA LITERACY AND NEW MEDIA LITERACIES}

Expanding from a tradition that developed during the 20th century, media and new media literacy frameworks have continued to evolve in the 21st century in response to the rapid pace of media technology innovation and the transformation of the communication environment. Academics, policymakers, educators, and activists, mainly from Europe, Australia, and the U.S., have developed these frameworks in an attempt to address questions about media access, production, interpretation, and distribution, and their relationship to participation in society, culture, and the economy (Buckingham, 2007; Bulger \& Davison, 2018; De Abreu, Mihailidis, Lee, Melki, \& McDougall, 2017; Hobbs, 2010; Hobbs \& Jensen, 2009; Livingstone, 2003; Tyner, 1998). Although both media and new media literacies have common roots and share similar aims and purposes, the main difference is that media literacy focuses on personal and individual engagement with mass media, popular culture, and digital media while new media literacies also acknowledge community involvement and participatory culture ${ }^{18}$ as part of skill development (Jenkins et al., 2006).

During the 1990s and early 2000s, stakeholders arrived at a comprehensive definition of media literacy that included skills at multiple levels of media engagement: access, analysis, evaluation, and content creation (Buckingham, 2003; Gee, 2010; Masterman, 1993). Balancing protectionism and participation, and identifying a range of media literacy skills, broad media literacy frameworks have been consolidated in official documents by national and international policymakers, including the U.S. National Leadership Conference of Media Literacy (Aufderheide, 1993), Ofcom (2004), the European Commission ${ }^{19}$ (2007), and UNESCO (Grizzle et al., 2013). Likewise, scholars have developed conceptual frameworks, researched media literacy skills, and investigated media literacy teaching practices and effectiveness. While some theorized about media literacy education and its implementation in formal and informal learning settings (Bazalgette, 2008;
Buckingham, 2003, 2007; Hobbs \& Jensen, 2009; Livingstone, Van Couvering, \& Thumim, 2008; Tyner, 1998), others investigated and identified different kinds of media literacy skills (Adams \& Hamm, 2001; Brown, 1998; Hobbs \& Frost, 2003; Livingstone, 2008; Pérez Tornero \& Varis, 2010). Still others focused their research on the practical aspects of teaching media literacy and evaluating its effectiveness (Alvermann, Moon, \& Hagood, 1999; Duran, Yousman, Walsh, \& Longshore, 2008; Hart, 1997).

At the start of the 21st century, the notion of "new media literacies" emerged as part of the development of the interdisciplinary field of New Literacy Studies (NLS). Led by Jean Paul Gee, the New Literacy Studies initiative brought together leading scientists, historians, sociologists, and communication and media scholars to understand literacy as a sociocultural phenomenon. By recognizing literacy as a discourse, and acknowledging situated cognition, or the importance of one's experiences in the context of learning, NLS scholars validated the possibility of mastering a broad range of discourses or literacies (Gee, 2010). NLS had a direct impact on the aims and purposes of media literacy as it opened a space for the recognition of multiple new literacies across a rich variety of social and cultural mediated practices. The notion of "new media literacies," developed by Henry Jenkins and his team in the white paper Confronting the Challenges of Participatory Culture (Jenkins et al., 2006), emerged in the context of recognizing multiple literacies and NLS. After studying the emerging sociocultural practices that youth, mainly in the U.S., develop as they interact with digital media tools, networks, and communities, Jenkins et al. (2006) identified eleven "new media literacy" skills, including play, appropriation, collective intelligence, transmedia navigation, networking, and negotiation. These skills are meant to build on the foundation of traditional literacy (i.e., reading and writing) as well as research and critical analysis skills.

\footnotetext{
${ }^{18}$ Please see part I, section 2 to learn more about participatory culture (Jenkins et al., 2006).

${ }^{19}$ For a helpful review of the history of European Union policy around media and digital literacy, please see Pérez Tornero and Pi (2013).
} 


\section{21ST CENTURY SKILLS}

Technological advancement, globalization, and demographic shifts around the turn of the 21 st century started to shape the way stakeholders - including policymakers, NGOs, international organizations, the private sector, and academics - have conceptualized the skills needed to thrive in today's society and the workforce. As Chu, Reynolds, Tavares, Notari, and Lee (2017) point out, in 1996, UNESCO's Delors Report, developed by the organization's International Commission on Education for the Twenty-first Century, helped to initiate the conversation around the notion of 21 st century skills. The report emphasized the importance of lifelong education in the 21st century, recommending that education be developed along four pillars: learning to do, learning to know, learning to be, and learning to live together. When Jacques Delors, who chaired the commission, was asked what the key message was for education in the future, he noted, "make human beings more aware of themselves and of what is around them" (Delors, 1994, p. 348) - highlighting both "learning to be" and "learning to live together" (Elfert, 2015). ${ }^{20}$

In response to the Delors Report, government, international organizations, academics, and the private sector developed frameworks to both describe the skills youth need to succeed in today's information society and offer learning objectives for the 21st century skills valued in school, the workplace, and the broader community (Chu et al., 2017; Kay, 2010). Several include the World Economic Forum's framework of 21st century skills (2015); the National Research Council's (2012) model of 21st century skills; the Partnership for 21st Century Learning's (P21) Framework for 21st Century Learning (2019); the Organisation for Economic Cooperation and Development's (OECD) three-dimensional framework of 21 st century skills (Ananiadou \& Claro, 2009); and the Assessment and Teaching of Twentyfirst Century Skills' model (Griffin, McGaw, \& Care, 2012). Chu and colleagues (2017) examined the latter three frameworks and grouped common skills under three areas: 1) learning and innovation (e.g., critical thinking, collaboration, creativity); 2) information, media, and technology skills (e.g., media literacy, information, and communication technology skills); and 3) life and career skills (e.g., adaptability, cross-cultural competency). ${ }^{21}$ Thus, while conceptual models vary in terms of specific skills included, Chu et al.'s (2017) definition offers a helpful way of understanding the core ideas across existing 21 st century skills frameworks.

In another review of 21 st century skill frameworks, Dede (2010) compared frameworks from stakeholders such as the Metiri Group and the North Central Regional Educational Laboratory (Lemke, 2003) and the Association of American Colleges \& Universities (2007) (in addition to P21 and OECD) to highlight consistencies across the skills included in the frameworks. Dede acknowledges, however, that stakeholders vary in terms of what skills or sub-skills they consider to be especially important (e.g., "acting autonomously" or "risk taking") (Dede, 2010). Regardless of the particular emphasis a framework may have, Dede explains how technological development and globalization are changing the nature of perennial skills (i.e., skills that have been important throughout historical changes in the workforce) and creating new contextual skills (i.e., skills that are uniquely relevant to the workplace and society more broadly in the 21 st century) (Dede, 2010). For instance, collaboration is a capability that has been perennially critical in workplaces throughout history. In the context of the 21 st century, collaboration has become even more important as individuals increasingly engage in information-based economies and use digital tools to connect with others. As Silva (2009, p. 631) notes, the skills within 21 st century skills frameworks are "not new, just newly important" in the context of a changing global economy.

\footnotetext{
${ }^{20}$ Nearly two decades after the publication of the report, UNESCO explored how the four pillars are applied in schools today in nine countries/jurisdictions in the Asia-Pacific region (Care \& Luo, 2016). UNESCO now terms these four pillars "transversal competencies," defined as the "knowledge, skills, values, and attitudes that are integral to life in the 21 st century" (2016, p. 1). The report revealed that while these competencies are on the educational agenda of the countries/jurisdictions studied, there were several key barriers to assessment, including 1) defining what exactly constitutes "skills" and "competencies" and deciding which are valuable to assess; 2) equipping teachers with the tools to understand how skills develop over time and how to adjust pedagogical strategies accordingly; and 3) the tension between 21 st century skills and a specific country's views about what the educational system should emphasize.

${ }^{21}$ For a detailed account of each of these areas, please refer to Chu et al. (2017).
} 


\section{DIGITAL COMPETENCE}

Much like the emergence of 21st century skills, against the backdrop of increasing globalization, demographic changes, and digital technology development around the start of the 21st century, in 1997, the OECD introduced the Programme for International Student Assessment (PISA) (Ananiadou \& Claro, 2009). The assessment aimed to measure the degree to which students nearing the completion of their compulsory schooling (at the age of 15) have gained skills and knowledge around areas such as mathematics, reading, science, and increasingly important domains, such as lifelong learning. For instance, the assessment asked students about specific learning strategies they use, their motivation to learn, and their confidence in their ability to learn (OECD, 2005). The same year, the OECD launched the DeSeCo ${ }^{22}$ program to help guide the identification of competencies ${ }^{23}$ for all youth and adults, and further refine international assessments of competence levels within these populations (OECD, 2005). The DeSeCo program, framed around the importance of lifelong learning, categorized these competencies along three broad domains: 1) the ability to use an array of tools (ranging from the physical, such as digital technologies, to the sociocultural, such as language) to interact with one's environment; 2) the ability to take responsibility for one's life and act autonomously; and 3) the ability to work effectively with others in diverse groups (OECD, 2005).

Shortly after the launch of the DeSeCo program, in 2005, the European Commission called upon Member States to modify their educational systems to help equip youth with the competences needed for lifelong learning (von Hebel, 2009). In 2006, the Recommendation of the European Parliament and the Council of the European Union (2006) on Key Competences for Lifelong Learning aimed to offer a common European framework for such competences, geared towards stakeholders such as educators and policymakers. The Recommendation proposed eight key competences - among them, digital competence.
Digital competence was defined as "the confident and critical use of Information Society Technology (IST) for work, leisure and communication" (2006, p. 13). To more fully explore the skills, knowledge, and attitudes associated with digital competence, in 2011, the European Commission's Joint Research Centre began to develop a framework around the concept titled the Digital Competence Framework for Citizens (DigComp). Now in its third iteration, DigComp 2.1, the framework defines digital competence along five key domains: 1) information and data literacy, 2) communication and collaboration, 3) digital content creation, 4) safety, and 5) problem solving (Carretero, Vuorikari, \& Punie, 2017). Across these five domains are in total 21 competences, with eight levels of proficiency for each. DigComp 2.1 is being implemented in over 20 countries in and outside of Europe in various ways, such as the development of formal and informal learning programs to cultivate digital competences, policymaking for digital education, and digital competency assessments ${ }^{24}$ (Kluzer \& Pujol Priego, 2018).

The European Commission's DigComp is meant for a broad audience of both youth and adults (Kluzer \& Pujol Priego, 2018). Some frameworks around digital competence, however, while applicable to a general audience, were specifically developed in the context of a target group of individuals. For instance, Calvani, Cartelli, Fini, and Ranieri (2008) proposed a definition centered around three dimensions of digital competence (technological, ethical, and cognitive) that they assessed in a sample of secondary school students (Calvani, Fini, Ranieri, \& Picci, 2012). The authors developed their definition and assessment of digital competence to shed light on young people's digital skills - technical knowledge as well as higherorder cognitive skills, and sociocultural knowledge around digital technology usage ${ }^{25}$ - and inform school-based educational interventions.

Krumsvik (2008) also situated his conceptualization of digital competence within the educational

\footnotetext{
22 "DeSeCo" stands for "Definition and Selection of Competences: Theoretical and Conceptual Foundations."

${ }^{23}$ Some stakeholders choose to spell the plural of "competence" as "competencies," and others "competences." The variation in spelling in this paper reflects each stakeholder's overall preference.

${ }^{24}$ For a comprehensive review of how DigComp2.1 is being implemented in countries in and outside of Europe, please see Kluzer and Pujol Priego (2018).
} 
setting. He initially created his definition in response to the inclusion of digital competence as one of the five basic core competences in Norway's national curriculum (Krumsvik, 2008). According to Krumsvik (2012), digital competence is defined as "the individual teacher's proficiency in using ICT in schools with good pedagogical judgement, and his/her awareness of its implications for learning strategies and the digital Bildung ${ }^{26}$ of pupils" (p. 466). Thus, while Calvani and colleagues (2012) propose a more general definition of digital competence, listing a variety of cognitive abilities, Krumsvik's definition centers on teachers' level of expertise in using ICT for professional means and the implications this usage has on student learning.

Some scholars view digital competence as more closely related to other literacies. As Ferrari, Punie, and Redecker (2012) note, there are generally two camps around the digital competence (and digital literacy) discourse. One perspective views digital competence as the convergence of several related literacies, such as media, information, Internet, and computer literacy (Ala-Mutka, 2011). Others, however, hold that digital competence is a new literacy that extends beyond the sum of related literacies, such as information and media literacy (Ferrari, 2012; Gallardo-Echenique, de Oliveira, Marques-Molias, \& Esteve-Mon, 2015). Livingstone (2003), for instance, notes that literacy itself is primarily dependent on tools and objects, and given the rapid proliferation of new tools and technologies, the competences needed to navigate them are changing. In this vein, Kress (2010) holds that digital technologies necessitate new approaches to both audio and visual text. As Ferrari (2012) points out, digital technologies now allow for "a convergence between the reader and the writer, as the decoding and encoding processes are made at faster speeds and texts - blogs, newspaper articles, Wikipedia entries - allow and encourage the reader to become an author" (p. 19). Thus, in this perspective, digital competency is an evolving concept that is bound neither to specific literacies nor to the convergence of such literacies, but to the tools or objects in one's environment.

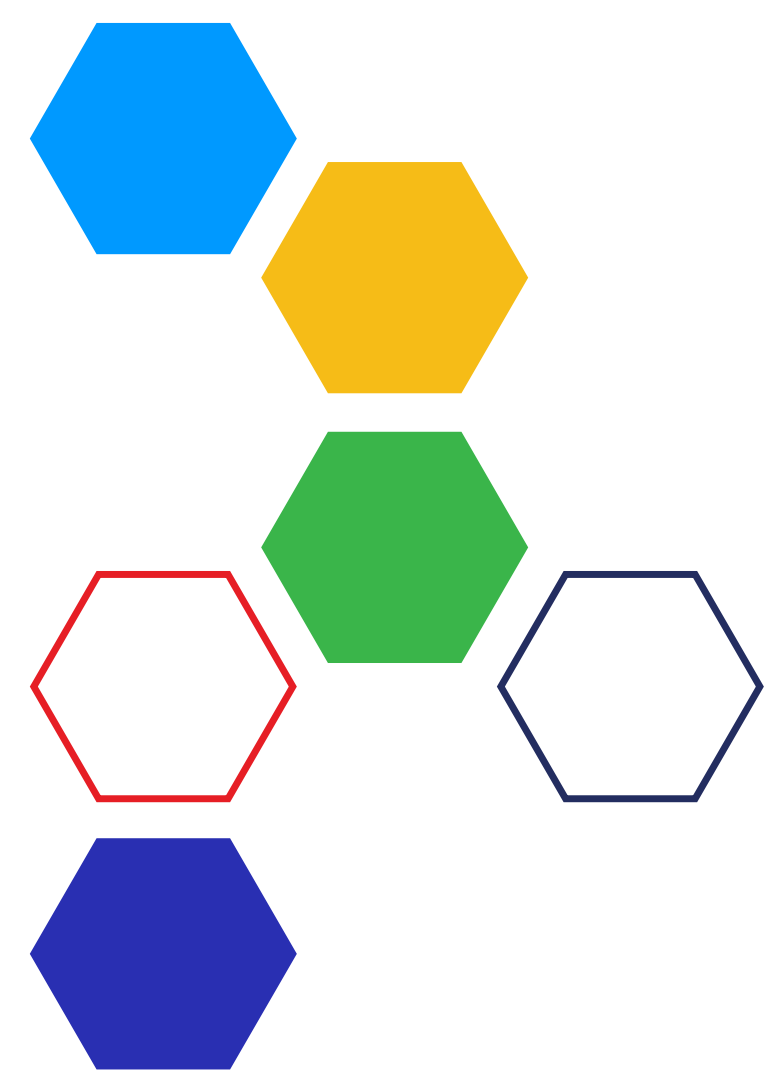

\footnotetext{
25 "Technological" knowledge is measured by indicators such as the ability to recognize interfaces and symbols and solve common technical issues, as well as a conceptual understanding of technology; "cognitive" knowledge by, for example, the ability to organize data and critically evaluate information; and "ethical knowledge" through level of respect for others, an understanding of privacy online, and an understanding of digital inequities across countries (both the extent and how it impacts individuals' ability to communicate with others) (Calvani et al., 2012).

${ }^{26}$ Krumsvik (2008) proposes the following definition: "Digital Bildung [digital danning in Norwegian] focuses on how pupils' participation, multi-membership of different communities and identity development in the digital era are influenced by the digitisation of society" (p. 288). In the context of the school setting, according to Krumsvik (2008), both teachers and students can practice digital competence by critically consuming information online, and developing an ethical understanding of the social ramifications of digital technologies.
} 


\section{MAPPING OF DIGITAL CITIZENSHIP FRAMEWORKS}

As noted, over the past two decades we have seen the emergence of a range of digital citizenship frameworks, addressing relevant skills that aim to help young people critically, ethically, and effectively use digital technologies. While we have decided to develop a framework around the term "digital citizenship+ (plus)," ${ }^{27}$ we are mindful of how others in government, international organizations, NGOs, and academia have developed and applied their own frameworks addressing digital citizenship and its associated skills. Against this backdrop, we selected and studied $\mathbf{3 5}$ frameworks around digital citizenship and intersecting concepts such as media literacy, 21 st century skills, and online safety. In this part III, section 1, we describe the process we used to select the frameworks and how we mapped the frameworks onto areas of life related to the digital landscape - such as civic and political engagement, artificial intelligence, and privacy and reputation. Section 2 showcases the results we derived from that analysis - more specifically, the $\mathbf{1 7}$ areas of life our current digital citizenship+ (plus) framework includes and that we feel future digital citizenship frameworks, and frameworks on similar concepts, should address. Additionally, this section illustrates a possible way to group these 17 areas, and how they may be applied in practice, with a focus on the educational space. Section 3 incorporates the visualization that positions our findings within this complex landscape of frameworks and skills.

\section{THE MAPPING PROCESS AND CREATION OF DIGITAL CITIZENSHIP+ (PLUS)}

This part III, section 1 describes the process we used to map frameworks addressing digital citizenship and similar concepts, and how we created our own conceptualization of digital citizenship: digital citizenship+ (plus).

\section{Initial Broad Search of Frameworks}

We first performed searches across an array of databases using general keywords in varying combinations of "youth" and "teenagers;" "digital citizenship" or a term related to digital citizenship, such as "media literacy," "21st century skills," or "online safety;" and "framework," "definition," or "initiative."
Our search strategy also involved combinations of "digital citizenship," "youth," and "[specific country]" search terms. We searched for digital citizenship frameworks both within the U.S. and around the world (e.g., Spain, New Zealand, and Singapore) and from a diverse range of stakeholders (i.e., government, international organizations, NGOs, and academia). Due to our rapidly evolving technological landscape, we generally focused our searches on frameworks published in the past decade, but also explored widely cited frameworks that are slightly older (e.g., Mossberger and colleagues' conceptualization of digital citizenship, put forth in 2007).

${ }^{27}$ The rationale behind why we decided to use the term "digital citizenship+ (plus)" is described in part I, section 6, and the manner in which we developed our framework around this term and how we define the term is elaborated upon in this part III, sections 1 and 2, respectively. 


\section{Selection of a Subset of Frameworks}

For the framework mapping itself, we decided to reduce the initial large number of frameworks and study a subset of 35 in further detail (see Appendix A), based on two main criteria. First, our subset of selected frameworks translated their definitions of digital citizenship (or a related concept) into action through 1) educational materials and/ or programming, 2) a report or study, and/or 3) legislation. Second, the frameworks focused on youth ages 12-18 (we retained some of the frameworks that were designed with primarily adults or the general public in mind but were very much applicable to youth as well).

\section{Initial Identification of Areas of Life ${ }^{28}$ Connected to the Digital World (Bottom-up)}

To systematically organize the frameworks we selected, we adopted a bottom-up strategy by identifying what areas of life each framework incorporated. We initially mapped frameworks along a set of approximately 25 areas (e.g., civic and political engagement, positive/respectful behavior, safety and well-being).

\section{Inclusion of Additional Areas of Life Based on YaM's Work (Top-down)}

We then adopted a top-down approach. We compared the initial 25 areas with YaM's own research, advocacy, and development initiatives around young people and digital technology. Based on this comparison, we worked with Berkman Klein Center fellows, staff, and youth from the Center's 2017 summer internship program to collectively identify 15 additional areas perceived to be important in navigating the digital world (e.g., artificial intelligence, digital economy; see Appendix $\mathrm{B}$ for the full list of 40 areas).

\section{Clustering and Grouping the Areas}

We organized several collaborative and engaging sessions with fellows, staff, and summer interns to arrange the 40 areas into broader themes by grouping similar areas under the same overall umbrella heading (e.g., "the engaged Internet," "the interpersonal Internet"). Please see Appendix C for photos from these sessions.

\section{Parallel Deep Dive into Scholarly Work}

In parallel with these sessions, we reviewed a body of literature to understand how other scholars are defining and discussing areas such as safety and well-being (Livingstone, Mascheroni, Ólafsson, \& Haddon, 2014), civic and political engagement (Levine, 2007), and media literacy (Hobbs, 2010). We ultimately arrived at our current list of 17 areas that we term "digital citizenship+ (plus)."

\section{Assessing Youth Involvement in the Frameworks}

Based on YaM's premise that involving young people's perspectives is essential to shaping research, education, and policy frameworks and practices geared towards youth, we examined whether youth ages 12-18 were involved in the development of each framework we selected. We operationalized "youth involvement" as young people providing input in the curation of the framework through direct means (e.g., directly telling researchers what areas of life related to the digital environment are personally meaningful) or indirect means (e.g., participating and providing feedback on a pilot digital citizenship curriculum implemented in schools). As stated in point two in this part III, section 1, the vast majority of frameworks we selected were designed by youth-serving stakeholders. In other words, these stakeholders developed their framework and the associated content (educational materials and/or programming, a report or study, and/or legislation) to apply it within a youth setting, such as a formal or informal learning environment. In assessing youth involvement, however, we draw a distinction between stakeholders who develop content to be used primarily by youth versus those who create content to be used by young people and involve youth in the development process itself.

\footnotetext{
${ }^{28}$ We define an area of life as a facet of life with associated skills that help one thrive academically, socially, ethically, politically, and/or economically in our rapidly evolving digital world.
} 


\section{THE 17 AREAS THAT CURRENTLY CONSTITUTE DIGITAL CITIZENSHIP+ (PLUS)}

We define "digital citizenship+ (plus)" as the skills needed for youth to fully participate academically, socially, ethically, politically, and economically in our rapidly evolving digital world.

The 17 areas that make up digital citizenship+ (plus) are described in this part III, section 2. Additionally, we provide examples of how several of these areas might be applied within a formal learning setting. We use five subject areas to illustrate this application: history, English, science, math, and world language. For each application, we also indicate a specific educational tool our team has developed that one can use to engage youth in the activity. We also offer examples of ways our educational tools might be grouped in engaging and interesting ways, which can be applied in formal or informal learning spaces.

To view all of the $100+$ educational tools (e.g., learning experiences, podcasts, visualizations) we have developed around these 17 areas, please visit our team's Digital Citizenship+ (Plus) Resource Platform at https://dcrp.berkman.harvard.edu. From the home to the classroom to the libraries and museums, our team's educational tools can be used in different settings for both individual and group learning (Cortesi, Lombana, \& Hasse, 2018). We have designed the tools with and for youth - with the help of internal and external experts, Youth Advisors (i.e., groups of youth from different contexts who help shape YaM's efforts), summer interns, and research assistants - and have embedded the principles of connected learning (Ito et al., 2013; Ito et al., 2020) within them.



Artificial Intelligence (Al): The ability to understand the algorithms involved in the Al-based platforms one interacts with, and the ethical conversations happening around the development of these technologies.

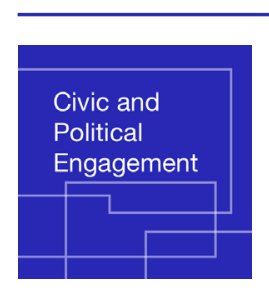

Civic and Political Engagement:

The ability to participate in public matters (e.g., LGBTQ rights, peace-building, addressing hate speech) and advocate for issues one cares about - using digital and non-digital tools - ideally to improve the quality of life in one's community, from micro to macro levels (Levine, 2007).

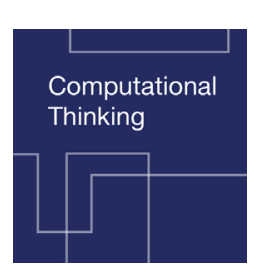

Computational Thinking: The ability to understand and apply computational concepts, practices, and perspectives. Computational concepts include concepts individuals leverage as they program (e.g., "sequencing," or identifying a set of steps for a task; "loops," or running the same series of steps multiple times). Computational practices represent the practices individuals cultivate while they program (e.g. "experimenting and iterating;" "reusing and remixing," or creating something by building upon current ideas or projects). Finally, computational perspectives refer to the perspectives individuals develop about themselves, their connections to others (such as within the context of collaborative online communities), and the technological world more broadly (e.g., "connecting," or understanding the power of developing content both with and for others) (Brennan \& Resnick, 2012). 


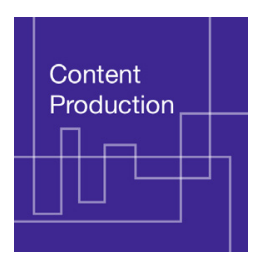

Content Production: The ability to produce (digital) content using (digital) tools.

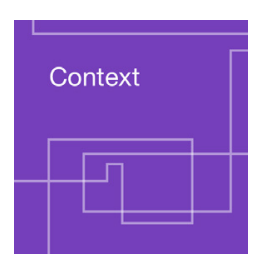

Context: The ability to be aware of, understand, and interpret the contextual factors of relevance (e.g., cultural, social, local/regional/ global) in a given situation - with a particular emphasis on the experiences and perspectives of underrepresented groups, whether in terms of age, ethnicity, race, gender and sexual identity, religion, national origin, location, skill and educational level, and/ or socioeconomic status - and effectively engage in the situation.

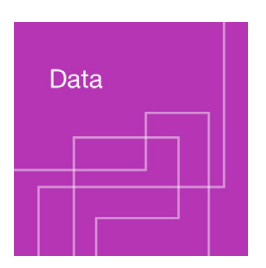

Data: The ability to be aware of, create, collect, represent, evaluate, interpret, and analyze data from digital and non-digital sources.

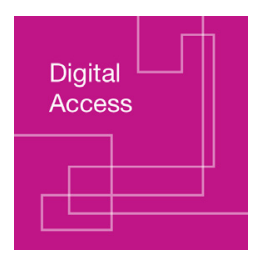

Digital Access: The ability to connect to and access the Internet, individually or collectively (e.g., mesh technologies).



Digital Economy: The ability to navigate economic activities online and offline to earn different forms of economic, social, and/or cultural capital (e.g., earning money, increasing social connections, building personal brands).

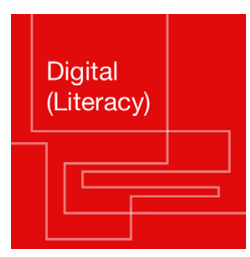

Digital (Literacy): The ability to use the Internet and other digital tools and platforms effectively to find, interact with, evaluate, create, and reuse information (Palfrey \& Gasser, 2016). The ability to comprehend and work through conceptual problems in digital spaces (Carretero et al., 2017).



Identity Exploration and Formation: The ability to use (digital) tools to explore elements of one's identity and understand how the communities one is part of shape one's identity.

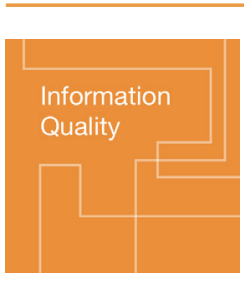

Information Quality: The ability to find, interact with, evaluate, create, and reuse information (broadly speaking, e.g., news, health information, personal information) effectively (Palfrey \& Gasser, 2016).

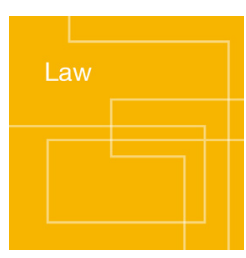

Law: The ability to engage with legal frameworks, concepts, and theories surrounding the Internet and other digital tools (e.g., copyright, fair use), and the ability to apply these frameworks to one's activities.

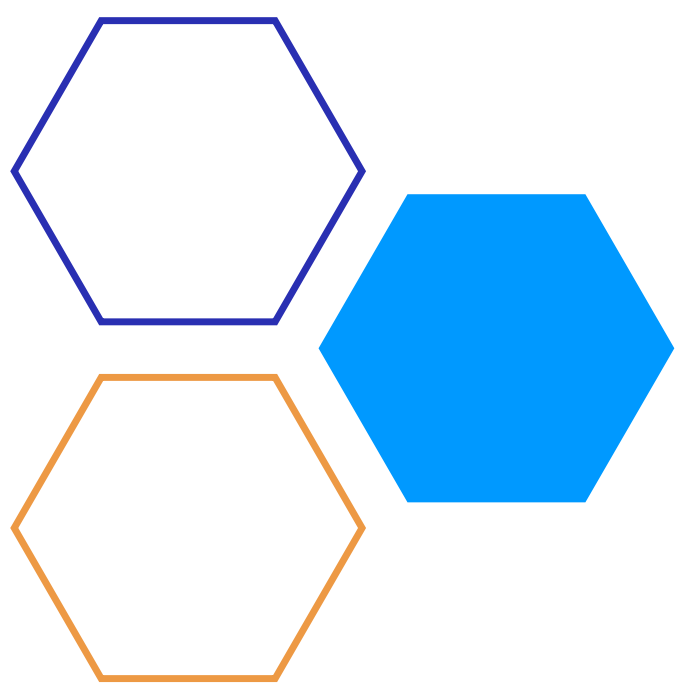


Media (Literacy): The ability to analyze, evaluate, circulate, and create content in any media form (e.g., print, visual, interactive, audio), and to participate in communities and networks. "Media literacies," in the plural, include "media literacy" (Hobbs, 2010), what some researchers have conceptualized as "new literacies" (Lankshear \& Knobel, 2007), and "new media literacies" (Jenkins et al., 2006). That is, they encompass literacy approaches that not only focus on individual engagement with media (media literacy) but also that address community involvement and participatory cultures. "Media literacies" also include literacies such as reading and writing.

Positive /

Respectful

Behavior

我

Privacy and

Reputation
Positive/Respectful Behavior: The ability to interact with others (both individuals and the larger collective (James, 2014)) online in a respectful, ethical, socially responsible, and empathic manner.

Privacy and Reputation: The ability to protect one's personal information online, and that of others. An understanding of the digital "trail" left behind as a result of the activities one engages in online, the short- and long-term consequences of this trail, the appropriate management of one's virtual footprint, as well as an understanding of inferred data (i.e., new data derived from capturing and analyzing other data points, which may result in new knowledge about a person (van der Hof, 2016)).
Safety and

Well-being
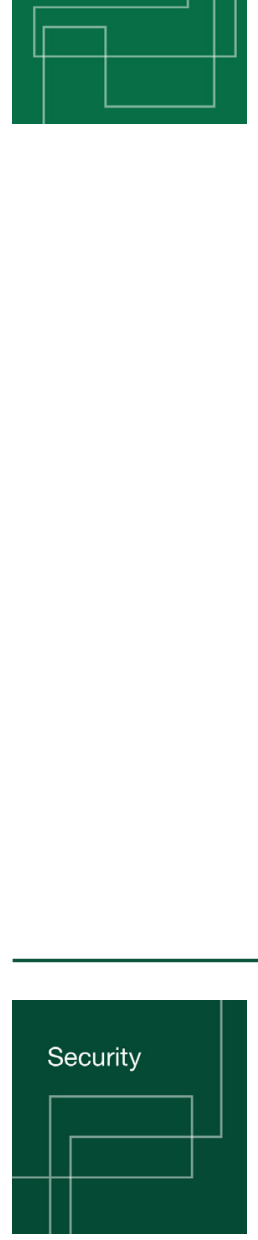

Safety and Well-being: The ability to counteract the risks that the digital world may come with to protect one's physical and mental well-being (e.g., guarding against Internet addiction and repetitive stress syndrome). Online risks can be classified along three main dimensions: conduct (e.g., cyberbullying, sexual harassment/ unwelcome "sexting"); contact (e.g., face-to-face meeting after online contact, communication with individuals pretending to be another person); and content (e.g., exposure to pornographic content, violent or aggressive content, harmful speech, content about drugs, racist content) (Livingstone, Kirwall, Ponte, \& Staksrud, 2014).

Security: The ability to protect the integrity of one's information, digital devices, and assets (e.g., login information such as passwords, profiles, websites). 


\section{THE AREAS APPLIED IN A SCHOOL CONTEXT}

Civic and Political Engagement/History » Make

a comparison between a historical social movement and a more recent one. Ask students: how did people communicate with each other within the movement? How were the movements covered in the media? As part of this exercise, you could introduce students to the "Hashtags" learning experience.

Digital Economy/Science » Online media that teaches about various scientific concepts has grown popular. YouTubers, bloggers, and personalities like Bill Nye and Neil deGrasse Tyson utilize digital communication tools to build an online brand that makes complex scientific ideas accessible to a mass audience. With your students, identify how these popular science online content creators establish trust with their audience, how they cite scientific information, and the different strategies they use to make their content entertaining for their audience. Discuss the skills students think are involved in developing this content (e.g., research, creative thinking, media production). Using these best practices, have your students create content for a popular science YouTube channel, webpage, or blog, and have them reflect on some of the skills they developed in this process. Discuss the differences in preparing content for a science-professional audience vs. a general population audience. As part of this exercise, you could introduce students to the "Identifying Our Strengths" learning experience.

\section{Identity Exploration and Formation/English »} Have students create a social media profile for characters in a literary text the class is reading. Ask students to choose the profile picture, handle or username, and compose the "About Me" section, friends list, and a few sample posts and/ or images the character would share. Consider having multiple students create a profile for the same character and then have the class compare and contrast each of the profiles created. Why did the students make the decisions they made about what to include in the profile they created? As part of this exercise, you could introduce students to the "Online Presence" learning experience.

Information Quality/Math »Identify a news story that presents a mathematical concept in an unclear way. A good example of this is a misleading statistic. Have students identify the source of the statistic (e.g., from what research article is the statistic from?). Do they see the statistic presented in other news stories? If so, encourage students to make a timeline of the sources where this statistic appeared. Discuss: across the different sources, what potentially motivated the use of the statistic? What is the impact (potential or actual) of including such a statistic in the story/stories? As part of this exercise, you could introduce students to the "Beyond the Original" learning experience.

Security/English » Have students write persuasive essays on a security-related topic. An example could include students arguing for or against connecting personal devices to the school WiFi network. In the process, students will likely interact with technical texts. One of their goals will be to make this information understandable to a general audience. As part of this exercise, you could introduce students to the "Public Wi-Fi" learning experience.

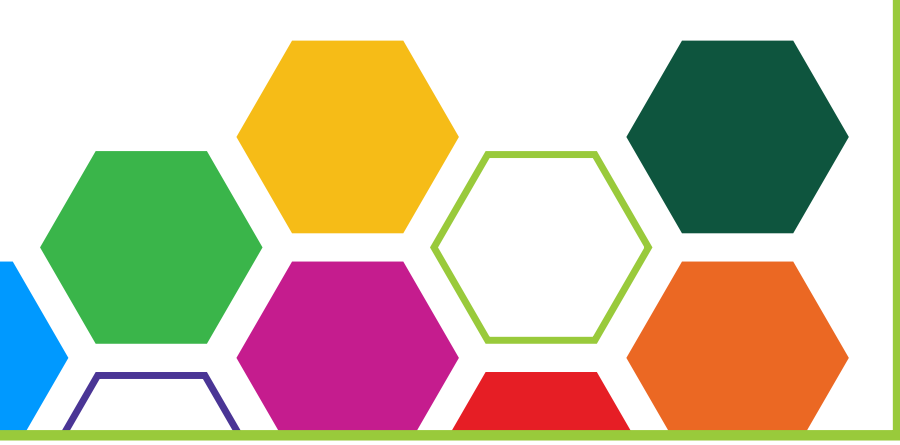




\section{THE AREAS IN SETS OF EDUCATIONAL TOOLS}

Our learning experiences and other educational tools can be mixed and matched in countless ways. Just as examples, imagine the following two scenarios:

Scenario 1. You are an organization whose mission is to reverse the increasing gender digital divide and empower women and girls in acquiring skills that will help them become both ICT users and creators in the digital world. You have an afternoon to work with a group of young women - some of the themes you may want to reflect on might include: social media habits; how others may perceive what they post online; ways they can present themselves differently online to different people; and how they can feel more empowered to tackle changes they want to see in their communities. Here is a grouping of activities, along with an assignment, that could be interesting:

- [15 minutes] Activity: Social Media Use

- [40 minutes] Activity: Thinking Caps

- [20 minutes] Activity: Reflections on Perspective

- [30 minutes] Activity: What Is Advocacy?

- [50 minutes] Assignment
Scenario 2. You are working on a project that harnesses the power of creative arts for youth and community development. Once a week, you work closely with young artists and cultural creatives as they use their creativity to bring the community together for dialogue and action. Here is a grouping of activities, along with an assignment, that you might find helpful to engage in with the youth you mentor to show how various types of media can be used to promote awareness around an issue:

- [15 minutes] Activity: Using Media for Change

- [15 minutes] Activity: Activism Using Hashtags

- [15 minutes] Activity: Knowing How Reverse Image Search Works

- [65 minutes] Assignment

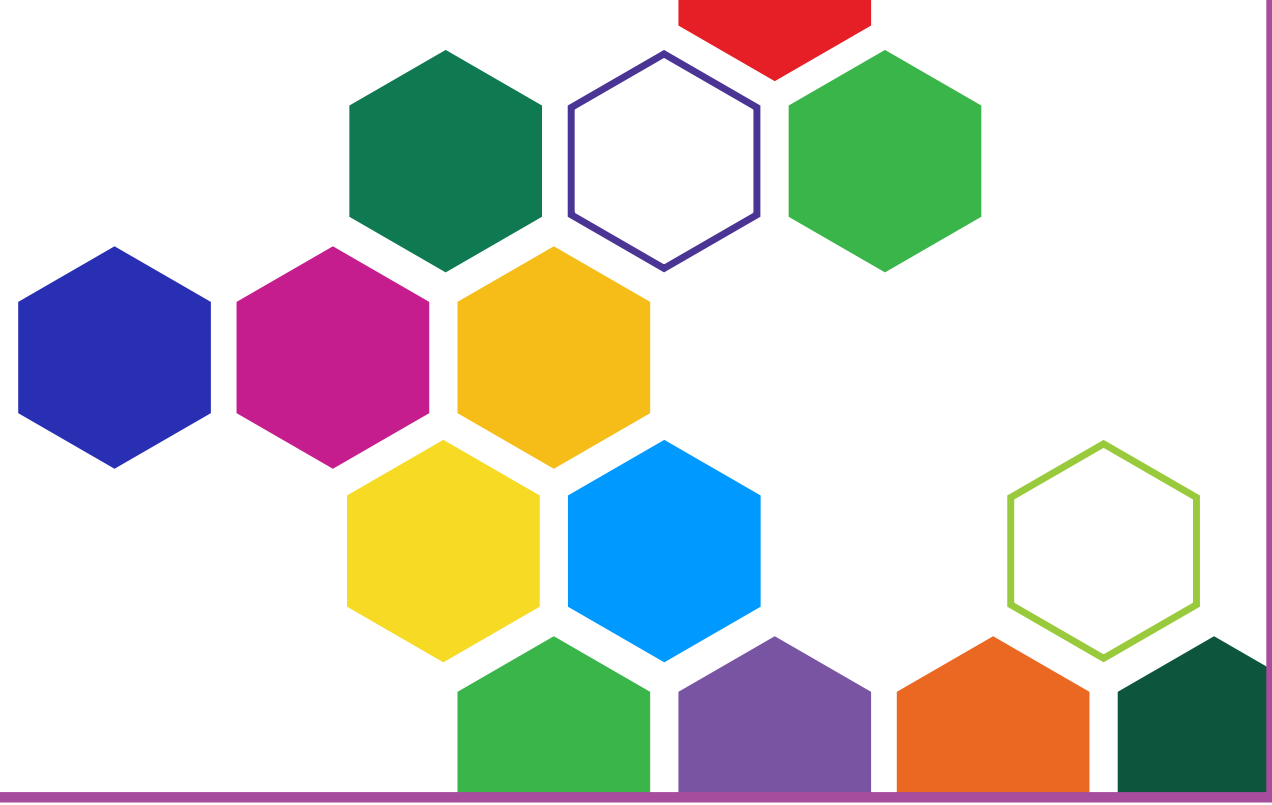




\section{A POSSIBLE GROUPING}

Here, we provide a possible way to group the 17 areas of life that comprise "digital citizenship+ (plus)" into four clusters: 1) participation, 2) empowerment, 3) engagement, and 4) wellbeing. Although this clustering may help highlight common themes among certain areas, we prefer to retain focus on the areas themselves, versus the groupings.

$$
\begin{aligned}
& \text { 1. Participation } \\
& \text { - Digital Access } \\
& \text { - Digital (Literacy) } \\
& \text { - Content Production } \\
& \text { - Security } \\
& \text { - Law }
\end{aligned}
$$

\section{Engagement \\ - Digital Economy \\ - Data \\ - Computational \\ Thinking \\ - Artificial Intelligence}

2. Empowerment

- Civic and Political

Engagement

- Context

- Information Quality

- Media (Literacy)

4. Well-being

- Privacy and

Reputation

- Identity Exploration and Formation

- Positive/Respectful

Behavior

- Safety and Well-being

\section{Empowerment}

The educational tools under this grouping help youth participate in public matters and advocate for issues they care about; develop the ability to be aware of and interpret the contextual factors of relevance (e.g., cultural, social, local/regional/ global) in a given situation and effectively engage in it; and find, evaluate, create, and share information and other content in different media forms.

Areas: Civic and Political Engagement, Context, Information Quality, and Media (Literacy).

\section{Engagement}

The educational tools under this grouping help youth cultivate the ability to navigate economic activities online and offline; engage in data creation, collection, interpretation, and analysis; understand and apply computational concepts; and understand and take part in conversations around artificial intelligence.

Areas: Digital Economy, Data, Computational Thinking, and Artificial Intelligence.

\section{Well-being}

The educational tools under this grouping help youth protect their personal information online (and that of others); explore their identity; engage with others (both individuals and the larger collective) online in empathic, ethical, and positive ways; and counteract the risks the digital environment may come with to protect their physical and mental health.

Areas: Privacy and Reputation, Identity Exploration and Formation, Positive/Respectful Behavior, and Safety and Well-being.

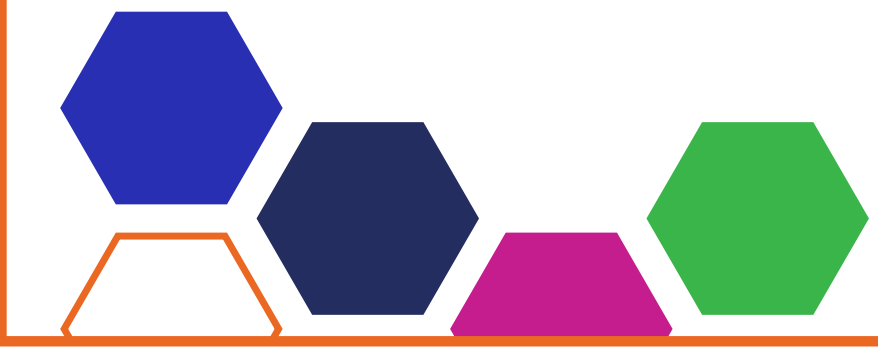

Areas: Digital Access, Digital (Literacy), Content Production, Security, and Law. 


\section{A VISUALIZATION OF OUR FINDINGS WITHIN THE 35 FRAMEWORKS}

The visualization in this part III, section 3 aims to illustrate part of the current digital citizenship dialogue. The 17 areas of life connected to the digital environment that YaM used to organize these frameworks are listed on the horizontal axis. To the far right, "Youth Involvement" indicates whether or not youth (12-18-year-olds) were involved in the development of each framework. Selected stakeholders who have developed a digital citizenship framework (or a framework on a related concept, listed under "Other Frameworks") are displayed on the vertical axis.

It is important to keep in mind that this visualization does not represent a value judgment of the frameworks within it. We selected the frameworks because we feel that each represents a significant contribution to the field of youth and digital technologies, and, as noted in this part III, section 1 , has resulted in an action-oriented output(s) (i.e., educational materials and/or programming, a report or study, and/or legislation). The explicit inclusion of a greater number of areas in one framework versus another does not make one framework "better" - each is shaped by specific guiding principles and beliefs, which vary across the landscape of frameworks included in this visualization.

That being said, if you have worked or are planning to work on digital citizenship (and you explicitly would like to use that term), it may be helpful for you and those to whom you are communicating your efforts to consider how you are framing your work. More specifically, it may be useful to reflect on the following questions:
1. Is your work meant to be holistic and cover a wide array of areas? If so, how did you decide which ones to focus on, and for what reasons?

2. Alternatively, is your work a more specific effort, focusing on a smaller subset of areas? Again, if so, how did you decide which ones to focus on, and for what reasons?

3. Do you feel that the term "digital citizenship" reflects the areas included within your framework? If so, why? If not, might there be ways to adjust the areas included in your framework and/or the overall term you're employing?

We also recognize that frameworks around digital citizenship and related concepts will continue to evolve. Against this backdrop, we welcome further discussion around the areas that various stakeholders deem important in the context of young people and the digital world. If your framework is represented in the visualization and you plan to modify the content, please do not hesitate to reach out to us - we would be most happy to include your updated work in further versions of the visualization. Additionally, if you have developed a digital citizenship framework, or a framework on a similar concept, and would like for your work to be represented in future versions, please feel free to contact us.

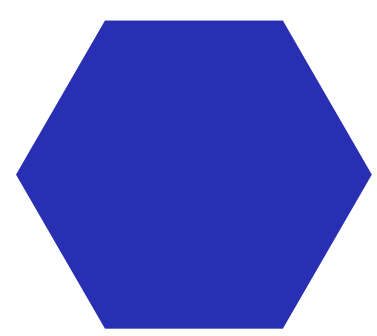

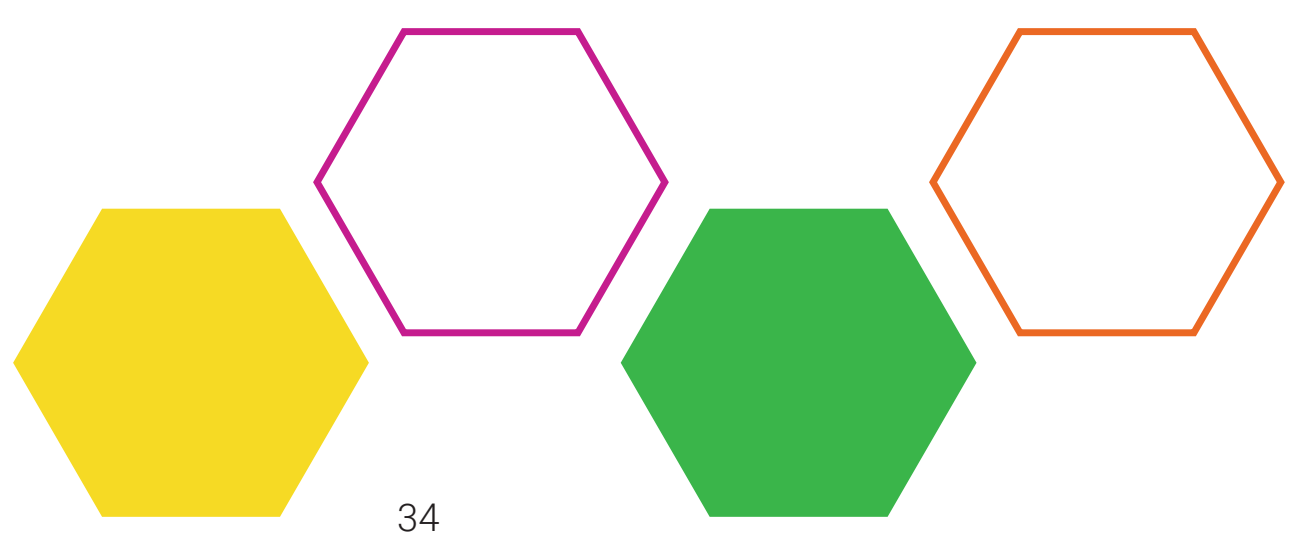




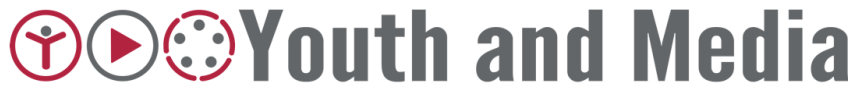

5 This visualization illustrates the frameworks mapped as part of the Youth and Digital Citizenship+ (Plus) spotlight by Youth and Media (YaM) at the Berkman Klein Center for Internet and Society. One side illustrates the 17 areas of life connected to the digital world YaM used to organize these frameworks and whether or not youth (12-to 18-year-olds) were involved in the development of each framework. The other side lists each stakeholder, their sector(s), and location.

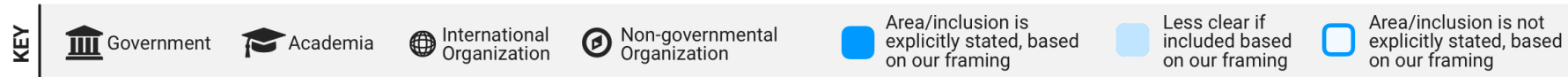

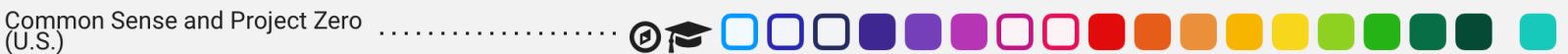

DQ Institute (Singapore) $\ldots \ldots \ldots \ldots \ldots \ldots \ldots \ldots \ldots \ldots$ ( )

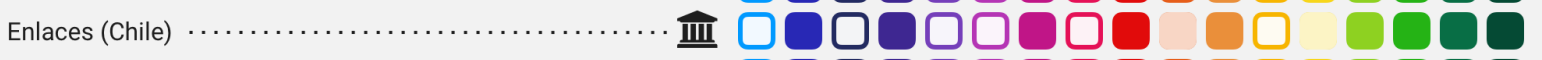

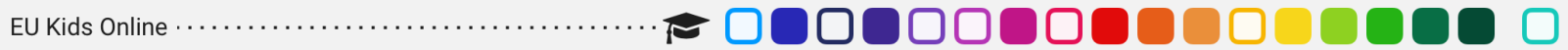

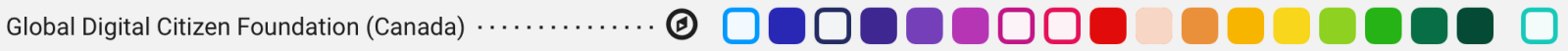

International Society for Technology in Education (U.S.) .... (.)

Jones, Lisa and Mitchell, Kimberly (U.S.) .............. 00000000000000000000

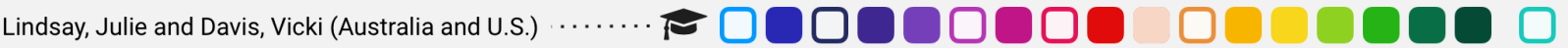

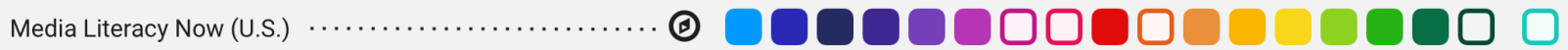

Mossberger, Karen; Tolbert, Caroline; .....................
and McNeal, Ramona (U.S.)

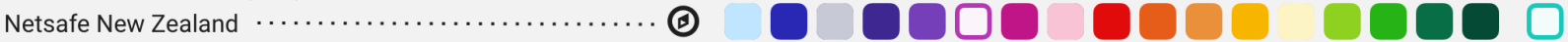

New South Wales Department of Education ............. IIII
(Australia)

PantallasAmigas (Spain) $\ldots \ldots \ldots \ldots \ldots \ldots \ldots \ldots \ldots \ldots$ (a)

Ribble, Mike (U.S.) $\ldots \ldots \ldots \ldots \ldots \ldots \ldots \ldots \ldots \ldots \ldots \ldots \ldots$

UNICEF $\ldots \ldots \ldots \ldots \ldots \ldots \ldots \ldots \ldots \ldots \ldots \ldots \ldots \ldots \ldots \ldots \ldots \ldots$

(II......................

Washington State Legislature

(0)00000000 0000000

- 0000000000000000

- 000000000000000

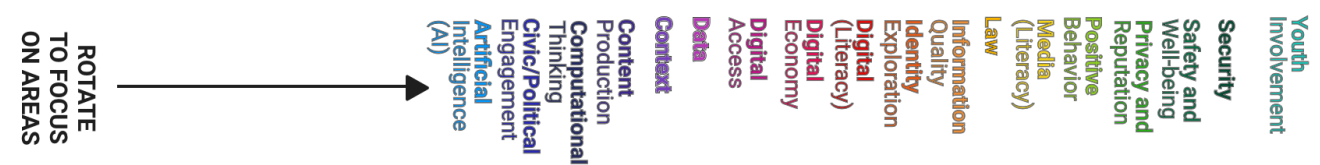

Child Exploitation and Online Protection Command (U.K.) . IIII $\square 00000000000000000$ Convergence Design Lab (U.S.) $\ldots \ldots \ldots \ldots \ldots \ldots \ldots \ldots \ldots \cap 00000000000000000$

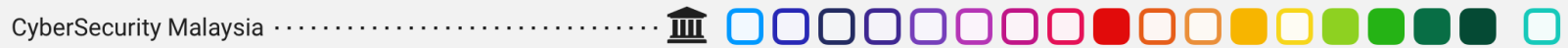

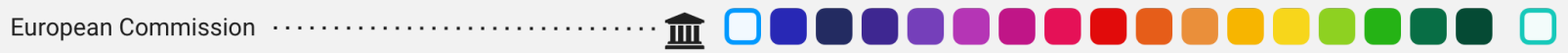

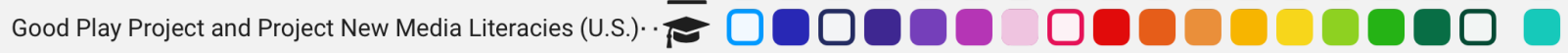

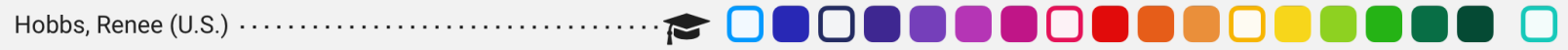
International Computer Driving License (ICDL) Foundation . (1) 0 000000000000000 Malaysian Communications and Multimedia Commission * IIII 000000000000000

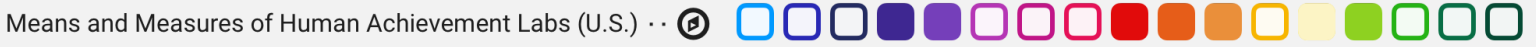

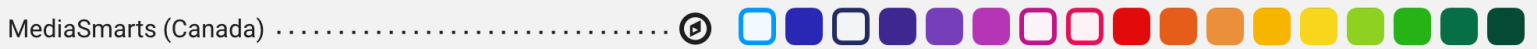

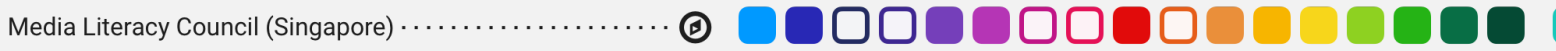

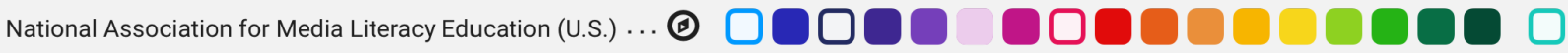
National Coalition for Core Arts Standards (U.S.) .......... (0)

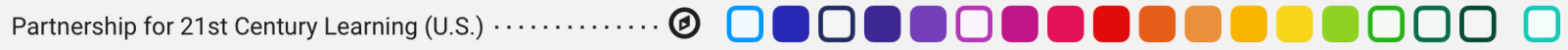

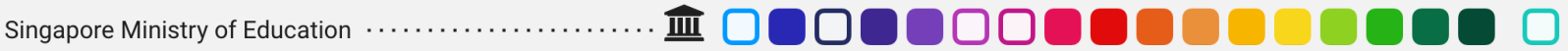

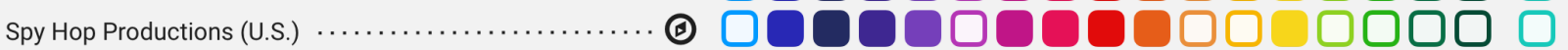

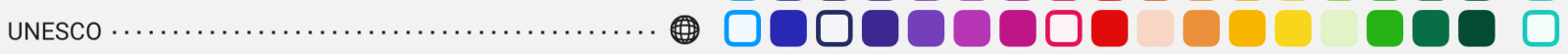

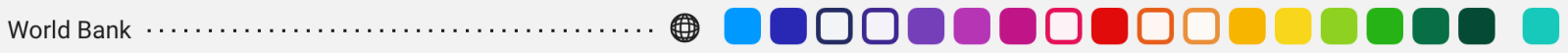

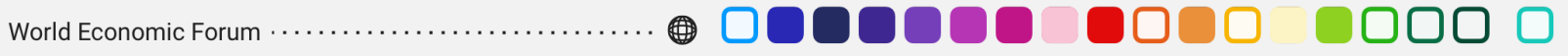

인 One can view this visualization by individual framework, multiple frameworks, and/or area(s). To learn more, please see the full spotlight. If you would like your framework to be added to this visualization or you feel that your work has not been accurately represented, please do not hesitate to email YaM at youthandmedia@cyber.harvard.edu. 


\section{CONSIDERATIONS}

Based on our digital citizenship mapping exercise described in part III, we note six important observations that may be helpful in the development and deployment of digital citizenship frameworks, and frameworks addressing other concepts (e.g., digital literacy, 21st century skills). In section 1 , we present a brief overview of several terms that various stakeholders use to describe how an individual masters an area of life connected to the digital world (e.g., "skills," "literacies," "abilities," etc.) and how the term(s) relates to the overall goal of the framework. In section 2, we explain that while we designated 17 areas (presented in part III, section 2), it is important to keep in mind the highly interconnected nature of these areas. In section 3 , we demonstrate how it may be helpful to take into account contextual factors - including age, ethnicity, race, gender and sexual identity, religion, national origin, location, skill and educational level, and/or socioeconomic status - in how youth engage with digital citizenship efforts. In section 4, we describe how the current digital citizenship discourse may benefit from a broadened scope to encompass additional educational, economic, and cultural opportunities available online to young people today. In section 5 , we note the importance of including young people in the curation of digital citizenship initiatives to ensure these opportunities are tailored to their diverse backgrounds, needs, and interests. And in section 6, we observe that once digital citizenship initiatives are implemented, it may be useful to consider how to assess the skills youth acquire over time as they engage with the materials associated with the frameworks.

\section{UNDERSTANDING OF THE LENS AND CONNECTED TERMS}

Our framework mapping has intentionally had a thematic lens, meaning we identified 17 areas of life we feel are currently relevant and important to address. In part III, section 2, we define what we mean by each area, where each area is presented as a noun. We acknowledge, however, that in several cases, framing an area as a noun has been difficult as these nouns rarely stand alone in an educational context - often, the words "literacy" or "competency" are attached to the noun. This was particularly relevant for digital (literacy/competency) and media (literacy), though we also ran into similar considerations around the areas of data and information quality. However, for consistency reasons, we decided to designate each thematic area as a noun, placing "literacy," even in the two most challenging cases, in parentheses after the area (i.e., digital (literacy) and media (literacy)).

One of the main challenges we encountered when thinking about how to frame each area centered on how to define a "literacy," versus a "competency" (the latter, in the plural, often referenced by others as "competencies" or "competences"), versus a "skill/set of skills." When reviewing the frameworks we mapped in part III, section 3, we noticed that the main term that a framework utilizes varies whether that might be a digital "skill," "literacy," or "competency." So too, do definitions of each term. 
Let us turn now to a few examples of how the conceptualization of these terms varies.

Van Deursen (2010), for instance, defines digital literacy as consisting of competencies and knowledge, while digital skills encompass the applied aspects of such competencies and knowledge. ${ }^{29}$ Van Dijk and van Deursen (2014) prefer the term "skills" over "literacies" and "competencies" as they feel that the word "skills" implies a more interactive engagement with media than, for instance, the word "literacy," which they associate with traditional print literacy (i.e., reading and writing texts).

According to van Deursen (2010) and van Dijk and van Deursen (2014), in the context of the digital environment ...

Literacy $=$

- Competence

- Knowledge » Applying competencies and knowledge requires skills

Others view digital skills under the overall umbrella of digital competence. For instance, according to the European Commission's DigComp 2.1 framework $^{30}$ (Carretero et al., 2017), a "competence" is comprised of knowledge, skills, and attitudes. More specifically, "knowledge" refers to the "body of facts, principles, theories and practices ... related to a field of work or study;" "skills" address the application of this knowledge and are described as "practical (involving manual dexterity and the use of methods, materials, tools and instruments)" and "cognitive (involving the use of logical, intuitive, and creative thinking);" and "attitudes" include the values and goals that motivate one's performance (Vuorikari, Punie, Carretero, \& Van den Brande, 2016, p. 39).

\footnotetext{
${ }^{29}$ For a more in-depth look at van Deursen's framework around digital skills, please see part II, section 1 .

${ }^{30}$ To learn more about the DigComp 2.1 framework, please see part II, section 4 .
}

According to Carretero et al. (2017), in the context of the digital environment ...

Competencies $=$

- Attitude

- Knowledge

- Skills = application of knowledge

» Cognitive

» Practical

The OECD Learning Compass 2030 also clusters skills, attitudes and values, and knowledge under "competencies." "Skills" are defined as "the ability and capacity to carry out processes and be able to use one's knowledge in a responsible way to achieve a goal" (OECD, 2019, p. 13). And "knowledge" encompasses "theoretical concepts and ideas in addition to practical understanding based on the experience of having performed certain tasks" (2019, p. 13). "Attitudes and values" are defined as the "principles and beliefs that influence one's choices, judgements, behaviours and actions on the path towards individual, societal and environmental wellbeing" (2019, p. 13). According to the OECD, knowledge, skills, and attitudes and values are not competing concepts; they are developed interdependently - for instance, attitudes and values often influence the transfer of knowledge and skills.

According to the OECD (2019), in the context of the digital environment ...

Competencies $=$

- Attitudes and values (which influence an individual's choices, judgements, and actions)
» Personal
» Societal
»Social
» Human

- Knowledge

»Disciplinary » Epistemic

» Interdisciplinary » Procedural

- Skills

» Practical and physical

»Cognitive and meta-cognitive

» Social and emotional 
A detailed history of the conceptual debate around "literacy," "competency," and "skill" is beyond the scope of this paper - ideally, this section (and the simplified illustrations) showcases just some of the ways these terms are operationalized differently. For the purposes of this paper and our ongoing work, we chose to work with the term "skills" and disregarded other terms and concepts to reduce complexity. We are working with the term "skill" as defined by the OECD. According to the OECD (2018), "skills" encompass 1) practical (e.g., utilizing new digital technology devices) and physical (e.g., using a digital device, such as a tablet or mobile phone, to achieve a specific outcome, like finding information online for a school assignment) skills, 2) social and emotional skills (e.g., collaboration, self-efficacy, empathy), and 3) cognitive and meta-cognitive skills (e.g., self-regulation, motivation to learn, creativity, and critical thinking) (p. 5). Under the umbrella of practical and physical skills, we interpret the capacity to "use technological devices" as the ability to connect to the Internet, access resources and information, set up accounts/profiles, and operate digital device software and hardware (e.g., turning on a computer or mobile device, typing on the keyboard, knowing how to use spreadsheets and word processing applications) (Broadband Commission for Sustainable Development, 2017). To cognitive skills, we would also add an understanding of an area (e.g., understanding what an algorithm is, or determining if a work is in the public domain). In the definitions of our 17 areas of life in part III, section 2, we use the term "ability" to refer to the capacity to apply practical and physical, cognitive and metacognitive, and social and emotional skills to engage in the activities specified for each area.

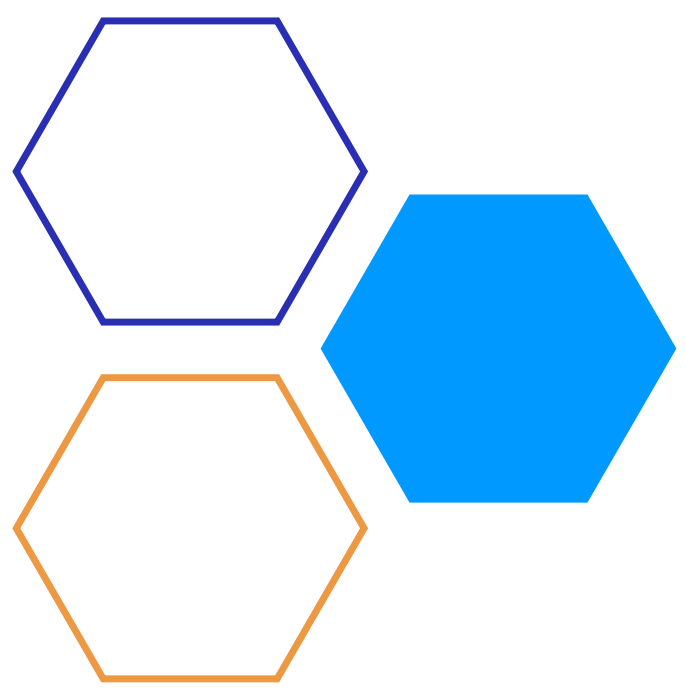

According to our YaM team, in the context of the digital environment...

Ability =

- Capacity to apply the following skills...

» Practical and physical

» Cognitive and meta-cognitive

» Social and emotional

- To engage in the activities specified in YaM's 17 areas of life, such as...

» Understanding the algorithms involved in the Al-based platforms one interacts with (Artificial Intelligence)

»Interacting with others (both individuals and the larger collective) online in a respectful, ethical, socially responsible, and empathic manner (Positive/ Respectful Behavior)

While our team adopts the OECD framing for skills, there is a myriad of other ways to conceptualize skills and skill sub-categories - some of which are framed in the context of Internet use, while others are operationalized in a broader sense. As elaborated upon in part II, section 1 of this paper, for example, van Dijk and van Deursen (2014) define skills in the context of Internet usage along six dimensions: 1) operational skills, 2) formal skills, 3) informational skills, 4) strategic skills, 5) content creation skills, and 6) communication skills (van Deursen et al., 2014; van Dijk \& van Deursen, 2014). More broadly, as described in part II, section 3, P21 (2019) conceptualizes three categories of skills: 1) learning and innovation skills, 2) life and career skills, and 3) information, media, and technology skills. These sets of skills are complemented by content knowledge around domains including math, science, English, and other subjects.

Still others adopt an approach that divides skills into "hard skills" and "soft skills." As Goodspeed (2016) points out, one way some have operationalized "hard skills" and "soft skills" has been "hard cognitive skills" and "soft behavioral/dispositional skills." Hard cognitive skills may be viewed as the capacity to "interpret, reflect, reason, think abstractly, and assimilate 
complex ideas, solve problems and generalize from what is learned" (Ayrton Senna Institute \& UNESCO, 2014, p. 9). In practical terms, they often include content knowledge, as well as higher-order thinking measured by grades or standardized achievement assessments (Goodspeed, 2016). By contrast, soft skills often encompass individuals' capacity "to relate to others and themselves, understand and manage emotions, set and attain goals, make autonomous and responsible decisions, and creatively and constructively confront adverse situations" (Ayrton Senna Institute \& UNESCO, 2014, p. 9). Researchers refer to "soft skills" in a wide array of ways, including "social and emotional skills," "non-cognitive skills," and "character skills," and they define these skills in different ways. Regardless of the debate around the meaning of soft skills and the varying terms used, soft skills are unique in that they are 1) conceptually distinct from hard cognitive skills (soft skills are perceived as beneficial to individuals and society at large) and 2) expressed in different ways depending on the context (Duckworth \& Yeager, 2015). Though our team does not adopt the "hard skills" versus "soft skills" distinction, if this framing is useful, we suggest that you think of "practical and physical" and "cognitive and meta-cognitive" skills as hard skills and "social and emotional" skills as soft skills.

Additionally, it is important to note that we don't draw an online/offline distinction in the way we conceptualize the skills associated with the areas in part III, section 2. As Palfrey and Gasser
(2016) point out, many youth are "living partly in a digital environment and partly in a face-to-face environment. From their perspective, there is no 'online life' and 'offline life.' There's just 'life'" (p. 341). In the context of young people's online and offline social networks, for instance, research indicates an overlap (Reich, Subrahmanyam, \& Espinoza, 2012; Subrahmanyam, Reich, Waechter, \& Espinoza, 2008). Against this backdrop, we view skills related to offline activities as part of digital citizenship+ (plus) if they can be applied to the digital landscape. Some frameworks that we examined framed the area of positive/respectful behavior, for instance, in general terms, such as "social awareness." According to the Means and Measures of Human Achievement (MHA) Labs, "social awareness" encompasses capacities such as understanding the consequences of one's actions and taking into account norms associated with different cultures and contexts (MHA Labs, n.d.). We feel that if someone engages in social awareness, as defined by MHA Labs, with others offline, they could potentially apply these skills as they interact with others online.

As you develop or build upon a program or initiative on digital citizenship or a related concept, we recommend that you are somewhat critical of these terms - whether you use "skill," "literacy," "competency," or another similar term. It may be helpful to reflect on what these terms mean to you and why you might prefer a certain term(s) over others.

\section{RECOGNIZING THE INTERCONNECTEDNESS OF AREAS}

From our framework mapping process, we derived a list of 17 areas that are designed to act as a helpful guide in thinking about how to equip youth with the skills needed to be able to navigate areas of life connected to the digital environment. While each area represents a single category of activity, it is helpful to keep in mind that many of these areas intersect. In exploring identity online, for instance, young people have the opportunity to "brand" themselves on different digital platforms by producing an array of content - sharing status updates on Facebook, posting photos on Instagram, or, on the more active spectrum, creating and uploading videos to YouTube. These "intentional digital contributions. . are central to a young person's identity" (Palfrey \& Gasser, 2016, p. 25). By sharing this information, youth have the ability to create an image of both how they see themselves and how they want others to view them (Williams \& Merten, 2008). Part of young people's decision to share information about themselves in digital spaces is tied to social norms around what researchers term "reciprocity of self- 
disclosure" (Joinson, 2001). Within the online world, this construct refers to the expectation that one reciprocally exchanges information with others. Palfrey and Gasser (2016) suggest, however, that "the expectation that one ought to reciprocate when someone else shares personal information, for example, may lead a 16-year-old to share information about herself with little regard for risks" (p. 27). These risks range from the ways third parties may use information that youth knowingly (and unknowingly) share online to the impact the persistent nature of online information may have on young people's academic and professional futures (Palfrey \& Gasser, 2016). Thus, within the context of the single area of identity exploration and formation, we envision that youth navigate a range of challenges and opportunities connected to other areas, such as forming and maintaining relationships, working through information quality issues, and managing their reputation and privacy, while staying safe and taking care of their well-being.

\section{BEING MINDFUL OF CONTEXT}

As we studied the selected frameworks addressing digital citizenship and other concepts (e.g., media literacy, 21st century skills), we observed that several of the initiatives presented areas of life in a hierarchical fashion. However, we chose not to order the areas provided in part III, section 2 into a particular hierarchy as we believe the perceived importance of each area depends upon one's context. We recommend developing digital citizenship initiatives that remain mindful of young people's context and how factors such as gender, age, ethnicity, race, sexual identity, physical ability, geography, religion, socioeconomic status, national origin, and educational attainment may affect their access to and use of digital technologies. ${ }^{31}$ For example, UNICEF (2017) estimates that around $29 \%$ of young people around the world, or 346 million individuals ages 15-24, do not have access to the Internet, with almost $90 \%$ of youth without access living in Africa, Asia, or the Pacific. On a global level, there is an Internet user gender gap of $17 \%$, which is particularly marked in developing countries (International Telecommunication Union [ITU], 2019b). Additionally, in the least developed countries, only about $19 \%$ of the population is online, compared to almost $87 \%$ of individuals within developed countries (ITU, 2019b). Those from regions with large inequities in Internet access may then perceive digital access as one of the most integral areas of life related to online engagement, compared to, for instance, content production or law.

With respect to national origin, studies exploring social media use among Indigenous youth in Australia, for example, reveal that social media can offer Indigenous youth opportunities to express their identity and connect with other members of the community, helping them to define, affirm, and strengthen their identity (Healy, 2013; Kral, 2010; Lumby, 2010). Social media accounts such as @IndigenousX on Twitter provide a space for Indigenous peoples to share their stories with others, with a different member from the Indigenous community tweeting each week from the account (Rice, Haynes, Royce, \& Thompson, 2016). Nominated for a Shorty Award, which recognizes content creators on social media, @IndigenousX has been praised for "shar[ing] Indigenous knowledge and stories, challeng[ing] stereotypes, and reflect[ing] the diversity of Indigenous people" (Sweet, Pearson, \& Dudgeon, 2013, p. 107). Scholars note that social media-based communities can help bring together and heal the Indigenous community (Rice et al., 2016) and that a well-formed cultural identity is associated with increased educational achievement (Dockery, 2013) and the prevention of self-harm among Indigenous youth (Dudgeon et al., 2012). Thus, in the case of young

${ }^{31}$ For a more in-depth discussion of the potential impact that demographic factors - specifically, gender, race, and socioeconomic status - have on youth accessing, using, and developing skills around digital technologies, please see part VI, section 1. 
people from Indigenous communities, certain areas of life, such as identity exploration and formation, may be particularly salient to their online engagement. ${ }^{32}$

Against the backdrop of these contextual dimensions, we acknowledge that youth skill development can be impacted by youth's prior experiences and opportunities, as well as young people's access conditions, among other factors. We encourage individuals to consider the following questions to keep the importance of context in mind when creating initiatives that promote youth online engagement:

Does the young person in question have access to the Internet and digital technologies? If so,
- What primary digital tools and platforms does the person use (e.g., tools such as a desktop computer, laptop, or mobile device; platforms such as Twitter)?

- Who is using these technologies (e.g., individual vs. shared family device)?

- Where are the technologies being used (e.g., at school, at home, on the go)?

- What underlying purpose are these technologies being used for (e.g., learning, social life, entertainment)?

\section{CHOOSING A MORE BALANCED APPROACH}

As we mapped the different frameworks, we observed that the majority of explicitly included areas of life (see the visualization in part III, section 3) were clustered around areas traditionally associated with online risks and potential harms. These areas include safety and well-being, security, privacy and reputation and, to an extent, positive/respectful behavior. Areas connected to leveraging online opportunities appeared with less frequency but were still prevalent. For instance, more than half of the initiatives explicitly included the areas of civic and political engagement, information quality, and content production. Less surprisingly, few frameworks explicitly included digital economy, data, and artificial intelligence. Thus, our review suggests that while digital citizenship initiatives are making efforts to balance the discourse around challenges and opportunities, there are still key areas that should be further addressed for youth to be able to acquire the skills to fully harness the opportunities the digital environment may offer.

\section{INVOLVING YOUTH}

Although the vast majority of the digital citizenship frameworks we mapped specifically focused on the youth population, few initiatives incorporated direct or indirect youth involvement ${ }^{33}$ in the design, implementation, and curation process. As youth are the primary target population for many of these educational efforts, we recommend developing digital citizenship initiatives that are tailored to their diverse backgrounds, needs, and interests.
For example, the Good Play Project and Project New Media Literacies (2011) pilot tested their Our Space curriculum with students in formal and informal learning settings in different regions of the U.S. Based upon this testing, the projects further refined the format, framing, and substance of the curriculum. In another example of youth involvement, in the design of ISTE's Standards for Students, the organization solicited and incorporated feedback on the standards

\footnotetext{
${ }^{32}$ Please note that this discussion around the perceived importance of areas of life in terms of context should not be interpreted as generalizations that apply to all members of the communities noted in this section.

${ }^{33}$ As noted in part III, section 1, we operationalized "youth involvement" as youth providing input in the curation of the framework through direct means (e.g. directly telling researchers what areas of life related to the digital environment are personally meaningful), or indirect means (e.g., participating and providing feedback on a pilot digital citizenship curriculum implemented in schools).
} 
(drawn from individual surveys and comments on online forums) from more than 2,500 individuals including "hundreds of students" (ISTE, 2016, p. 4).

At YaM, our own work around co-designing educational tools in collaboration with young people of diverse ethnicities, socioeconomic backgrounds, and educational levels has allowed us to incorporate youth perspectives and attitudes towards areas of life such as content production, civic and political engagement, identity exploration and formation, privacy and reputation, security, and artificial intelligence. From 2016 to 2017, for example, the YaM team partnered with several youth-serving organizations in the Boston area to co-design four curriculum playlists (i.e., a set of learning experiences in a specific sequence) with and for youth (LombanaBermudez, 2016). These playlists focused on areas such as law, civic and political engagement, the digital economy, and identity exploration and formation. Selected for their interest in digital technology and design, our youth collaborators engaged in a codesign process in which they identified the themes, goals, and potential audiences of each playlist before prototyping and testing the playlist materials. Closely mapped to the phases of the design thinking process (i.e., empathize, define, ideate, prototype, and test) (Hasso Plattner Institute of Design at Stanford, n.d.), YaM's co-design workshops enabled youth to become part of a participatory and collaborative environment where their knowledge, curiosity, and creativity were invited and valued. The inclusion of diverse youth in the co-design process resulted in the discovery of new playlist themes and activities (e.g., creating a playlist around job hunting based on feedback from youth). Involving young people in the co-design process also helped our team better understand how we can adjust the content and framing of our educational tools to be more mindful of different cultural contexts. While developing effective co-design sessions ${ }^{34}$ can require great flexibility, time, and investment, the inclusion of youth in the development and deployment of digital citizenship initiatives can help ensure that the content is meaningful and engaging to young people (Gasser, 2019).

\section{ASSESSING FRAMEWORK EFFICACY}

In order to better understand the effectiveness of initiatives around digital citizenship, and related concepts, it may be helpful to measure the skills youth are acquiring as they engage with the learning materials associated with these efforts. The DQ Institute, for example, recently assessed their DQ World program, an eight-week digital citizenship online learning program for youth ages 8 to 12 (DQ World, n.d.). By the end of the program, results from the survey, which collected data across 29 countries, demonstrated a 10\% increase in youth's overall "digital intelligence" (or "DQ") score, as well as a 15\% decrease in young people's exposure to online risks (DQ Institute, 2018).
Although many stakeholders developed frameworks with accompanying materials designed to be implemented within formal or informal learning settings, we observed that few published data measuring the efficacy of these efforts. In the absence of such information, it is difficult to measure the effectiveness of these initiatives and whether youth are actually learning how to be digital citizens. How can stakeholders effectively measure the acquisition of skills associated with various areas of life and track skill development over time? Additionally, can frameworks be refined to improve the end goal of teaching youth how to be better digital citizens, and if so, in what ways? As the Broadband Commission for Sustainable Development (2017, p. 6) points out,

${ }^{34}$ For more suggestions around how to develop and engage in the co-design process with youth, please see Lombana-Bermudez (2016). 
in the context of frameworks that address skills related to the digital environment, "enlarging the research and evidence base is essential to clarify best practices and build upon them."

More broadly, Reich, Cortesi, Haduong, and Gasser (2014) suggest several useful approaches for obtaining evidence around indicators of an organization's progress towards its goals. These three complementary strategies include 1) assessing program participation, 2) observing the program, and 3) gathering stakeholder reflections. In the context of digital citizenship initiatives, evaluation through program participation may include collecting metrics such as the number of young people engaging in the program and how often they participate in it (e.g., two workshops/classes per week over 10 weeks). Assessing an initiative through an observation of the program might encompass the evaluation of concrete outputs (e.g., videos that youth produce around civic and political engagement) by a rubric. Ideally, rubrics should include a set of categories that the product should address (e.g., integration of knowledge from multiple sources, critical analysis of sources), and benchmarks that indicate specific levels of proficiency for each category (Reich et al., 2014). Gathering stakeholder reflections may involve asking youth themselves - through surveys and/or interviews - about their experiences with the initiative. As Reich and colleagues (2014) point out, there is a vast array of methods to evaluate the success of a program; the approaches described in this part IV, section 6 represent just three potential ways of thinking about the evaluation process.

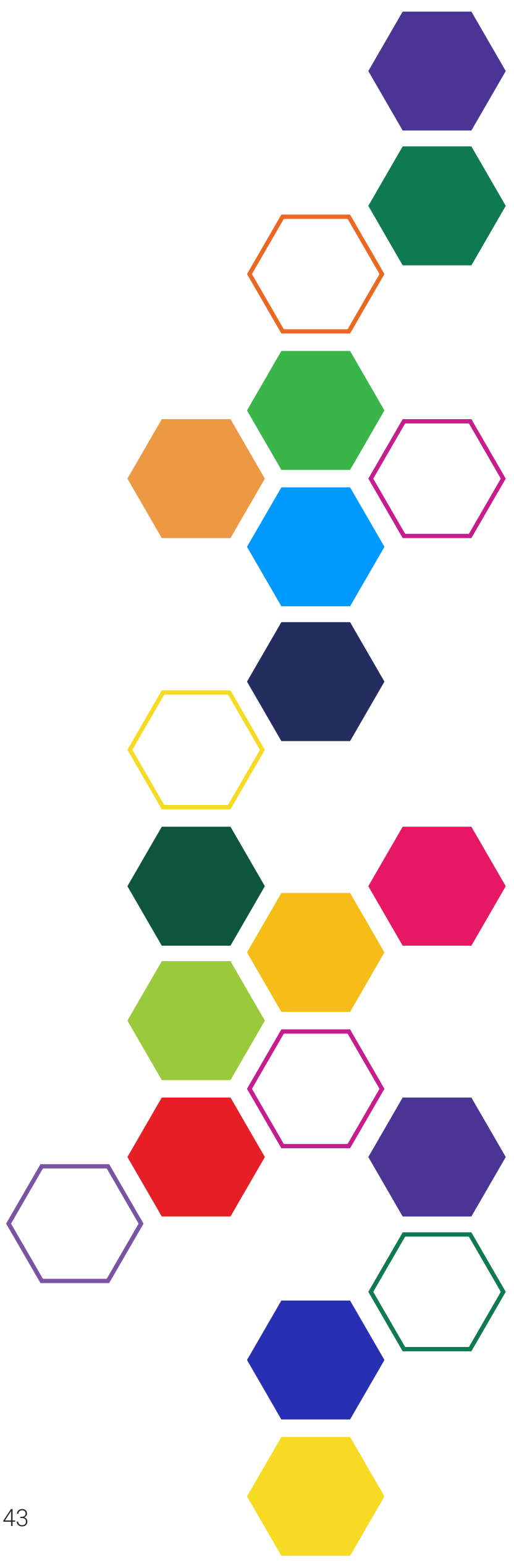




\section{LOOKING AHEAD: UNDEREXPLORED AREAS}

Based on the mapping of the frameworks, described in part III of this paper, we observed that the current digital citizenship conversation may benefit from increased dialogue around several areas of life that, thus far, seem to have received less attention within the frameworks we explored: data, computational thinking, artificial intelligence (AI), and the digital economy. In the majority of frameworks, these areas were rarely explicitly included. ${ }^{35}$ In this part $\mathrm{V}$, we provide a brief overview of how various formal and informal educational initiatives are addressing these first three areas. ${ }^{36}$ We hope that this overview will help foster further dialogue among stakeholders in terms of ways these areas of life can be further incorporated into digital citizenship efforts.

Additionally, we believe it is important to frame the three areas of life described in this part $\mathbf{V}$ not only in terms of physical (e.g., knowing how to engage with Al interfaces) and practical skills (e.g., understanding how to use an Al-powered voice assistant to look up information on Wikipedia) but also cognitive and meta-cognitive (e.g., visualizing data in creative and accessible ways) and social and emotional skills (e.g., using principles from computational thinking to advocate for social good). These types of skills become all the more important as these areas of life themselves may be perceived as predominantly technical; this perception may, in turn, diminish some youth communities' interest in exploring them. Additionally, as described in part IV, section 2, given the highly interconnected nature of areas of life, we feel it is helpful for educational initiatives to explore not only how data, computational thinking, and Al relate to each other, but how these areas connect to the larger digital ecosystem.

\section{DATA}

The area of life around data - which entails the technical ability and critical thinking skills needed to create, collect, represent, evaluate, interpret, and analyze data from digital and non-digital sources - is becoming increasingly important for youth in today's data-driven society. In the U.S., the Common Core standards in math, recently adopted by 42 states and Washington, D.C., include data analysis, probability, and statistics as mainstream strands in the kindergarten through 12th grade curriculum (Common Core State Standards Initiative [CCSSI], n.d.-a). According to the standards, young learners begin to collect, represent, and interpret data starting in primary school (CCSSI, n.d.-b). From middle to high school, students are introduced to fundamental concepts in probability and statistics, coupled with real-world applications (CCSSI n.d.-c). Curricular kindergarten through 12th grade initiatives are also underway to introduce students to big data and data analytic tools, along with the skills needed to work with vast amounts of data (Touretzky, GardnerMcCune, Breazeal, Martin, \& Seehorn, 2020). Beyond the U.S., math and science curricula that incorporate data in primary and secondary schools can be found

${ }^{35}$ In our visualization in part III, section 3, we denoted where it might be less clear if these areas of life are included, based on our framing.

${ }^{36}$ To learn more about youth and the digital economy, please see YaM's forthcoming paper Youth and the Digital Economy: Exploring Youth Practices, Motivations, Skills, Pathways, and Value Creation by Lombana-Bermudez et al. (2020). 
in countries such as Finland, Norway, New Zealand, and Thailand (Trends in International Mathematics and Science Study [TIMSS] \& Progress in International Reading Literacy Study [PIRLS], 2015).

Scholars such as D'Ignazio (2017) note the importance of building inclusive pathways towards an understanding of and engagement with data that can promote not only learners' technical skill development but also their civic engagement. In addition to incorporating the perspectives of diverse professionals - including educators, designers, artists, community organizers, and civil servants - into data skill initiatives, introducing communityoriented data sets and supporting collaborative data-oriented activities can further cultivate creative data skills in and out of the classroom (D'lgnazio, 2017). Notable programs in data that incorporate the aforementioned principles include MAPSCorps (Meaningful, Active, Productive Science in Service to Communities) and Mobile City Science, in which high school students are trained as data scientists to help strengthen their local communities. In both programs, youth gather data about their community on smartphones with specific mobile-based applications and engage in data analysis to help translate findings to their community (MAPSCorps, n.d.; Mobile City Science, n.d.). MAPSCorps, for example, pairs high school and university students to collect and analyze data around community resources, in fields such as healthcare or employment, to make this information more accessible to community members (MAPSCorps, n.d.). One MAPSCorps project partnered with the organization NowPow to help health care providers prescribe self-care resources (e.g., smoking cessation workshops, or basic resources, such as food pantries) to their patients (Benefit Chicago, 2019). Another MAPSCorps project connected youth to the organization Voices of Youth Count to gather information about homeless young people in Chicago, which helped to inform the organization's intervention efforts (MAPSCorps, n.d.). These and other efforts by MAPSCorps, and the similarly structured Mobile City Science, provide youth the opportunity to engage in data collection and scientific research using digital technologies while helping to promote career readiness and civic engagement (University of North Carolina Center for Health Equity Research, n.d.).

The digital world also offers rich informal learning opportunities around data. DataBasic, for instance, a project between the Engagement Lab at Emerson College and Massachusetts Institute of Technology's (MIT) Center for Civic Media, has developed a set of web-based tools that promote novel and relevant ways to work with data - in particular, textual data (DataBasic, n.d.-a). The tool ConnectTheDots, for instance, encourages users to generate textual data and then explore patterns in a multilayered network representation (DataBasic, n.d.-b), the type of which revolutionized Google searches (Engagement Lab, 2017). Using another tool, SameDiff, learners can explore quantitative text analysis by comparing text files to understand their similarities and differences (DataBasic, n.d.-c). DataBasic's tools also come with activities that can be implemented in formal or informal learning settings for those in middle school to higher education. SameDiff, for instance, features an activity that encourages learners to use the tool to compare the lyrics of two songs of their choosing and create a new song based upon this comparison (DataBasic, n.d.-d). Given that youth produce content that is not limited to numerical representation (e.g., memes and text-based posts), it may be helpful for future initiatives to continue to support the development of image and text analysis strategies.

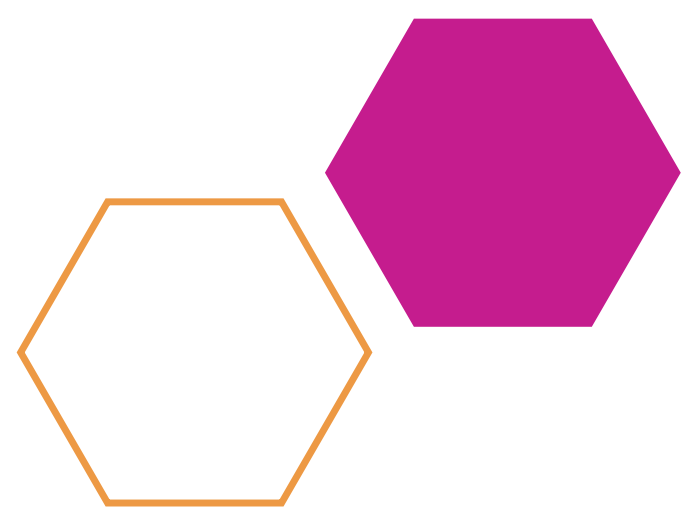




\section{COMPUTATIONAL THINKING}

Just as the area of data provides a road map for young people to navigate today's data-rich world, competency in computer science - particularly computer programming - affords youth the opportunity to engage with rapidly emerging digital technologies. Israel was one of the first countries to introduce computer science as an academic subject in high schools, starting in the mid-1970s (Gal-Ezer \& Stephenson, 2014). More recently, 18 European countries - including Bulgaria, Estonia, Greece, Italy, Portugal, Slovakia, and Spain - and other countries around the world, such as Australia and Japan, have been working on integrating computer science as part of the kindergarten through 12th grade curriculum (Touretzky, Gardner-McCune, Martin, \& Seehorn, 2019). In the U.S., the 2016-2017 school year saw an increase in the number of high schools offering computer science, with $40 \%$ of schools teaching a class where students can learn coding or computer programming (Google Inc. \& Gallup Inc., 2016). To encourage programming in the classroom, the organization Code.org has developed free online courses in computer science for teachers, along with an array of computer science courses suitable for the kindergarten through 12th grade curriculum (Code. org, 2019b). Additionally, the organization's Hour of Code initiative consists of one-hour online tutorials in coding for students of all ages (Code.org, n.d.). These tutorials have been translated into more than 45 languages and have reached millions of students in more than 180 countries (Hour of Code, 2020).

Whether coding computer programs with $\mathrm{C}++$, Java, or Python, one of the most important aspects of computer programming is the development of computational thinking. Placing programming in the context of a collaborative online community, Brennan and Resnick (2012) define computational thinking along three main dimensions: computational concepts (e.g., sequences, iterations, and conditionals); computational practices (e.g., debugging, abstracting and modularizing, reusing and remixing); and computational perspectives (e.g., selfexpression, collaboration). This conceptualization of computational thinking is based on the study of how young people learn to program and create interactive designs using Scratch. Developed at the MIT Media Lab, Scratch is an online programming environment that enables young people (geared towards ages 8-16) to create their own interactive stories, games, and simulations, and share these creations in an online community with other young programmers from around the world (Maloney, Resnick, Rusk, Silverman, \& Eastmond, 2010). Three design principles have guided Scratch: an interface that 1) encourages youth to tinker with programming blocks, testing different combinations to see the result, 2) promotes meaningful learning by supporting a wide variety of projects (e.g., videos, simulations, games) and 3) fosters a social, collaborative environment ${ }^{37}$ by, for instance, allowing users to share their work with others on the platform; build upon others' work, remixing it; exchange knowledge in discussion forums; and create projects together (e.g., animations, games, etc.) (Resnick et al., 2009). With an online community of over 50 million users (Scratch, 2019) in more than 150 countries, Scratch has been translated into over 40 languages and is found in an array of settings, including homes, schools, libraries, and community centers (Scratch, n.d.).

Scratch's Community Blocks enables young people to actively reflect on data that they generate online, as they use programming to access, analyze, and visualize the data they create while participating in Scratch (Dasgupta \& Hill, 2017). This platform helps shift the paradigm of adult data scientists analyzing the data that youth share online knowingly (e.g., using social media platforms, posting photos) and unknowingly (e.g., likes and shares, online shopping, using mobile apps, sensors, and trackers) to youth actively analyzing their own generated data.

${ }^{37}$ To learn more about collaboration within the Scratch community, please see Lombana-Bermudez et al. (2020), which presents a case study of virtual collaboration on Scratch. 


\section{ARTIFICIAL INTELLIGENCE}

Related to the areas of data and computational thinking is the ability to understand Al systems. With the advent of big data and rapid increases in computing power, Al-based technologies are reshaping a wide range of sectors of the economy and impacting domains ranging from health and well-being to the future of work, and creativity and entertainment (Brossi, Dodds, \& Passeron, 2019; Hasse, Cortesi, Lombana-Bermudez, \& Gasser, 2019a; UC Berkeley Human Rights Center Research Team, 2019; UNESCO, 2019a; UNESCO, 2019b; UNICEF, 2019a; UNICEF, 2019b; World Economic Forum, 2019). As many of today's youth encounter and interact with Al-powered technologies, such as Netflix's recommendation system or Google's suggested search queries, it may be helpful to think about how we want to prepare today's youth for Al's current and future impact on their lives.

Here is one young girl's inspiring story, as covered by popular media outlets in the U.S. When New Yorker Emma Yang was 7 years old, her grandmother, who lived thousands of miles away from her in Hong Kong, started to become more and more forgetful (Peters, 2018). As her grandmother's memory deteriorated due to early-onset Alzheimer's, Emma decided to intervene. Emma, who learned to code at a young age, started developing a mobile application, Timeless, that uses Al-based technologies to help her grandmother and others with Alzheimer's recognize their loved ones, remember events, and stay connected and engaged with those around them. To develop an app that relies on identifying faces in photos, Emma, who is now 15, turned to online tutorials on machine learning and $\mathrm{Al}$, consulted specialists in Alzheimer's, and connected with an Al facial recognition platform start-up.

How do we inspire and support youth around the globe, who, like Emma, want to create change in the world around them, and are interested in utilizing Albased technologies to do so? Educational initiatives, whether in formal or informal learning spaces, may want to introduce students, starting in primary school, to the fundamental concepts, methods, and issues associated with $\mathrm{Al}$, such as machine learning and algorithms. In the formal educational setting, Al might be incorporated in subjects such as computer science and math. In math, for instance, at the primary school level through data analysis (e.g., collecting and representing data and recognizing patterns in it) and in middle school and high school through statistics, probability, and calculus. At the university level, initiatives such as Harvard University's Embedded EthiCS program seeks to bring ethical reasoning into the university's computer science courses (Grosz et al., 2019). For example, in a machine learning course, an Embedded EthiCS module encourages students to consider the various ways machine learning systems can exhibit discrimination and how discriminatory impact can be prevented. As Grosz and colleagues (2019) explain, through the program, "Students can learn to think not only about what technology they could create, but also whether they should create that technology" (p. 56).

Outside of the classroom, various educational initiatives aim to teach youth about Al through project-based learning and the application of concepts to real-world issues. MIT's Beaver Works Summer Institute (BWSI), for example, consists of a STEM-focused online course and summer program for rising high school seniors (MIT BWSI, 2019). BWSI's four-week summer program promotes STEM skill development in a creative environment where youth have the opportunity to work in teams to learn about and build Al-based technologies. BWSI's most recent summer program featured a variety of courses, including Cog*Works, where young people worked together to create an autonomous cognitive assistant while learning data analysis, math, and programming skills (MIT BWSI, 2019). In another course, Medlytics, youth learned about and applied an understanding of the intersection of data science, health, and medicine by developing a health application prototype in teams. The course, enriched by visits from Boston-based clinicians and academics, exposed young people to innovations in the fields of health and machine learning and provided 
insight into concerns associated with health data. MIT's BWSI (2019) thus provides a learning setting where youth have the opportunity to cultivate social skills, such as collaboration, in addition to building a strong understanding of fundamental Al concepts applied to real-world issues while considering ethical concerns around Al systems.

\section{Ethical Conversations}

As the formal and informal educational initiatives around $\mathrm{Al}$ described in this part $\mathrm{V}$, section 3 illustrate, it may be helpful for educational interventions to emphasize both the physical and practical skills youth may need to be able to engage with $\mathrm{Al}$, as well as the ethical conversations (connected to cognitive and meta-cognitive, and social and emotional skills) around the development and deployment of Al-based technologies. As one example, MIT's Moral Machine experiment (Awad et al., 2018), the largest study to date of machine ethics, highlights the importance of taking into account various cultural and regional differences when considering how individuals might respond to ethical concerns related to Al. The study surveyed over two million individuals across 233 countries and territories about how they would want self-driving cars to respond to moral dilemmas arising from unpreventable autonomous vehicle accident scenarios involving humans and/or animals. The authors found that many of the moral guidelines that may shape drivers' decisions vary based on country. For instance, some countries exhibited a preference for safeguarding the lives of older versus younger people, or individuals from a specific socioeconomic class over other classes.

Ethical variations across cultures and countries highlight the complexity of moral dilemmas and decision-making in the context of Al. Given the opportunity digital technologies afford to interact with others from around the world, it might be useful for youth to not only aim to understand and engage with cultural, social, and regional nuances on an individual level but also strive to do so in ways that take into account the impact their actions may have on the wider online community. James (2014) terms this latter mode of thinking "ethical thinking," which entails "considering the effect of one's actions on multiple and distant stakeholders and on the integrity of a larger community" (p. 4). When youth, for instance, share online how they think about and engage with various Al-based technologies whether that might be Al-powered voice assistants or mental health chatbots - it may be useful for them to consider how different individuals, groups, communities, and geographies relate to $\mathrm{Al}$.

In light of the importance of context, it may also be useful for young people to recognize that while $\mathrm{Al}$ systems can have impacts on a global scale, the relatively small group of companies leading the development of Al-powered technologies typically have little insight from a variety of disciplines, cultures, and socioeconomic classes (Ashar \& Cortesi, 2018), underscoring the importance of including underrepresented groups in the design and deployment of Al (Frey, Patton, Gaskell, \& McGregor, 2020). Against this backdrop, there is a growing gap between those who have access to information about Al systems and understand their impact and those who do not (Ashar \& Cortesi, 2018). As young people engage in conversation around Al-based technologies online, it may be helpful for youth to keep in mind that not all others they interact with in the digital world may have the same level of understanding and engagement with $\mathrm{Al}$.

This very brief overview of the ethical considerations surrounding $\mathrm{Al}$-based technologies ${ }^{38}$ demonstrates the complexity of the ways individuals understand and engage with Al systems. It may be helpful for initiatives around digital citizenship and related concepts to discuss Al - as well as all 17 areas, and particularly those with a traditionally technical orientation (e.g., computational thinking, data, security) - in the context of the impact these technologies may have on society, including ethical questions and concerns surrounding them.

\footnotetext{
${ }^{38}$ Please see Fjeld, Achten, Hilligoss, Nagy, and Srikumar (2020) to learn more about ethical and human-rights based frameworks designed to provide direction around the development and use of Al systems.
} 


\section{SUPPLEMENTARY MATERIALS}

In this part VI, section 1, we discuss how the opportunities youth have to access digital technologies and meaningfully participate online can differ based on various demographic factors. Although more young people around the world are connecting to the Internet due to increased access to mobile devices and computers in school and at home, disparities in participation persist for youth across factors such as gender, race and ethnicity, and socioeconomic status. In addition to these demographics, other contextual factors of relevance, such as age, national origin, location, and skill and education level, can further impact youth access and engagement with digital tools, resulting in unequal exposure to opportunities that may promote skill development.

As one example, youth from diverse backgrounds have differing access to robust learning experiences involving digital technologies within educational environments, which can affect their successful completion of STEM courses of study and their preparation for STEM-related careers. As this part VI, section 2 expands upon, initiatives around the world are working to bring more underrepresented groups - including women and girls - into STEM fields like computer science by, for instance, creating a strong support network in the field and encouraging youth to apply computer science concepts towards societal issues (e.g., environmental conservation, bias in the criminal justice system). Despite this progress, understanding how disparities in participation for youth from different communities continue to evolve in local, regional, and global contexts is critical for designing educational and policy interventions that promote digital equity and foster the skills youth need to thrive in our digital world.

\section{DEMOGRAPHIC FACTORS AND DIFFERING EXPERIENCES}

\section{Gender}

The presence of gender differences in the context of digital technologies becomes apparent when examining the access girls and women around the world have to digital tools, the quality of their online experiences, the skills they develop, and the education and career pathways they select and pursue. Despite the limited availability of data on these aspects of gender differences worldwide - especially data from countries in the Global South, data from youth, and data that is both longitudinal and internationally comparable - recent studies do reveal a gender gap in the usage of mobile phones, computers, and the Internet in the majority of countries with reportable data (Sey \& Hafkin, 2019). The ITU estimates that, on a global level, $48 \%$ of women are using the Internet, versus 58\% of men (ITU, 2019b). From 2013 to 2019, the gender gap has decreased in certain regions of the world, including Europe and the Commonwealth of Independent States, but widened in Africa, the Arab States, and Asia and the Pacific (ITU, 2019b). Large country- and regionlevel differences, however, do exist. Countries such as Jamaica, Mongolia, and Panama, for example, have higher rates of women using the Internet (ITU, 2019a). In the U.S., teenage girls are more likely than teenage boys to use the Internet "almost constantly" (Anderson \& Jiang, 2018, p. 8). 
Contrasting trends in access and basic use such as these reveal that identifying gender inequalities through these measures alone is insufficient, as gaining access to the Internet or digital technologies does not eliminate the inequalities girls and women face when online. Differences in the quality of the online experiences individuals of different genders have reveal a more nuanced understanding of gender inequalities for digital technology users. In the U.S., for example, a 2018 Pew report found that teenage boys and girls have equal access to desktop and laptop computers, with girls having slightly higher rates of access to smartphones than boys (Anderson \& Jiang, 2018). These equivalent rates of access, however, belie differences in boys' and girls' experiences of cyberbullying ${ }^{39}$ or online harassment. Teenage girls in the U.S., for example, are more likely than their male counterparts to experience more than one form of online bullying, with 15\% of girls surveyed having experienced four or more types (Anderson, 2018). Additional studies in the U.S., and beyond, have echoed the finding of higher victimization rates among females ${ }^{40}$ (e.g., Heiman \& Olenik-Shemesh, 2015; Kim, Kimber, Boyle, \& Georgiades, 2019; Låftman, Modin, \& Östberg, 2013; Schultze-Krumbholz et al., 2015; Tarablus et al., 2015; Walrave \& Heirman, 2011). Other studies note gender disparities among young adults engaging in more active online behaviors, such as content production. For example, Hargittai and Shaw (2015) found that lower levels of Internet skills ${ }^{41}$ in young women in their early 20 s compared to young men in the same age group could help explain the lower rates of female users contributing to authorship on Wikipedia. Corroborating this skills gap, the ITU (2018) found that adult women in 31 countries around the world had lower levels of basic digital skills, such as sending emails with attached files and transferring files between a computer and another device, compared to adult men. Data from the same report showed that the percentage of men worldwide who have advanced digital skills, such as being able to write a computer program, is twice that of women (ITU, 2018).

Lower skill levels and rates of active participation, coupled with being victimized online, can diminish the quality of the experiences girls and women have online and can hinder their ability to engage in positive and meaningful behaviors online in the future. Such inequities are further compounded by trends in formal education, which reveal gender differences in STEM subject enrollment and completion that impact female students' skill development and female workers' professional development (Sey \& Hafkin, 2019). Looking at the primary and secondary school level on a global scale, as math and science classes are often part of the national curriculum for many students, exposure to these subjects tends to be similar at such grade levels (Sey \& Hafkin, 2019). Gender differences start to emerge globally at the secondary school level when students begin selecting more of their own academic coursework (Spearman \& Watt, 2013; UNESCO, 2017). For example, female students accounted for only $29 \%$ of all students taking AP computer science exams ${ }^{42}$ in 2019 (Code. org, 2019a). At the university level, female students comprise a mere $36 \%$ of students majoring in STEMrelated domains around the world (Sey \& Hafkin, 2019). Negative stereotyped perceptions of who pursues technical careers and a lack of confidence in girls play a large role in discouraging girls and young women from the pursuit and exploration of computer science and other STEM-related activities (Hur, Andrzejewksi, \& Marghitu, 2017). Scholars have also observed a paradoxical trend, noting that "countries with high

\footnotetext{
39 To learn more about the prevalence of online bullying in and beyond the U.S., as well as practical, impactful guidance on preventing and responding to cyberbullying, please see Hasse, Cortesi, Lombana-Bermudez, and Gasser (2019b).

${ }^{40}$ Other studies in and outside of the U.S., however, suggest that boys are more likely to be cyberbullied than girls (e.g., Fanti, Demetrious, \& Hawa, 2012; IPSOS Ltd Ghana, 2017; Marret \& Choo, 2017; Sittichai \& Smith, 2018). While other research in the U.S. and beyond has found no gender differences in terms of cyberbullying victimization (e.g., Griezel, Finger, Bodkin-Andrews, Craven, \& Yeung, 2012; Kowalski \& Limber, 2013; Lazuras, Barkoukis, Ourda, \& Tsorbatzoudis, 2013; Mura \& Diamantini, 2013; Navarro, Ruiz-Oliva, Larrañaga, \& Yubero, 2015; Shin \& Ahn, 2015).

${ }^{41}$ Hargittai and Shaw (2015) define Internet skills as "the ability to use the Internet effectively and efficiently" (p. 427). For more comprehensive information around these skills, please see Hargittai and Shaw (2015).

42 There are currently two AP exams available for high school-level students studying computer science: AP Computer Science and AP Computer Science Principles (College Board, 2018).
} 
levels of gender equality have some of the largest STEM gaps in secondary and tertiary education" (Stoet \& Geary, 2018, p. 581). Stoet and Geary (2018) note that one possible explanation could be that in such countries, when boys are relatively better in math and science while girls are relatively better at reading, versus other academic subjects, students tend to be advised to pursue academic paths according to those strengths. In less gender-equal countries, a STEM pathway that pays well may appear to be an investment in a more secure future and thus pursued by students across genders.

The gender gap continues to manifest once students are part of the adult workforce. In the U.S., for example, a 2018 Brookings Institute report mentions a decrease in recent years of female representation in highly digital occupations such as computer programming and information systems management (Muro, Liu, \& Whiton, 2018). In newer fields, such as Al, studies have also found a gender gap; for example, only $18 \%$ of researchers publishing in 21 leading Al conferences identify as female (Element Al, 2019). There are also gender differences in the occupations and skills Al professionals around the world are likely to hold. The World Economic Forum's Global Gender Gap Report 2018 found that women are more likely than men to work as data analysts, librarians, and teachers, whereas men are more likely to hold more senior positions such as head of engineering, head of Information Technology, and CEO (World Economic Forum, 2018). In addition to the Al industry, entrenched gender gaps exist in STEMadjacent fields such as technology entrepreneurship and policy (Sey \& Hafkin, 2019), revealing the critical importance of initiatives that support the inclusion and advancement of women in roles related to the development of innovative technologies. Others also call for initiatives that present gender equality in nonbinary (male/female) terms, in order to promote the inclusion of transgender and other intersectional identities. To learn more about the gender gap in the field of computer science, as well as several initiatives around the world that promote the interest, inclusion, and mentorship of girls and young women in this domain, please see this part VI, section 2.

\section{Socioeconomic and Racial Factors}

Looking at socioeconomic and racial demographics, differences emerge both across and within countries in regard to individuals' access to digital technologies, high-quality online experiences, and opportunities for skill development. As with data on gender differences, most sources of data come from high-income countries, with fewer sources available, especially for youth, in low- to middle-income countries. The limited availability of country, regional, and global data from around the world complicates the ability to make international and longitudinal comparisons for demographic factors such as socioeconomic status, race, and ethnicity. As noted in part IV, section 3, UNICEF (2017) estimates that around $29 \%$ of young people around the world, or 346 million individuals ages $15-24$, do not have access to the Internet. Nearly $90 \%$ of youth without access live in Asia, Africa, or the Pacific. Barriers such as poor infrastructure and high data costs create large disparities in access for youth: around $60 \%$ of youth in Africa are not online, compared to only $4 \%$ of youth in Europe (UNICEF, 2017). Country-level data from low-income countries also reveal limitations in Internet connectivity. In Bangladesh and Zimbabwe, for instance, less than $5 \%$ of children and young people under the age of 15 use the Internet (UNICEF, 2017). Among those young people who have access to digital technologies, ${ }^{43}$ significant differences may exist across countries and in terms of which device they use to access the digital environment (UNICEF Office of Research-Innocenti, 2019).

Recent data from higher-income countries, especially those with rich sources of data across racial or socioeconomic demographics, reveal a complex landscape in which youth from low-income backgrounds (Paus-Hasebrink, Kulterer, \& Sinner,

\footnotetext{
${ }^{43}$ For a visual representation of the percentage of children (ages 9-17) who use a desktop computer or mobile phone to access the Internet at least weekly, by country (including Albania, Argentina, Brazil, Bulgaria, Chile, Italy, Ghana, Montenegro, the Philippines, South Africa, and Uruguay), please see pages 10-11 of UNICEF Office of Research-Innocenti (2019).
} 
2019) and youth of color encounter differences in the quality of their online experiences, even if they have basic access to digital technologies (Watkins et al., 2018). In the U.S., for example, teens have almost universal access to smartphones, regardless of their race, ethnicity, or socioeconomic background (Anderson \& Jiang, 2018). Hispanic teens (82\%) are less likely than white teens (90\%) to report access to a computer at home, and only $75 \%$ of lower-income teens report access, compared to $96 \%$ of higherincome teens (Anderson \& Jiang, 2018). A 2015 Common Sense study found higher rates of daily smartphone use among Black, Hispanic, and lowerincome teens in the U.S. compared to white, middleincome, and higher-income teens, suggesting that youth from the former backgrounds may have greater smartphone dependence due to their decreased access to other devices, such as personal computers (Rideout, 2015). This smartphone dependence can already be seen in the numbers of Hispanic, Black, and low-income adults in the U.S. (Pew Research Center, 2019) as well as individuals living in low- to middle-income countries who lacking high-speed broadband service at home primarily rely on their mobile devices to connect to the Internet (UNICEF, 2017).

Although smartphones are undeniably powerful tools that can, with a data plan, provide greater Internet access and online participation, youth who rely primarily on the constraints of smaller, mobile screens can have a lower quality online experience that limits their opportunity to engage in more active, skill-building activities, from programming and robotics to media production and design, that computers can more easily support. Scholars such as Watkins et al. (2018) thus point to a mobile paradox whereby Black and Latino youth in countries such as the U.S. are seen as "mobile trendsetters" and "early adopters" of the mobile Internet, but, in lacking equal access to home broadband service, face larger barriers in terms of accessing a broad range of social and educational opportunities that "promote digital exploration, experimentation, and content creation" (Watkins et al., 2018, p. 58). Research from outside the U.S. also reveals a "reverse gap" in which students from lower-income families spend more time online than their wealthier counterparts but are less likely to engage in active behaviors such as "reading news or obtaining practical information from the Internet" (OECD, 2015, p. 135; Valdivia, Brossi, Cabalin, \& Pinto, 2019). Therefore, differences in young people's access to a range of Internet services, devices, and activities at home can further impact their ability to develop relevant skills and fully participate in rich experiences using digital tools.

In light of the barriers that youth of different socioeconomic, ethnic, and racial backgrounds face at home, school can play a critical role in providing opportunities for quality online experiences. In fact, many low-income youth around the world can only access a computer or the Internet while at school. The OECD (2015) reported that over 30\% of the lowest-income students in countries such as Costa Rica, Mexico, and Turkey are particularly reliant on school access because they do not have computers or Internet connectivity at home (OECD, 2015). In efforts to provide digital opportunities to youth from low-income backgrounds, countries such as Japan, Portugal, and Tunisia have maintained lower studentto-computer ratios in schools serving students from this demographic compared to schools serving higher-income populations (OECD, 2015). Equal, or even greater, access to devices at school, however, does not necessarily translate into equitable opportunities for skill development. Van Deursen (2010) notes that individuals who are primarily relegated to Internet use at school have limited time to engage with the digital environment, which can hinder their skill development and their opportunity to acquire forms of social, economic, or cultural capital in the future. Students with computer access at school but only smartphone access at home may experience a persistent homework gap, in which they are expected to use the Internet to complete school assignments but are unable to do so with the same level of ease or quality as their higherincome counterparts (Watkins et al., 2018). This gap is particularly seen in high- and middle-income countries (UNICEF, 2017). In the U.S., for instance, Common Sense's recent nationally representative 
survey of youth and digital media reveals that teenagers in higher-income households spend more time using computers to complete their homework, while young people from lower-income households spend more time using their smartphones for homework ${ }^{44}$ (Rideout \& Robb, 2019).

Research from over 60 countries around the world also indicates that a lack of effective classroom teaching can impede students' ability to reap the benefits of using digital technologies in schools (OECD, 2015). The crucial need for strong pedagogy can be seen in countries such as the U.S., where lowincome, Black, and Latino youth have similar rates of Internet and computer access at school compared to their higher-income and white counterparts but are more likely to learn under "curriculum-poor conditions," with less experienced teachers, smaller budgets for educational resources, fewer creative or collaborative activities using digital tools, and limited instruction in topics like computer science (Watkins et al., 2018, p. 114). These differences in exposure to high-quality learning experiences contribute to the low rates of Black and Latino youth taking AP computer science exams: in 2018 , only $5 \%$ of test takers identified as Black or African-American, while around 15\% identified as Hispanic or Latino (College Board, 2018). Compared to their non-AP counterparts, students who take AP Computer Science exams are twice as likely to take computer science-related courses in college and six times more likely to major in computer science, with Black and Latino AP students having even higher rates of majoring in the field (Morgan \& Klaric, 2007). Thus, while access to robust STEM learning opportunities, especially coupled with well-trained educators, has the potential to impact youth academic interests and promote continued skill development in the future, lower-quality STEM education has cumulative effects that can negatively impact students throughout their early and later schooling. For instance, Black, Latino, and Native American college students in the U.S. aspire to major in STEM fields at virtually identical rates compared to their white counterparts but are significantly less likely to graduate with bachelor's degrees in STEM subjects (Higher Education Research Institute,
2010), potentially revealing a "lack [of] access to the educational preparation necessary to realize their desire to earn degrees in STEM" (Watkins et al., 2018, pp. 128-129). Students from lower-income high schools in the U.S. are also less than half as likely to earn STEM undergraduate degrees compared to students from higher-income high schools (National Student Clearinghouse Research Center, 2016).

Differences in skill development and educational preparation can hinder the ability of individuals from diverse countries, racial and ethnic backgrounds, and income levels to compete in a global workforce. The World Bank (2016) reported that $40 \%$ of urban workers in Vietnam, $30 \%$ in Bolivia, and over $15 \%$ in Kenya found that a lack of ICT skills can impede wage growth and employment. Higher-income individuals around the world are more likely to have the relevant access and skills to conduct online job searches, for example, with less than $5 \%$ of urban workers in countries such as Vietnam, Bolivia, and Ghana using online tools to search for jobs (World Bank, 2016). In terms of the global ICT sector, competition is high to enter the field: while ICT professionals in low- and middle-income countries earn wages that are 1.5 times higher than their counterparts in other fields, they are also twice as likely to have completed postsecondary education compared to non-ICT professionals (World Bank, 2016).

When examining racial and ethnic differences in STEM employment within individual countries, data from countries such as the U.S. reveal large discrepancies. Although Black and Hispanic professionals make up, respectively, $11 \%$ and $16 \%$ of the total U.S. workforce, $9 \%$ of the STEM workforce is Black, while only $7 \%$ is Hispanic (Funk \& Parker, 2018). Among software developers, for instance, $5 \%$ identify as Black, and only $4 \%$ identify as Hispanic (Landivar, 2013). STEM professionals also experience discrepancies in pay. Black, Hispanic, and Native American science and engineering graduates earn, on average, around $\$ 13,400$ less per year compared to their white counterparts (Landivar, 2013). The underrepresentation of racial and ethnic minorities in managerial or leadership positions could

\footnotetext{
${ }^{44}$ Teens from higher-income homes spend about 55 minutes/day using a computer for their homework, while youth from lower-income homes spend 33 minutes/day. And teens from lower-income households spend approximately 21 minutes/day using their smartphone to complete their homework, while young people from higher-income homes spend 12 minutes/day (Rideout \& Robb, 2019).
} 
play a contributing role in these salary differences. Within industry positions, less than $6 \%$ of engineering managers identify as Black, while less than $7 \%$ identify as Hispanic or Latino (National Science Foundation, 2017). Black (40\%), Hispanic (19\%), and AsianAmerican (31\%) STEM professionals in the U.S. are significantly more likely than their white counterparts (5\%) to report that their race or ethnicity has posed barriers to their professional success, citing reasons such as negative treatment from coworkers (Funk \& Parker, 2018). When asked about diversifying STEM fields, professionals from racial and ethnic minority backgrounds emphasize the need for quality STEM education beginning in the elementary school years, as well as strong mentors and role models who can inspire and support students and young professionals (Funk \& Parker, 2018). Others mention the importance of creating educational and workplace initiatives that promote the inclusion and advancement of girls and young women of color, racial or ethnic minority youth from low-income backgrounds, and those with other intersectional identities (Funk \& Parker, 2018).

\section{A CASE STUDY: ADDRESSING THE GENDER GAP IN COMPUTER SCIENCE}

In the U.S. alone, it is projected that computer science-related occupations (e.g., computer programmers, software developers, computer network architects) will increase over a ten-year span by $12 \%$ - by 2028 , adding approximately 546,200 new jobs to the labor market (U.S. Bureau of Labor Statistics, 2019). Against this backdrop, it may be useful for efforts within formal and informal learning settings to help youth develop the knowledge and skills necessary for careers in computer science, data science, and related fields. In conjunction with 100 experts, the Oceans of Data Institute (2014), for example, produced an occupational profile of a big-data specialist, describing the roles and responsibilities careers in big data could entail, as well as the skills, knowledge, and behavior needed for positions in an increasingly data-driven economy. Initiatives in this arena may serve as a guide for educators in designing curricula and programs to help prepare youth for the workplace of tomorrow.

In developing these programs, it is important to address disparities in gender, racial, and socioeconomic representation. When examining gender disparities in computer science, for example, a global survey of women in the field demonstrates a decline in female computer science graduates since 2000, which is especially pronounced in high-income countries (Huyer, 2015). From 2000 to 2012, the number of women graduates in computer science has decreased in countries such as the U.S., New
Zealand, and Australia (Huyer, 2015). In the U.S., for example, only $18 \%$ of women obtain a bachelor's degree in computer science (National Center for Education Statistics, 2016). In other regions of the world, such as the Caribbean and Latin America, the proportion of female graduates in computer science has fallen between 2 and 13 percentage points from 2000 to 2012 (Huyer, 2015).

While, on a global scale, the percentage of women obtaining computer science degrees and entering the workforce in the field is low, when one looks outside of the Western world, there is a growing body of literature offering a more diversified landscape (Kelkar, Shrestha, \& Veena, 2005; Ng \& Mitter, 2005; Saloma-Akpedonu, 2005; Wajcman \& Lobb, 2007). In Malaysia, for example, the percentage of women completing education and securing positions in software and computer science departments is equivalent to the percentage of men (Mellström, 2009). The large proportion of women in the field primarily stems from several historical factors, including the race-based quota system for university admission in Malaysia and the predominance of women in the Malay electronics industry, the precursor to the information technology industry. Per the former, up until 2005, those students who entered state universities were divided into "bumiputeras" or "sons of the soil," meaning they are Malaya or from a Malay-related group - and non-bumiputeras. The university quota system guaranteed that at least 
half of all students were "bumiputeras." Mellström (2009) points out that this system has helped open opportunities for Malay women to study computer science as they were "favoured on the grounds of the race 'positive' policy," which "granted students places that possibly would not have been open without the quota system" (p. 893). In terms of the latter, exportfueled industries such as electronics and garments became increasingly popular as Malaysia ushered in a global economic market in the 1970s; women soon flocked to these job opportunities, partially due to their perceived dexterity (Levidow, 1996; Lie \& Lund, 1994; Ong, 1987). The large-scale recruitment of women into the electronics industry opened up a new field for women and made this field "symbolically associated with femininity” (Mellström, 2009, p. 896).

In areas of the Western world, such as the U.S., what are some of the driving social and cultural forces that contributed to the gender gap in computer science? Interestingly, women represented a major presence during the early decades of computing. Ada Lovelace, viewed as the first computer programmer, was a trailblazer in the field who conducted much of her work during the 1840s (Corbett \& Hill, 2015). During World War II, the majority of computer programmers were women, such as Grace Hopper, who developed the notion of a "compiler," which generated a process for converting code into a language that a variety of machines could understand (Chang, 2018). Around the mid-1900s, computing represented an emerging field without a gender identity, attracting both men and women (Abbate, 2012; Ensmenger, 2010; Koput \& Gutek, 2010). However, as Koput and Gutek (2010) point out, "Over a . . short period of time, a field that was once relatively gender integrated has become solidly male dominated" (p. 103).

Researchers and historians note a variety of explanations for this shift. Computing historian Nathan Ensmenger (2010) points out, for instance, that in the 1960s and 1970s, companies recruiting computer programmers adopted aptitude and personality tests that favored male-stereotyped characteristics. The widely-used Cannon-Perry test - based on a sample of 1,378 programmers, only 186 of whom were women - concluded that "programmers [share] one striking characteristic: they 'don't like people'" (Chang, 2018). Ensmenger (2010) elaborates by describing how the "industry selected for antisocial, mathematically inclined males, and therefore, antisocial, mathematically inclined males were overrepresented in the programmer population" (p. 78). These hiring practices, in turn, "reinforced the popular perception that programmers ought to be antisocial and mathematically inclined (and ... . male)" (p. 78), despite little empirical evidence that men who are antisocial are more skilled in math or computing, and no evidence that men are inherently more adept in math than women (Chang, 2018).

Several researchers attribute the rise of the personal computer in the 1980s as another force behind the computer industry's shift in gender representation. In 1981, IBM released the personal computer, and Apple launched the Macintosh in 1984. As Corbett and Hill (2015) explain, "Before that, few people's homes or businesses had computers, and girls and boys had similar exposure to computers - generally none" (p. 16). As computers entered the home, however, they were quickly adopted by boys and men as a new type of toy (Margolis \& Fischer, 2002). Haddon (1992) notes that the personal computer tied the computing industry more broadly to game-playing domains (e.g., arcades), which were largely the arena of boys and men. In the U.S., enrollment in university computer science courses surged with the rapid rise of computers (Chang, 2018). As schools struggled to hire enough faculty to meet the growing demand, they began imposing strict, grade-based requirements for admission into and completion of undergraduate computing programs. Armbrecht (2015) elaborates on the implications of such stipulations:

The result was that by the time young men arrived at university, they had already been exposed to computers and computer programming, while women were often starting from scratch. The uneven playing field left many women discouraged. Female enrollment rates in computer science programmes plummeted. At its 1984 peak, $37 \%$ of computer programmers were women. By 2011, it was only 12\% (para 10). 
Moving forward, how do stakeholders such as policymakers, NGOs, and educators help close the computer science gender gap? Initiatives within formal and informal learning spaces are helping to shape a more equitable future. For example, Harvey Mudd College, a science and engineering school in Southern California, has helped to spearhead a more inclusive computer science community for students (Nickelsburg, 2019). To help counter the stereotype of an "isolated, antisocial" computer programmer, Harvey Mudd redesigned introductory computer science courses to focus more on collaborative problem solving, versus solely programming (Sydell, 2017). To assist students with no prior coding background who are, as Harvey Mudd President Maria Klawe points out, "disproportionately women" (Klawe, 2013, para. 9), the school divided introductory classes into two sections: one for students with no prior computer science experience and one for those with a background in this domain. Klawe explains that having two sections helped remove the "intimidation that comes from being in a class where you've had no prior experience and somebody else has been programming since they were eight"' (Sydell, 2017, para. 7).

Harvey Mudd also helps to connect female students to the broader computer science community; each year, the school sends 40 to 60 students to the Grace Hopper Celebration of Women in Computing, the world's largest conference for women in technology (DeNisco Rayome, 2016). Over the course of a decade, from 2006 to 2016, the percentage of women computer science majors at Harvey Mudd increased from 15\% to 55\% (DeNisco Rayome, 2016). Other institutions, such as Carnegie Mellon, have also engaged in efforts to promote a more inclusive environment within the field of computer science and have similarly seen significant increases in the percentage of female computer science majors (Sydell, 2017).

There are also a variety of initiatives within informal learning settings, both in the U.S. and around the world, that aim to make coding a more inclusive discipline. For example, the U.S.-based AI4ALL program seeks to empower groups of high school- aged youth from underrepresented communities, including women, to learn the basics of Al and apply them to societal issues (AI4ALL, n.d.). The initiative offers university-based summer programs and an educational program that can be integrated in formal and informal learning settings. One alum, Lindsay, for example, applied her learnings from the program at a NASA internship, where she is leveraging machine learning to help develop a technology that will be incorporated in rovers looking for evidence of life on Mars (AI4ALL, 2019a). The program also seeks to connect youth to a mentorship network of researchers, institutions, and organizations (AI4ALL, 2019b). Data from Al4ALL's most recent 2019 summer program demonstrates that youth alumni feel a sense of belonging and community with others in the Al field, an interest in further exploring Al, and a connection to mentors (AI4ALL, 2019b). More specifically, a majority of alumni indicated that 1) they feel they are part of an Al and computer science community $(88 \%), 2)$ are interested in pursuing a career in $\mathrm{Al}(81 \%), 3)$ and have female role models in $\mathrm{Al}(86 \%)$.

Outside of the U.S., Indian Girls Code is a program that offers free coding and robotics education to young girls (Rajendra, 2018). The initiative brings coding lessons to after-school programs, summer camps, and an all-girls orphanage in India, where nearly 40 girls are taught robotics and coding every week (Pal, 2017). Similar to AI4ALL and Harvey Mudd's educational programs, Indian Girls Code focuses on real-world applications of $\mathrm{Al}$, such as using coding to create animations showing the harmful impact of pollution. The initiative also aims to make coding accessible to all learners. In this vein, the program has developed an educational robot, Philo, that can adapt to learners with varying levels of proficiency (Pal, 2017). In Latin America, the program Laboratoria, designed for an older age range (ages 18 and up), offers a six-month program to help prepare young women, particularly those from low-income backgrounds, to succeed as web developers (Laboratoria, n.d.). In addition to cultivating participants' coding skills, the initiative, which runs programming in locations including Peru, 
Chile, and Mexico, focuses on women's self-esteem. Students consult with the initiative's psychologists as part of their training to help mitigate the barriers women face in the computer science industry (Dalia Gonzalez, 2016).

In Africa, the mentorship and educational program Tech Needs Girls, based in Ghana, provides coding lessons to girls, with a focus on reaching girls from underrepresented communities (Soronko Solutions, n.d.). Participants are taught by 200 female engineers and computer scientists, who act as both role models and mentors for the young girls while cultivating their coding skills. Founder Regina Agyare describes the importance of mentorship in helping to bring more women to the ICT field: "Women and girls do not have many female role models who work in the field of ICT that they can look up to. We are socialized to attend school, get a job, and get married" (López, 2018, para. 10). She further notes that "entrepreneurship is seen as a risk, but we need to start socializing girls to think differently and start taking risks" (López, 2018, para. 10). The program has trained over 4,000 girls across eight regions of Ghana, some of whom have later developed online businesses, and one of whom created a website to promote awareness around sickle cell disease (López, 2018).

Whether implemented in formal or informal settings, these initiatives helping to bring more women to the computer science field have three key themes in common: 1) cultivating a strong support and mentorship network, 2) creating engaging, collaborative opportunities that help youth apply their understanding of computer science to societal problems impacting communities, and 3) making the field of computer science accessible to learners with varying levels of background knowledge in this field (e.g., through multilevel introductory courses).

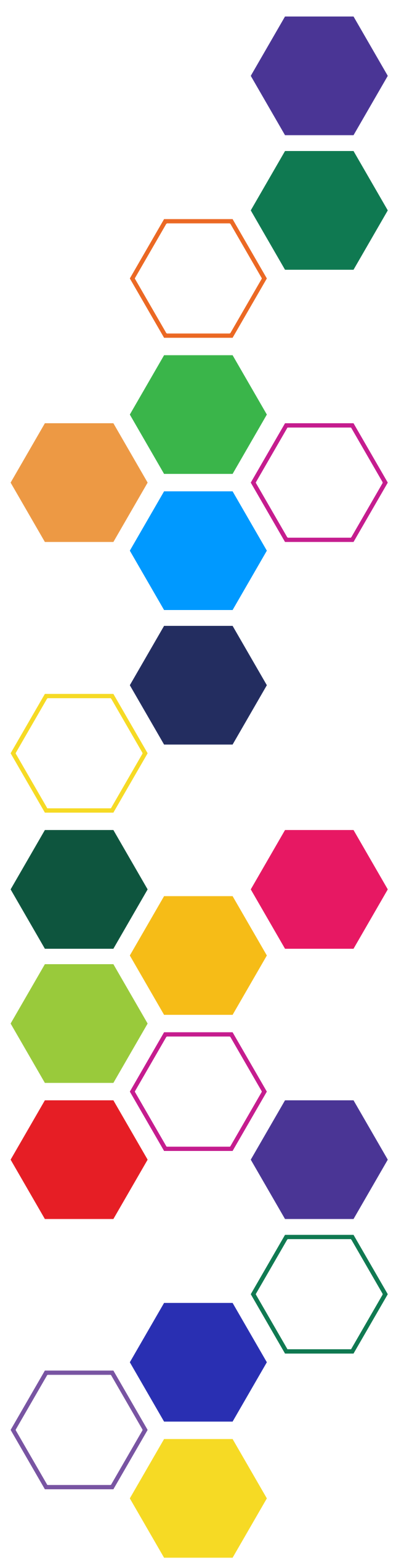




\section{REFERENCES}

Abbate, J. (2012). Recoding gender: Women's changing participation in computing. Cambridge, MA: MIT Press.

Adams, D., \& Hamm, M. (2001). Literacy in a multimedia age. Norwood, MA: Christopher-Gordon.

AI4ALL. (n.d.). Home. Retrieved from http://ai-4-all.org

Al4ALL. (2019a, December 13). CS education week: Student stories series. Medium. Retrieved from https://medium.com/ai4allorg/cs-education-week-spotlight-series-11de4e6f132

Al4ALL. (2019b). Results. Retrieved from http://ai-4-all.org/about/results/

Ala-Mutka, K. (2011). Mapping digital competence: Towards a conceptual understanding [PDF file]. Retrieved from European Commission Joint Research Centre website: ftp://jrc.es/pub/EURdoc/JRC67075_TN.pdf

Alexander, B., Adams Becker, S., \& Cummins, M. (2016). Digital literacy: An NMC horizon project strategic brief. Retrieved from EDUCAUSE website: https://library.educause.edu/resources/2016/8/nmc-horizon-projectstrategic-briefs-2014-2017

Alvermann, D. E., Moon, J. S., \& Hagood, M. C. (1999). Popular culture in the classroom: Teaching and researching critical media literacy. Newark, DE: International Reading Association and the National Reading Conference. doi: 10.4324/9781315059327

American Library Association. (2013). Digital literacy, libraries, and public policy. Retrieved from District Dispatch website: https://www.districtdispatch.org/2013/01/on-the-front-lines-of-digital-inclusion/

Ananiadou, K., \& Claro, M. (2009). 21st century skills and competences for new millennium leaders in OECD countries. Retrieved from Organisation for Economic Co-operation and Development website: https://www.oecd-ilibrary.org/education/21st-century-skills-and-competences-for-new-millenniumlearners-in-oecd-countries_218525261154

Anderson, M. (2018). A majority of teens have experienced some form of cyberbullying. Retrieved from Pew Research Center website: https://www.pewinternet.org/2018/09/27/a-majority-of-teens-haveexperienced-some-form-of-cyberbullying/

Anderson, M., \& Jiang, J. (2018). Teens, social media \& technology 2018. Retrieved from Pew Research Center website: http://www.pewinternet.org/2018/05/31/teens-social-media-technology-2018/

Armbrecht, A. (2015, December 30). Where are the missing women in tech? Retrieved from World Economic Forum website: https://www.weforum.org/agenda/2015/12/where-are-the-missing-women-in-tech/

Ashar, A., \& Cortesi, S. (2018). Why inclusion matters for the future of artificial intelligence. Medium. Retrieved from https://medium.com/berkman-klein-center/why-inclusion-matters-for-the-future-ofartificial-intelligence-2cb9d3b1b92b

Association of American Colleges \& Universities. (2007). College learning for the new global century. Retrieved from https://www.aacu.org/publications-research/publications/college-learning-new-global-century

Aufderheide, P. (1993). Media literacy: A report of the national leadership conference on media literacy. Aspen, CO: Aspen Institute. doi: 10.4324/9781351292924-4 
Awad, E., Dsouza, S., Kim, R., Schulz, J., Henrich, J., Shariff, A., . . Rahwan, I. (2018). The moral machine experiment. Nature, 563(7729), 59-64. doi: 10.1038/s41586-018-0637-6

Ayrton Senna Institute \& United Nations Educational, Scientific and Cultural Organization. (2014). Competências socioemocionais. Material de discussão [PDF file]. Retrieved from http://educacaosec21.org.br/wp-content/ uploads/2013/07/COMPET\%C3\%8ANCIAS-SOCIOEMOCIONAIS_MATERIAL-DE-DISCUSS\%C3\%830_IAS_ v2.pdf

Banaji, S., \& Buckingham, D. (2013). The civic web: Young people, the internet, and civic participation. Cambridge, MA: MIT Press.

Barbosa, A. F. (2014). ICT Kids Online Brazil 2014. Survey on the internet use by children in Brazil [PDF file]. Retrieved from the Brazilian Internet Steering Committee website: http://www.lse.ac.uk/media@lse/research/ EUKidsOnline/EUKidsIV/PDF/TIC-Kids-2014-livro-eletronico.pdf

Bawden, D. (2008). Origins and concepts of digital literacy. In C. Lankshear \& M. Knobel (Eds.), Digital literacies: Concepts, policies and practices (pp. 17-32). New York, NY: Peter Lang.

Bazalgette, C. (2008). Transforming literacy. In U. Carlsson, S., S. Tayie, G. Jacquinot Delaunay, \& J. M. Pérez Tornero (Eds.), Empowerment through media education: An intercultural dialogue (pp. 245-250). Göteborg, Sweden: Nordicom.

Benefit Chicago. (2019). A new way to manage health. Retrieved from https://benefitchicago.org/news/a-newway-to-manage-health/

Benkler, Y. (2006). The wealth of networks: How social production transforms markets and freedom. New Haven, CT: Yale University Press.

Bennett, W. L. (1998). The uncivic culture: Communication, identity, and the rise of lifestyle politics. PS: Political Science and Politics. 31(4), 741-761. doi: 10.1017/S1049096500053270

Bennett, W. L. (2007). Civic learning in changing democracies: Challenges for citizenship and civic education. In P. Dahlgren (Ed.), Young citizens and new media: Learning democratic engagement (pp. 59-77). New York, NY: Routledge.

Bennett, W. L. (2008). Changing citizenship in the digital age. In W. L. Bennett (Ed.), Civic life online: Learning how digitalmedia can engage youth (pp. 1-24). Cambridge, MA: MITPress. doi:10.7551/mitpress/7893.003.0002

Bennett, W. L. (2012). The personalization of politics: Political identity, social media, and changing patterns of participation. The ANNALS of the American Academy of Political and Social Science, 644(1), 20-39. doi: $10.1177 / 0002716212451428$

Bennett, W. L., Freelon, D., \& Wells, C. (2010). Changing citizen identity and the rise of a participatory media culture. In L. R. Sherrod, J. Torney-Purta, \& C. A. Flanagan (Eds.), Handbook of research on civic engagement in youth (pp. 393-423). Hoboken, NJ: John Wiley \& Sons. doi: 10.1002/9780470767603.ch15

Bennett, W. L., Wells, C., \& Rank, A. (2009). Young citizens and civic learning: Two paradigms of citizenship in the digital age. Citizenship Studies, 13(2), 105-120. doi: 10.1080/13621020902731116

Bhatt, I., de Roock, R., \& Adams, J. (2015). Diving deep into digital literacy: Emerging methods for research. Language and Education, 29(6), 477-492. doi: 10.1080/09500782.2015.1041972 
Blignaut, A. S., Hinostroza, J. E., Els, C. J., \& Brun, M. (2010). ICT in education policy and practice in developing countries: South Africa and Chile compared through SITES 2006. Computers \& Education, 55(4), 15521563. doi: 10.1016/j.compedu.2010.06.021

boyd, d. (2014). It's complicated: The social lives of networked teens. New Haven, CT: Yale University Press.

Brennan, K., \& Resnick, M. (2012). New frameworks for studying and assessing the development of computational thinking. In Proceedings of the 2012 annual meeting of the American Educational Research Association. Vancouver, Canada.

Brennan, K., \& Resnick, M. (2013). Imagining, creating, playing, sharing, reflecting: How online community supports young people as designers of interactive media. In C. Mouza \& N. Lavigne (Eds.), Emerging technologies for the classroom: A learning sciences perspective (pp. 253-268). New York, NY: Springer. doi: 10.1007/978-1-4614-4696-5_17

Broadband Commission for Sustainable Development. (2017). Digital skills for life and work. Retrieved from https://broadbandcommission.org/workinggroups/Pages/wgeducation.aspx

Brossi, L., Dodds, T., \& Passeron, E. (Eds.). (2019). Inteligencia Artificial y Bienestar de las Juventudes en América Latina. Santiago, Chile: LOM Ediciones.

Brown, J. A. (1998). Media literacy perspectives. Journal of Communication, 48(1), 44-57. doi: 10.1111/j.14602466.1998.tb02736.x

Buckingham, D. (2003). Media education: Literacy, learning and contemporary culture. Cambridge, UK: Polity.

Buckingham, D. (2006). Defining digital literacy: What do young people need to know about digital media? Nordic Journal of Digital Literacy, 4(1), 263-276. Retrieved from https://www.idunn.no/dk

Buckingham, D. (2007). Digital media literacies: Rethinking media education in the age of the internet. Research in Comparative and International Education, 2(1), 43-55. doi: 10.2304/rcie.2007.2.1.43

Bulger, M., \& Davison, P. (2018). The promises, challenges, and futures of media literacy. Journal of Media Literacy Education, 10(1), 1-21. doi: 10.23860/JMLE-2018-10-1-1

Byrne, J., Kardefelt-Winther, D., Livingstone, S., \& Stoilova, M. (2016). Global Kids Online research synthesis, 20152016. Retrieved from United Nations Children's Fund website: https://www.unicef-irc.org/publications/869/

Byron, T. (2008). Safer children in a digital world: The report of the Byron Review. London, UK: Department for Children, Schools and Families, and the Department for Culture, Media and Sport.

Calvani, A., Cartelli, A., Fini, A., \& Ranieri, M. (2008). Models and instruments for assessing digital competence at school. Journal of E-learning and Knowledge Society, 4(3), 183-193. Retrieved from https://www.je-lks. org/ojs/index.php/Je-LKS_EN

Calvani, A., Fini, A., Ranieri, M., \& Picci, P. (2012). Are young generations in secondary school digitally competent? A study on Italian teenagers. Computers \& Education, 58(2), 797-807. doi: 10.1016/j.compedu.2011.10.004

Care, E., \& Luo, S. (2016). Assessment of transversal competencies: Policy and practice in the Asia-Pacific region. Retrieved from United Nations Educational, Scientific and Cultural Organization website: https://unesdoc. unesco.org/ark:/48223/pf0000246590 
Carretero, S., Vuorikari, R., \& Punie, Y. (2017). DigComp 2.1: The digital competence framework for citizens with eight proficiency levels and examples of use. Retrieved from Publications Office of the European Union website: https://op.europa.eu/en/publication-detail/-/publication/3c5e7879-308f-11e7-9412-01aa75ed71a1/ language-en/format-PDF/source-111649968

Chang, E. (2018). Brotopia: Breaking up the boys' club of Silicon Valley. New York, NY: Portfolio/Penguin.

Chu, S. K. W., Reynolds, R. B., Tavares, N. J., Notari, M., \& Lee, C. W. Y. (2017). Twenty-first century skills and global education roadmaps. In S. K. W. Chu, R. B. Reynolds, N. J. Tavares, M. Notari, \& C. W. Y. Lee (Eds.), 21st century skills development through inquiry-based learning (pp. 17-32). Singapore: Springer. doi: 10.1007/978-981-10-2481-8_2

Clark, L. S., \& Marchi, R. (2017). Young people and the future of news: Social media and the rise of connective journalism. Cambridge, UK: Cambridge University Press.

Cobo, C., Cortesi, S., Brossi, L., Doccetti, S., Lombana, A., Remolina, N., . . Z Zucchetti, A. (Eds.). (2018). Jóvenes, transformación digital y formas de inclusión en América Latina. Montevideo, Uruguay: Penguin Random House.

Code.org. (n.d.). About. Retrieved from https://code.org/about

Code.org. (2019a). AP computer science over time [Data file]. Retrieved from https://code.org/promote/ap

Code.org. (2019b). What is Code.org? Retrieved from https://support.code.org/hc/en-us/articles/204784827What-is-Code-org-

Cohen, C. J., \& Kahne, K. (2012). Participatory politics: New media and youth political action. Chicago, IL: MacArthur Foundation.

College Board. (2018). Number of females and underrepresented students taking AP computer science courses spikes again [Press release]. Retrieved from https://www.collegeboard.org/releases/2018/number-offemales-and-underrepresented-students-taking-ap-computer-science-courses-spikes-again

Common Core State Standards Initiative. (n.d.-a). Development process. Retrieved from http://www. corestandards.org/about-the-standards/development-process/

Common Core State Standards Initiative. (n.d.-b). Measurement \& data. Retrieved from http://www. corestandards.org/Math/Content/MD/

Common Core State Standards Initiative. (n.d.-c). Statistics \& probability. Retrieved from http://www. corestandards.org/Math/Content/SP/

Corbett, C., \& Hill, C. (2015). Solving the equation: The variables for women's success in engineering and computing. Retrieved from American Association of University Women website: https://www.aauw.org/research/ solving-the-equation/

Cortesi, S., Lombana, A., \& Hasse, A. (2018). Sharing learning tools for youth digital life. Medium. Retrieved from https://medium.com/berkman-klein-center/sharing-learning-tools-for-youth-digital-life-dd8d6eb56e7a

Council of Europe [CoE]. (n.d.). Digital citizenship education project. Retrieved from https://www.coe.int/en/web/ digital-citizenship-education/digital-citizenship-education-project 
Council of Europe [CoE]. (2019a). Recommendation CM/Rec(2019)10 of the Committee of Ministers to member States on developing and promoting digital citizenship education. Retrieved from https://www.coe.int/en/ web/cm/cm-recommendations\#\{\%2254277205\%22:[0]\}

Council of Europe [CoE]. (2019b). Recommendation on developing and promoting digital citizenship education. Retrieved from https://www.coe.int/en/web/digital-citizenship-education/-/recommendationon-developing-and-promoting-digital-citizenship-education

Dalia Gonzalez, C. (2016). This Peruvian entrepreneur's startup is teaching young Latin American women to code. Retrieved from Remezcla website: https://remezcla.com/features/culture/mariana-costa-chicalaboratoria-women-code/

Dalton, R. J. (2008). The good citizen: How a younger generation is reshaping American politics. Washington, DC: CQ Press.

Dasgupta, S., \& Hill, B. M. (2017). Scratch community blocks: Supporting children as data scientists. In Proceedings of the $2017 \mathrm{CHI}$ Conference on Human Factors in Computing Systems (CHI'17). New York, NY: ACM Press. doi: 10.1145/3025453.3025847

DataBasic. (n.d.-a). About DataBasic. Retrieved from https://databasic.io/en/

DataBasic. (n.d.-b). ConnectTheDots. Retrieved from https://databasic.io/en/connectthedots/

DataBasic. (n.d.-c). SameDiff. Retrieved from https://www.databasic.io/en/samediff/

DataBasic. (n.d.-d). WordCounter. Retrieved from https://databasic.io/en/wordcounter/

De Abreu, B. S., Mihailidis, P., Lee, A. Y., Melki, J., \& McDougall, J. (Eds.). (2017). International handbook of media literacy education. London, UK: Taylor \& Francis.

Dede, C. (2010). Comparing frameworks for 21st century skills. In J. Bellance \& R. Brandt (Eds.), 21st century skills: Rethinking how students learn (pp. 51-76). Bloomington, IN: Solution Tree Press.

Delors, J. (1994). L’unité d’un homme: Entretiens avec Dominique Wolton. Paris, France: Odile Jacob.

DeNisco Rayome, A. (2016, September 5). What universities can do to graduate more women in computer sci: 7 tips from Harvey Mudd. TechRepublic. Retrieved from https://www.techrepublic.com/article/whatuniversities-can-do-to-graduate-more-women-in-comp-sci-7-tips-from-harvey-mudd/

D'Ignazio, C. (2017). Creative data literacy. Information Design Journal, 23(1), 6-18. doi: 10.1075/idj.23.1.03dig

Dockery, A. M. (2013). Cultural dimensions of Indigenous participation in vocational education and training: New perspectives. Adelaide, Australia: National Centre for Vocational Education Research.

DQ Institute. (2018). 2018 DQ impact report. Retrieved from https://www.dqinstitute.org/impactresearch/\#contentblock1

DQ Institute. (2019). DQ global standards report 2019. Retrieved from https://www.dqinstitute.org/dq-framework/

DQ World. (n.d.). What is DQ world? Retrieved from https://us.dqworld.net/lang:en/\#!//anding/whatisdqworld

Duckworth, A. L., \& Yeager, D. S. (2015). Measurement matters: Assessing personal qualities other than cognitive ability for educational purposes. Educational Researcher, 44(4), 237-251. doi: 10.3102/0013189X15584327 
Dudgeon, P., Cox, K., D’Anna, D., Dunkley, C., Hamms, K., Kelly, K., ... Walker, R. (2012). Hear our voices: Community consultations for the development of an empowerment, healing and leadership program for Aboriginal people living in the Kimberley, Western Australia. Canberra, Australia: Commonwealth of Australia.

Duran, R. L., Yousman, B., Walsh, K. M., \& Longshore, M. A. (2008). Holistic media education: An assessment of the effectiveness of a college course in media literacy. Communication Quarterly, 56(1), 49-68. doi: $10.1080 / 01463370701839198$

Element Al. (2019). Global Al talent report 2019. Retrieved from JF Gagnés website: https://jfgagne.ai/talent-2019/

Elfert, M. (2015). Learning to live together: Revisiting the humanism of the Delors Report. Retrieved from the United Nations Educational, Scientific and Cultural Organization website: https://unesdoc.unesco.org/ark:/48223/pf0000233814

Engagement Lab. (2017). Connect the Dots - DataBasic. Retrieved from https://vimeo.com/191074419

Enlaces. (2017, September 8). Red de ciudadanía digital realiza primera reunión de trabajo. Retrieved from http://www.internetsegura.cl/red-de-ciudadania-digital-realiza-primera-reunion-de-trabajo/

Enlaces. (2018, April 3). Orientaciones de ciudadanía digital para la formación ciudadana. Retrieved from http://www.internetsegura.cl/comunidad-educativa/orientaciones-ciudadania-digital/

Ensmenger, N. L. (2010). The computer boys takes over: Computers, programmers, and the politics of technical expertise. Cambridge, MA: MIT Press.

Eshet, Y. (2012). Thinking in the digital era: A revised model for digital literacy. In E. B. Cohen (Ed.), Issues in informing science \& information technology (Vol 9., pp. 267-276). Santa Rosa, CA: Informing Science.

Eshet-Alkalai, Y. (2004). Digital literacy: A conceptual framework for survival skills in the digital era. Journal of Educational Multimedia and Hypermedia, 13(1), 93-106. Retrieved from https://www.aace.org/pubs/jemh/

European Commission. (2007). Communication from the Commission to the European Parliament, the Council, the European Economic and Social Committee, and the Committee of the Regions. A European approach to media literacy in the digital environment. COM (2007) 833 final. Retrieved from https://eur-lex.europa.eu/ legal-content/EN/TXT/?uri=CELEX\%3A52007DC0833

European Commission. (2012). Communication from the Commission to the European Parliament, the Council, the European Economic and Social Committee and the Committee of the Regions. European strategy for a better Internet for children. COM (2012) 196 final. Retrieved from https://eur-lex.europa.eu/legal-content/ EN/ALL/?uri=CELEX\%3A52012DC0196

European Parliament and the Council of the European Union. (2006). Recommendation of the European Parliament and of the Council of 18 December 2006 on key competences for lifelong learning (2006/962/ EC). Official Journal of the European Union, 49, L 394, 10-18. Retrieved from https://eur-lex.europa.eu/ LexUriServ/LexUriServ.do?uri=0J:L:2006:394:0010:0018:en:PDF

Fanti, K. A., Demetriou, A. G., \& Hawa, V. V. (2012). A longitudinal study of cyberbullying: Examining risk and protective factors. European Journal of Developmental Psychology, 9(2), 168-181. doi: 10.1080/17405629.2011.643169

Ferrari, A. (2012). Digital competence in practice: An analysis of frameworks. Retrieved from Publications Office of the European Union website: https://op.europa.eu/en/publication-detail/-/publication/2547ebf4-bd2146e8-88e9-f53c1b3b927f/language-en/format-PDF/source-113995738 
Ferrari, A., Punie, Y., \& Redecker, C. (2012). Understanding digital competence in the 21st century: An analysis of current frameworks. In A. Ravenscroft, S. Lindstaedt, C. D. Kloos, \& D. Hernández-Leo (Eds.), 21st century learning for 21st century skills (pp. 79-92). Heidelberg, Germany: Springer. doi: 10.1007/978-3-642-33263-0_7

Fieldhouse, E., Tranmer, M., \& Russell, A. (2007). Something about young people or something about elections? Electoral participation of young people in Europe: Evidence from a multilevel analysis of the European Social Survey. European Journal of Political Research, 46(6), 797-822. doi: 10.1111/j.1475-6765.2007.00713.x

File, T. (2014). Young-adult voting: An analysis of presidential elections, 1964-2012 [PDF file]. Washington, DC: U.S. Census Bureau. Retrieved from https://www.census.gov/prod/2014pubs/p20-573.pdf

Fjeld, J., Achten, N., Hilligoss, H., Nagy, A. C., \& Srikumar, M. (2020). Principled artificial intelligence: Mapping consensus in ethical and rights-based approaches to principles for Al. Berkman Klein Center Research Publication No. 2020-1. Retrieved from https://papers.ssrn.com/sol3/papers.cfm?abstract_id=3518482

Frey, W. R., Patton, D. U., Gaskell, M. B., \& McGregor, K. A. (2020). Artificial intelligence and inclusion: Formerly gang-involved youth as domain experts in analyzing unstructured Twitter data. Social Science Computer Review, 38(1), 42-56. doi: 10.1177/0894439318788314

Funk, C., \& Parker, K. (2018). Women and men in STEM often at odds over workplace equity. Retrieved from Pew Research Center website: https://www. pewsocialtrends.org/2018/01/09/women-and-men-in-stem-oftenat-odds-over-workplace-equity/

Gal-Ezer, J. \& Stephenson, C. (2014). A tale of two countries: Successes and challenges in K-12 computer science education in Israel and the United States. ACM Transactions on Computing Education, 14(2), 8:18:18. doi: $10.1145 / 2602483$

Gallardo-Echenique, E. E., de Oliveira, J. M., Marqués-Molias, L., \& Esteve-Mon, F. (2015). Digital competence in the knowledge society. Journal of Online Learning and Teaching, 11(1), 1-16. Retrieved from https://jolt.merlot.org

Gasser, U. (2019, November 26). Al innovators should be listening to kids. Wired. Retrieved from https://www. wired.com/story/ai-innovators-should-be-listening-to-kids/

Gasser, U., \& Cortesi, S. (2017). Children's rights and digital technologies: Introduction to the discourse and some meta-observations. In M. D. Ruck, M. Peterson-Badali, \& M. Freeman (Eds.), Handbook of children's rights: Global and multidisciplinary perspectives (pp. 417-436). New York, NY: Routledge.

Gasser, U., Cortesi, S., \& Gerlach, J. (2012). Kinder und jugendliche im internet. Risiken und interventionsmöglichkeiten. With a contribution by Peter Gasser. Retrieved from https://www.hep-verlag.ch/kinder-jugendliche-internet-e-book

Gasser, U., Cortesi, S., Malik, M., \& Lee, A. (2012). Youth and digital media: From credibility to information quality. Berkman Klein Center for Internet \& Society. Retrieved from http://ssrn.com/abstract=2005272

Gee, J. P. (2010). New digital media and learning as an emerging area and "worked examples" as one way forward. Cambridge, MA: MIT Press.

Giddens, A. (1991). Modernity and self-identity: Self and society in the late modern age. Stanford, CA: Stanford University Press.

Gilster, P. (1997). Digital literacy. New York, NY: Wiley Computer Publications. 
Gleason, B., \& von Gillern, S. (2018). Digital citizenship with social media: Participatory practices of teaching and learning in secondary education. Journal of Educational Technology \& Society, 21(1), 200-212. Retrieved from https://www.j-ets.net

Global Kids Online. (2019). Global Kids Online: Comparative report. Retrieved from United Nations Children's Fund Office of Research - Innocenti website: https://www.unicef-irc.org/publications/1059-global-kidsonline-comparative-report.html

Good Play Project and Project New Media Literacies. (2011). Our space: Being a responsible citizen of the digital world. Retrieved from Project Zero website: http://www.pz.harvard.edu/resources/our-space-curriculum

Goodspeed, T. O. (2016). Untangling the soft skills conversation. Retrieved from Inter-American Dialogue website: https://www.thedialogue.org/analysis/untangling-the-soft-skills-conversation/

Google and Gallup Inc. (2016). Trends in the state of computer science in U.S. K-12 schools [PDF file]. Retrieved from http://goo.gl/j291E0

Gordon, E., \& Mihailidis, P. (2016). Civic media: Technology, design, practice. Cambridge, MA: MIT Press.

Gramlich, J. (2019). Young Americans are less trusting of other people - and key institutions - than their elders. Retrieved from Pew Research Center website: https://www.pewresearch.org/fact-tank/2019/08/06/ young-americans-are-less-trusting-of-other-people-and-key-institutions-than-their-elders/

Gray, M. L. (2009). Out in the country: Youth, media, and queer visibility in rural America. New York, NY: New York University Press.

Griezel, L., Finger, L. R., Bodkin-Andrews, G. H., Craven, R. G., \& Yeung, A. S. (2012). Uncovering the structure of and gender and developmental differences in cyber bullying. The Journal of Educational Research, 105(6), 442-455. doi: 10.1080/00220671.2011.629692

Griffin, P., McGaw, B., \& Care, E. (Eds.). (2012). Assessment and teaching of 21st century skills. Dordrecht, Netherlands: Springer. doi: 10.1007/978-94-007-2324-5

Grizzle, A., Moore, P., Dezuanni, M., Asthana, S., Wilson, C., Banda, F., \& Onumah, C. (2013). Media and information literacy: Policy and strategy guidelines. Retrieved from United Nations Educational, Scientific and Cultural Organization website: http://www.unesco.org/new/en/communication-and-information/resources/ publications-and-communication-materials/publications/full-list/media-and-information-literacy-policyand-strategy-guidelines/

Grosz, B. J., Grant, D. G., Vredenburgh, K., Behrends, J., Hu, L., Simmons, A., \& Waldo, J. (2019). Embedded ethicS: Integrating ethics across CS education. Communications of the ACM, 62(8), 54-61. doi: 10.1145/3330794

Haddon, L. (1992). Explaining ICT consumption: The case of the home computer. In R. Silverstone \& E. Hirsch (Eds.), Consuming technologies: Media and information in domestic spaces (pp. 82-96). London, UK: Routledge. doi: 10.4324/9780203401491_chapter_5

Hargittai, E. (2002). Beyond logs and surveys: In-depth measures of people's web use skills. Journal of the American Society for Information Science and Technology, 53(14), 1239-1244. doi: 10.1002/asi.10166

Hargittai, E. (2005). Survey measures of web-oriented digital literacy. Social Science Computer Review, 23(3), 371-379. doi: 10.1177/0894439305275911

Hargittai, E. (2009). An update on survey measures of web-oriented digital literacy. Social Science Computer Review, 27(1), 130-137. doi: 10.1177/0894439308318213 
Hargittai, E., \& Hsieh, Y. P. (2012). Succinct survey measures of web-use skills. Social Science Computer Review, 30(1), 95-107. doi: 10.1177/0894439310397146

Hargittai, E., \& Shaw, A. (2015). Mind the skills gap: The role of Internet know-how and gender in differentiated contributions to Wikipedia. Information, Communication \& Society, 18(4), 424-442. doi: $10.1080 / 1369118 \times .2014 .957711$

Hart, A. (1997). Textual pleasures and moral dilemmas: Teaching media literacy in England. In R. Kubey (Ed.), Media literacy in the information age (pp. 199-211). New Brunswick, NJ: Transaction. doi: 10.4324/9781351292924-9

Hasse, A., Cortesi, S., Lombana-Bermudez, A., \& Gasser, U. (2019a). Youth and artificial intelligence: Where we stand. Youth and Media, Berkman Klein Center for Internet \& Society. Retrieved from https://papers.ssrn. com/sol3/papers.cfm?abstract_id=3385718

Hasse, A., Cortesi, S., Lombana-Bermudez, A., \& Gasser, U. (2019b). Youth and cyberbullying: Another look. Youth and Media, Berkman Klein Center for Internet \& Society. Retrieved from https://papers.ssrn.com/sol3/ papers.cfm?abstract_id=3477297

Hasso Plattner Institute of Design at Stanford. (n.d.). An introduction to design thinking: Process guide [PDF file]. Retrieved from https://dschool-old.stanford.edu/sandbox/groups/designresources/wiki/36873/ attachments/74b3d/ModeGuideBO0TCAMP2010L.pdf

Healy, J. D. L. (2013). Yolngu Zorba meets Superman. Anthrovision, 1(1), 1-18. Retrieved from https://journals. openedition.org/anthrovision/

Heiman, T., \& Olenik-Shemesh, D. (2015). Cyberbullying experience and gender differences among adolescents in different educational settings. Journal of Learning Disabilities, 48(2), 146-155. doi: $10.1177 / 0022219413492855$

Higher Education Research Institute. (2010). Degrees of success: HERI report on STEM completion rates. Retrieved from: https://heri.ucla.edu/degrees-of-success-heri-report-on-stem-completion-rates/

Hinduja, S., \& Patchin, J. W. (2009). Bullying beyond the schoolyard: Preventing and responding to cyberbullying (1st ed.). Thousand Oaks, CA: Corwin.

Hobbs, R. (2010). Digital and media literacy: A plan of action. A white paper on the digital and media literacy recommendations of the Knight Commission on the information needs of communities in a democracy. Washington, DC: The Aspen Institute.

Hobbs, R. (2017). Create to learn: Introduction to digital literacy. Hoboken, NJ: John Wiley \& Sons.

Hobbs, R., \& Coiro, J. (2019). Design features of a professional development program in digital literacy. Journal of Adolescent \& Adult Literacy, 62(4), 401-409. doi: 10.1002/jaal.907

Hobbs, R., \& Frost, R. (2003). Measuring the acquisition of media-literacy skills. Reading Research Quarterly, 38(3), 330-355. doi: 10.1598/RRQ.38.3.2

Hobbs, R., \& Jensen, A. (2009). The past, present, and future of media literacy education. Journal of Media Literacy Education, 1(1), 1-11. Retrieved from https://digitalcommons.uri.edu/jmle/vol1/iss1/1/

Hobbs, R., \& Tuzel, S. (2017). Teacher motivations for digital and media literacy: An examination of Turkish educators. British Journal of Educational Technology, 48(1), 7-22. doi: 10.1111/bjet.12326 
Hour of Code. (2020). Hour of code. Retrieved from https://hourofcode.com/us

Hur, J. W., Andrzejewksi, C. E., \& Marghitu, D. (2017). Girls and computer science: Experiences, perceptions, and career aspirations. Computer Science Education, 27(2), 100-120. doi: 10.1080/08993408.2017.1376385

Huyer, S. (2015). Is the gender gap narrowing in science and engineering? Retrieved from United Nations Educational, Scientific and Cultural Organization website: https://unesdoc.unesco.org/ark:/48223/pf000 0235447?posInSet=9\&queryld=325117ad-f0e7-4ac1-94ea-76edd82bbb34

Inglehart, R. (1997). Modernization and postmodernization: Cultural, economic, and political change in 43 societies. Princeton, NJ: Princeton University Press.

International Society for Technology in Education [ISTE]. (n.d.). ISTE standards for students. Retrieved from https://www.iste.org/standards/for-students

International Society for Technology in Education [ISTE]. (2007). National educational technology standards for students. Retrieved from https://id. iste.org/docs/pdfs/20-14_ISTE_Standards-S_PDF.pdf

International Society for Technology in Education [ISTE]. (2016). Redefining learning in a technologydriven world. A report to support adoption of the ISTE standards for students [PDF file]. Retrieved from https://id.iste.org/docs/Standards-Resources/iste-standards_students-2016_research-validity-report_ final.pdf?sfvrsn=0.0680021527232122

International Telecommunication Union [ITU]. (2018). Measuring the information society report. Retrieved from https://www.itu.int/pub/D-IND-ICTOI

International Telecommunication Union [ITU]. (2019a). Gender ICT statistics [Data file]. Retrieved from https://www.itu.int/en/ITU-D/Statistics/Pages/stat/default.aspx

International Telecommunication Union [ITU]. (2019b). Measuring digital development: Facts and figures 2019. Retrieved from https://www.itu.int/en/mediacentre/Pages/2019-PR19.aspx

IPSOS Ltd Ghana. (2017). Risks and opportunities related to children's online practices: Ghana country report. Retrieved from Global Kids Online website: http://globalkidsonline.net/findings-ghana/

Ito, M., Arum, R., Conley, D., Gutiérrez, K., Kirshner, B., Livingstone, S., . . Watkins, C. (2020). The connected learning research network: Reflections on a decade of engaged scholarship. Irvine, CA: Connected Learning Alliance.

Ito, M., Baumer, S., Bittanti, M., boyd, d., Cody, R., Herr-Stephenson, B., . . . Tripp, L. (2010). Hanging out, messing around, and geeking out: Kids living and learning with new media. Cambridge, MA: MIT Press. doi: 10.7551/mitpress/11832.001.0001

Ito, M., Gutiérrez, K., Livingstone, S., Penuel, B., Rhodes, J., Salen, K., ... Watkins, C. (2013). Connected learning: An agenda for research and design. Irvine, CA: Digital Media and Learning Research Hub.

Ito, M., Horst, H., Brittanti, M., boyd, d., Herr-Stephenson, B., Lange, P., . . Robinson, L. (2008). Living and learning with new media: Summary of findings from the Digital Youth Project. Cambridge, MA: MIT Press. doi: 10.7551/mitpress/8519.001.0001

James, C. (2014). Disconnected: Youth, new media, and the ethics gap. Cambridge, MA: MIT Press.

Jenkins, H. (2006). Convergence culture. New York, NY: New York University Press.

Jenkins, H. (2019). Participatory culture: Interviews. Medford, MA: Polity. 
Jenkins, H., Clinton, K., Purushotma, R., Robison, A. J., \& Weigel, M. (2006). Confronting the challenges of participatory culture: Media education for the 21st century. Chicago, IL: MacArthur Foundation.

Jenkins, H., Ford, S., \& Green, J. (2013). Spreadable media: Creating value and meaning in a networked culture. New York, NY: New York University Press.

Jenkins, H., Ito, M., \& boyd, d. (2015). Participatory culture in a networked era: A conversation on youth, learning, commerce, and politics. Cambridge, UK: Polity.

Jenkins, H., Shresthova, S., Gamber-Thompson, L., Kligler-Vilenchik, N., \& Zimmerman, A. (2016). By any media necessary: The new youth activism. New York, NY: New York University Press.

Joinson, A. N. (2001). Self-disclosure in computer-mediated communication: The role of self-awareness and visual anonymity. European Journal of Social Psychology, 31(2), 177-192. doi: 10.1002/ejsp.36

Jones, L. M. (2010). The future of internet safety education. Critical lessons from four decades of youth drug abuse prevention. Boston, MA: Publius Project at the Berkman Klein Center for Internet \& Society, Harvard University. Retrieved from http://publius.cc/future_internet_safety_education_critical_lessons_four_ decades_youth_drug_abuse_prevention

Jones, L. M., \& Mitchell, K. J. (2016). Defining and measuring youth digital citizenship. New Media \& Society, 18(9), 2063-2079. doi: 10.1177/1461444815577797

Jones, L. M., Mitchell, K. J., \& Finkelhor, D. (2013). Online harassment in context: Trends from three Youth Internet Safety Surveys (2000, 2005, 2010). Psychology of Violence, 3(1), 53-69. doi: 10.1037/a0030309

Kahne, J., Hodgin, E., \& Eidman-Aadahl, E. (2016). Redesigning civic education for the digital age: Participatory politics and the pursuit of democratic engagement. Theory \& Research in Social Education, 44(1), 1-35. doi: 10.1080/00933104.2015.1132646

Kahne, J., Lee, N. J., \& Feezell, J. T. (2012). Digital media literacy education and online civic and political participation. International Journal of Communication, 6, 1-24. Retrieved from https://ijoc.org

Kahne, J., Middaugh, E., \& Allen, D. (2015). Youth, new media, and the rise of participatory politics. In D. Allen \& J. S. Light (Eds.), From voice to influence: Understanding citizenship in a digital age (pp. 35-55). Chicago, IL: University of Chicago Press.

Kay, K. (2010). 21st century skills: Why they matter, what they are, and how we get there. In J. Bellanca \& R. Brandt (Eds.), 21st century skills: Rethinking how students learn (pp. xiii-xxxi). Bloomington, IN: Solution Tree Press.

Kelkar, G., Shrestha, G., \& Veena, N. (2005). Women's agency and the IT industry in India. In C. Ng \& S. Mitter (Eds.), Gender and the digital economy: Perspectives from the developing world (pp. 110-131). New Delhi, India: Sage.

Kim, S., Kimber, M., Boyle, M. H., \& Georgiades, K. (2019). Sex differences in the association between cyberbullying victimization and mental health, substance use, and suicidal ideation in adolescents. The Canadian Journal of Psychiatry, 64(2), 126-135. doi: 10.1177/0706743718777397

Klawe, M. (2013, December 18). Increasing the participation of women in computing careers [Blog post]. Retrieved from http://socialissues.cs.toronto.edu/index.html\%3Fp=259.html 
Kleine, D., Hollow, D., \& Poveda, S. (2014). Children, ICT and development: Capturing the potential, meeting the challenges. Retrieved from United Nations Children's Fund Office of Research - Innocenti website: https://www.unicef-irc.org/publications/715-children-ict-and-development-capturing-the-potentialmeeting-the-challenges.html

Kligler-Vilenchik, N. (2017). Alternative citizenship models: Contextualizing new media and the new "good citizen." New Media \& Society, 19(11), 1887-1903. doi: 10.1177/1461444817713742

Kluzer, S., \& Pujol Priego, L. (2018). DigComp into action - Get inspired, make it happen. In S. Carretero, Y. Punie, R. Vuorikari, M. Cabrera, \& W. O’Keefe (Eds.), JRC Science for Policy Report, EUR 29115 EN. Retrieved from Publications Office of the European Union website. doi: 10.2760/112945

Koput, K. W., \& Gutek, B. A. (2010). Gender stratification in the IT industry: Sex, status and social capital. Cheltenham, UK: Edward Elgar.

Kowalski, R. M., \& Limber, S. P. (2013). Psychological, physical, and academic correlates of cyberbullying and traditional bullying. Journal of Adolescent Health, 53(1), S13-S20. doi: 10.1016/j.jadohealth.2012.09.018

Kral, I. (2010). Plugged in: Remote Australian indigenous youth and digital culture. Centre for Aboriginal Economic Policy Research, Working Paper No. 69. Retrieved from Australian National University website: https://caepr.cass.anu.edu.au/research/publications/plugged-remote-australian-indigenous-youth-anddigital-culture

Kress, G. (2010). Multimodality: A social semiotic approach to contemporary communication. New York, NY: Routledge.

Krumsvik, R. J. (2008). Situated learning and teachers' digital competence. Education and Information Technologies, 13(4), 279-290. doi: 10.1007/s10639-008-9069-5

Krumsvik, R. J. (2012). The digital school and teacher education in Norway. In R. Schultz-Zander, B. Eickelmann, H. Mozer, H. Niesyto, \& P. Grell (Eds.), Jahrbuch Medienpädagogik 9 [The annual book of Mediapedagogy 9] (pp. 455-480). Heidelberg, Germany: Springer VS. doi: 10.1007/978-3-531-94219-3_20

Laboratoria. (n.d.). Laboratoria for women. Retrieved from https://convocatoria.laboratoria.la/

Låftman, S. B., Modin, B., \& Östberg, V. (2013). Cyberbullying and subjective health: A large-scale study of students in Stockholm, Sweden. Children and Youth Services Review, 35(1), 112-119. doi: 10.1016/j.childyouth.2012.10.020

Landivar, L. C. (2013). Disparities in STEM employment by sex, race, and Hispanic origin. American Community Survey Reports, ACS-24. Retrieved from U.S. Census Bureau website: https://www.census.gov/library/ publications/2013/acs/acs-24.html

Lankshear, C., \& Knobel, M. (2007). Researching new literacies: Web 2.0 practices and insider perspectives. E- Learning and Digital Media, 4(3), 224-240. doi: 10.2304/elea.2007.4.3.224

Lazuras, L., Barkoukis, V., Ourda, D., \& Tsorbatzoudis, H. (2013). A process model of cyberbullying in adolescence. Computers in Human Behavior, 29(3), 881-887. doi: 10.1016/j.chb.2012.12.015

Lemke, C. (2003). enGauge 21st century skills: Digital literacies for a digital age. Naperville, IL: North Central Regional Educational Laboratory. 
Lenhart, A., Madden, M., Smith, A., Purcell, K., \& Zickuhr, K. (2011). Teens, kindness, and cruelty on social network sites. Retrieved from Pew Research Center website: https://www. pewresearch.org/internet/2011/11/09/ teens-kindness-and-cruelty-on-social-network-sites/

Levidow, L. (1996). Women who make the chips. In P. Ghorayshi \& C. Bélanger (Eds.), Women, work, and gender relations in developing countries (pp. 43-56). Santa Barbara, CA: Greenwood.

Levine, P. (2007). The future of democracy: Developing the next generation of American citizens. Medford, MA: Tufts University Press.

Levy, N., Cortesi, S., Gasser, U., Crowley, E., Beaton, M., Casey, J. A., \& Nolan, C. (2012). Bullying in a networked era: A literature review. Berkman Klein Center Research Publication No. 2012-17. Retrieved from http://ssrn.com/abstract=2146877

Lie, M., \& Lund, R. (1994). Renegotiating local values: Working women and foreign industry in Malaysia. Richmond, UK: Curzon.

Livingstone, S. (2003). The changing nature and uses of media literacy. Retrieved from London School of Economics and Political Science website: http://eprints.Ise.ac.uk/13476/

Livingstone, S. (2008). Internet literacy: Young people's negotiation of new online opportunities. In T. McPherson (Ed.), Digital youth, innovation, and the unexpected (pp. 101-122). Cambridge, MA: MIT Press.

Livingstone, S., \& Bulger, M. (2013). A global agenda for children's rights in the digital age: Recommendations for developing UNICEF's research strategy. Retrieved from United Nations Children's Fund Office of Research - Innocenti website: https://www.unicef-irc.org/publications/702-a-global-agenda-for-childrens-rights-inthe-digital-age-recommendations-for-developing.html

Livingstone, S., Haddon, L., Görzig, A., \& Ólafsson, K. (2011). Risks and safety on the internet: The perspective of European children. Full findings [PDF file]. London, UK: EU Kids Online. Retrieved from http://eprints.Ise.ac.uk/33731/1/Risks\%20and\%20safety\%20on\%20the\%20internet\%28lsero\%29.pdf

Livingstone, S., Kirwall, L., Ponte, C., \& Staksrud, E. (2014). In their own words: What bothers children online? European Journal of Communication, 29(3), 271-288. doi: 10.1177/0267323114521045

Livingstone, S., Mascheroni, G., Ólafsson, K., \& Haddon, L. (2014). Children's online risks and opportunities: Comparative findings from EU Kids Online and Net Children Go Mobile. Retrieved from London School of Economics and Political Science website: http://eprints.Ise.ac.uk/60513/

Livingstone, S., Mascheroni, G., \& Staksrud, E. (2015). Developing a framework for researching children's online risks and opportunities in Europe. Retrieved from London School of Economics and Political Science website: http://eprints.Ise.ac.uk/64470/

Livingstone, S., Van Couvering, E., \& Thumim, N. (2008). Converging traditions of research on media and information literacies: Disciplinary, critical, and methodological issues. In J. Coiro, M. Knobel, C. Lankshear, \& D. Leu (Eds.), Handbook of Research on New Literacies (pp. 103-132). New York, NY: Lawrence Erlbaum.

Lombana-Bermudez, A. (2016, December 22). Digital citizenship learning playlists: Co-design logistics and content preparation [Blog post]. Retrieved from https://www.hastac.org/blogs/lombana/2016/12/22/ digital-citizenship-learning-playlists-co-design-logistics-and-content

Lombana-Bermudez, A., Cortesi, S., Fieseler, C., Gasser, U., Hasse, A., Newlands, G., \& Wu, S. (2020). Youth and the digital economy: Exploring youth practices, motivations, skills, pathways, and value creation. Manuscript in preparation. 
López, J. (2018, February 11). This young entrepreneur is preparing girls to lead the tech industry in Ghana. Retrieved from IREX website: https://www.irex.org/success-story/young-entrepreneur-preparing-girlslead-tech-industry-ghana

Lumby, B. (2010). Cyber-indigeneity: Urban indigenous identity on Facebook. Australian Journal of Indigenous Education, 39(1), 68-75. doi: 10.1375/S1326011100001150

Maloney, J., Resnick, M., Rusk, N., Silverman, B., \& Eastmond, E. (2010). The Scratch programming language and environment.ACM Transactions on Computing Education, 10(4), 16:1-16:15. doi:10.1145/1868358.1868363

MAPSCorps. (n.d.). Mission. Retrieved from https://mapscorps.org

Margolis, J., \& Fisher, A. (2002). Unlocking the clubhouse: Women in computing. Cambridge, MA: MIT Press.

Marret, M. J., \& Choo, W. Y. (2017). Factors associated with online victimisation among Malaysian adolescents who use social networking sites: A cross-sectional study. BMJ Open, 7(6), 1-11. doi: 10.1136/bmjopen-2016-014959

Martin, A. (2005). DigEuLit - a European framework for digital literacy: A progress report [PDF file]. Journal of eLiteracy, 2(2), 130-136. Retrieved from http://citeseerx.ist.psu.edu/viewdoc/ download?doi=10.1 1.469.1923\&rep=rep1\&type=pdf

Martin, A., \& Grudziecki, J. (2006). DigEuLit: Concepts and tools for digital literacy development. Innovation in TeachingandLearningin InformationandComputerSciences, 5(4),249-267.doi:10.11120/ital.2006.05040249

Massachusetts Institute of Technology Beaver Works Summer Institute. (2019). MIT beaver works summer institute 2019 [PDF file]. Retrieved from https://beaverworks.ll.mit.edu/CMS/bw/sites/default/files/ Beaver\%20Works\%20Summer\%20Institute\%202019\%20Brochure\%20Final\%20Version.pdf

Masterman, L. (1993). The media education revolution. Canadian Journal of Learning and Technology, 22(1), 5-14. doi: 10.21432/T2JS5S

Means and Measures of Human Achievement (MHA) Labs. (n.d.). Social awareness. Retrieved from http://mhalabs.org/skill-building-blocks/social-awareness/

Media Literacy Now. (2016, April 4). Digital citizenship and internet safety education law in Washington state is national model. Retrieved from https://medialiteracynow.org/digital-citizenship-and-internet-safetyeducation-law-in-washington-state-is-national-model/

Media Literacy Now. (2020a). Putting media literacy on the public policy agenda. Retrieved from https://medialiteracynow.org/your-state-legislation/

Media Literacy Now. (2020b). U.S. media literacy policy report 2020. Retrieved from https://medialiteracynow. org/mlnpolicyreport/

Mellström, U. (2009). The intersection of gender, race and cultural boundaries, or why is computer science in Malaysia dominated by women? Social Studies of Science, 39(6), 885-907. doi:10.1177/0306312709334636

Mihailidis, P. (2014). Media literacy and the emerging citizen: Youth, engagement and participation in digital culture. New York, NY: Peter Lang.

Mihailidis, P. (2015). Digital curation and digital literacy: Evaluating the role of curation in developing critical literacies for participation in digital culture. E-learning and Digital Media, 12(5-6), 443-458. doi: $10.1177 / 2042753016631868$ 
Mihailidis, P. (2018). Civic media literacies: Re-imagining engagement for civic intentionality. Learning, Media and Technology, 43(2), 152-164. doi: 10.1080/17439884.2018.1428623

Mihailidis, P. (2019). Civic media literacies: Re-imagining human connection in an age of digital abundance. New York, NY: Routledge.

Mihailidis, P., \& Gerodimos, R. (2016). Connecting pedagogies of civic media: The literacies, connected civics, and engagement in daily life. In E. Gordon \& P. Mihailidis (Eds.), Civic media: Technology, design, practice (pp. 371-391). Cambridge, MA: MIT Press.

Mitchell, K. J., Jones, L. M., Finkelhor, D., \& Wolak, J. (2013). Understanding the decline in unwanted online sexual solicitations for U.S. youth 2000-2010: Findings from three Youth Internet Safety Surveys. Child Abuse \& Neglect, 37(12), 1225-1236. doi: 10.1016/j.chiabu.2013.07.002

Mobile City Science. (n.d.). Mobile city science. Retrieved from http://www.education.uw.edu/mcs/

Morgan, R., \& Klaric, J. (2007). AP students in college: An analysis of five-year academic careers. New York, NY: College Board.

Mossberger, K., Tolbert, C. J., \& McNeal, R. S. (2007). Digital citizenship: The internet, society, and participation. Cambridge, MA: MIT Press.

Mozilla. (2016). Web literacy. Retrieved from https://learning.mozilla.org/en-US/web-literacy

Mura, G., \& Diamantini, D. (2013). Cyberbullying among Colombian students: An exploratory investigation. European Journal of Investigation in Health, Psychology and Education, 3(3), 249-256. Retrieved from https://www.mdpi.com/journal/ejihpe

Muro, M., Liu, S., \& Whiton, J. (2018). Gender bias plays out in the digital workforce, but not in every industry. Retrieved from Brookings Institution website: https://www.brookings.edu/blog/the-avenue/2018/01/18/ gender-bias-plays-out-in-the-digital-workforce-but-not-in-every-industry/

National Center for Education Statistics. (2016). Bachelor's degrees conferred to females by postsecondary institutions, by race/ethnicity and field of study: 2013-14 and 2014-15. Retrieved from https://nces.ed.gov/programs/digest/d16/tables/dt16_322.50.asp?current=yes

National Research Council. (2012). Education for life and work: Developing transferable knowledge and skills in the 21st century. Retrieved from National Academies Press website: https://www.nap.edu/catalog/13398/ education-for-life-and-work-developing-transferable-knowledge-and-skills

National Science Foundation. (2017). Table 9-37: Scientists and engineers employed in business or industry, by sex, ethnicity, race, disability status, and managerial occupation: 2017 [Data file]. Retrieved from National Center for Science and Engineering Statistics website: https://ncses.nsf.gov/pubs/nsf19304/data

National Student Clearinghouse Research Center. (2016). High school benchmarks 2016: National college progression rates for high schools participating in the National Student Clearinghouse StudentTracker service. Retrieved from https://nscresearchcenter.org/hsbenchmarks2016/

Navarro, R., Ruiz-Oliva, R., Larrañaga, E., \& Yubero, S. (2015). The impact of cyberbullying and social bullying on optimism, global and school-related happiness and life satisfaction among 10-12-year-old schoolchildren. Applied Research in Quality of Life, 10(1), 15-36. doi: 10.1007/s11482-013-9292-0 
Netsafe. (2018). From literacy to fluency to citizenship:Digital citizenship in education (2nd ed.) [PDFfile]. Wellington, New Zealand: Netsafe. Retrieved from http://www.netsafe.org.nz/2017xyz/wp-content/uploads/2018/06/ From-literacy-to-fluency-to-citizenship.pdf

New South Wales Department of Education. (n.d.). About digital citizenship. Retrieved from https://www.digitalcitizenship.nsw.edu.au/about

Ng, C., \& Mitter, S. (2005). Valuing women's voices: Call center workers in Malaysia and India. Gender, Technology, and Development, 9(2), 209-233. doi: 10.4135/9788132103622.n6

Nickelsburg, M. (2019, June 13). Harvey Mudd president Maria Klawe has a message for computer science grads - and the tech industry. GeekWire. Retrieved from https://www.geekwire.com/2019/harvey-muddpresident-maria-klawe-message-computer-science-grads-tech-industry/

Oblinger, D. G., \& Oblinger, J. L. (2005). Educating the net generation. Louisville, CO: EDUCAUSE. Retrieved from https://www.educause.edu/research-and-publications/books/educating-net-generation

Oceans of Data Institute. (2014). Profile of a big-data-enabled specialist. Retrieved from Education Development Center website: http://www.oceansofdata.org/our-work/profile-big-data-enabled-specialist

Ofcom. (2004). Ofcom's strategy and priorities for the promotion of media literacy. Retrieved from https://www.ofcom.org.uk/consultations-and-statements/category-1/strategymedialit

O’Neill, B., Staksrud, E., \& McLaughlin, S. (Eds.). (2013). Towards a better Internet for children? Policy pillars, players, and paradoxes. Göteborg, Sweden: Nordicom.

Ong, A. (1987). Spirits of resistance and capitalist discipline: Factory women in Malaysia. Albany, NY: State University of New York Press.

Organisation for Economic Co-operation and Development [OECD]. (2005). Definition and selection of key competencies: Executive summary. Retrieved from https://www.oecd.org/education/skills-beyond-school/ definitionandselectionofcompetenciesdeseco.htm

Organisation for Economic Co-operation and Development [OECD]. (2015). Students, computers and learning: Making the connection. Retrieved from https://read.oecd-ilibrary.org/education/students-computers-andlearning_9789264239555-en\#page4

Organisation for Economic Co-operation and Development [OECD]. (2018). The future of education and skills: Education 2030. The future we want. Retrieved from https://www.oecd.org/education/2030-project/contact/

Organisation for Economic Co-operation and Development [OECD]. (2019). OECD future of education and skills 2030: Project background. Retrieved from https://www.oecd.org/education/2030-project/about/

Pal, S. (2017, January 30). Underprivileged orphan girls in India are learning robotics, thanks to this unique STEM initiative. Retrieved from The Better India website: https://www.thebetterindia.com/82869/indian-girlscode-robotix-phiro-aditi-prasad-deepti-rao-suchindran/

Palfrey, J., boyd, d., \& Sacco, D. (2010). Enhancing child safety and online technologies: Final report of the Internet safety technical task force to the multi-state working group on social networking of State Attorney Generals of the United States. Durham, NC: Carolina Academic Press. Retrieved from https://cyber.harvard.edu/ pubrelease/isttf/

Palfrey, J., \& Gasser, U. (2008). Born digital: Understanding the first generation of digital natives. New York, NY: Basic Books. 
Palfrey, J., \& Gasser, U. (2016). Born digital: How children grow up in a digital age. New York, NY: Basic Books.

Partnership for 21 st Century Learning. (2019). Frameworks \& resources. Retrieved from Battelle for Kids website: http://www.battelleforkids.org/networks/p21/frameworks-resources

Paus-Hasebrink, I., Kulterer, J., \& Sinner, P. (2019). Social inequality, childhood and the media: A longitudinal study of the mediatization of socialisation. Cham, Switzerland: Springer Nature Switzerland AG. doi: 10.1007/978-3-030-02653-0

Pérez Tornero, J. M., \& Pi, M. (2013). Media literacy policy in European Union: A new horizon. Retrieved from Universitat Autònoma de Barcelona website: https://ddd.uab.cat/record/174081

Pérez Tornero, J. M., \& Varis, T. (2010). Media literacy and new humanism. Retrieved from United Nations Educational, Scientific and Cultural Organization Institute for Information Technologies in Education website: https://iite.unesco.org/publications/3214678/

Peters, A. (2018, January 24). A 14-year-old made an app to help alzheimer's patients recognize their loved ones. Fast Company. Retrieved from https://www.fastcompany.com/40519094/a-14-year-old-made-anapp-to-help-alzheimers-patients-recognize-their-loved-ones

Pew Research Center. (2019). Internet/broadband fact sheet. Retrieved from https://www. pewinternet.org/factsheet/internet-broadband/

Rajendra, R. (2018, January 29). How two sisters brought robotics and coding to young girls. The Hindu. Retrieved from https://www.thehindu.com/society/indian-girls-code-how-two-sisters-brought-roboticsand-coding-to-young-girls/article22553067.ece

Reich, J., Cortesi, S., Haduong, P., \& Gasser, U. (2014). Evaluation in context: Reflections on how to measure success of your 'WNM' program. Berkman Klein Center Research Publication No. 2014-4. Retrieved from https://papers.ssrn.com/sol3/papers.cfm?abstract_id=2379011

Reich, S. M., Subrahmanyam, K., \& Espinoza, G. (2012). Friending, IMing, and hanging out face-to-face: Overlap in adolescents' online and offline social networks. Developmental Psychology, 48(2), 356-368. doi: $10.1037 / \mathrm{a} 0026980$

Resnick, M., Maloney, J., Monroy-Hernández, A., Rusk, N., Eastmond, E., Brennan, K., .. Kafai, Y. (2009). Scratch: Programming for all. Communications of the ACM, 52(11), 60-67. doi: 10.1145/1592761.1592779

Ribble, M. S., Bailey, G. D., \& Ross, T. W. (2004). Digital citizenship: Addressing appropriate technology behavior. Learning \& Leading with Technology, 32(1), 6-9. Retrieved from http://www.learningandleading-digital.com/ learningandleading/Store.action

Ribble, M., \& Park, M. (2019). The digital citizenship handbook for school leaders. International Society for Technology in Education: Arlington, VA.

Rice, E. S., Haynes, E., Royce, P., \& Thompson, S. C. (2016). Social media and digital technology use among Indigenous young people in Australia: A literature review. International Journal for Equity in Health, 15(81), e16. doi: 10.1186/s12939-016-0366-0

Rideout, V. (2015). The common sense census: Media use by tweens and teens, 2015. Retrieved from Common Sense website: https://www.commonsensemedia.org/research/the-common-sense-census-media-useby-tweens-and-teens 
Rideout, V., \& Robb, M. B. (2019). The common sense census: Media use by tweens and teens, 2019. Retrieved from Common Sense website: https://www.commonsensemedia.org/research/the-common-sensecensus-media-use-by-tweens-and-teens-2019

Saloma-Akpdeonu, C. (2005). Female spaces in the Philippines' ICT industry. In C. Ng \& M. Swasti (Eds.), Gender and the digital economy: Perspectives from the developing world (pp. 93-109). New Delhi, India: Sage Publications.

Schultze-Krumbholz, A., Göbel, K., Scheithauer, H., Brighi, A., Guarini, A., Tsorbatzoudis, H., ... Smith, P. K. (2015). A comparison of classification approaches for cyberbullying and traditional bullying using data from six European countries. Journal of School Violence, 14(1), 47-65. doi: 10.1080/15388220.2014.961067

Scratch. (n.d.) About Scratch. Retrieved from https://scratch.mit.edu/about

Scratch. (2019). Scratch statistics. Retrieved from https://scratch.mit.edu/statistics/

Sey, A., \& Hafkin, N. (Eds). (2019). Taking stock: Data and evidence on gender equality in digital access, skills and leadership. Macau: United Nations University Institute on Computing and Society/International Telecommunications Union. Retrieved from https://www.equals.org/

Shehata, A., Ekström, M., \& Olsson, T. (2016). Developing self-actualizing and dutiful citizens: Testing the AC-DC model using panel data among adolescents. Communication Research, 43(8), 1141-1169. doi: $10.1177 / 0093650215619988$

Sherrod, L. R., Flanagan, C., \& Youniss, J. (2002). Dimensions of citizenship and opportunities for youth development: The what, why, when, where, and who of citizenship development. Applied Developmental Science, 6(4), 264-272. doi: 10.1207/S1532480XADS0604_14

Shin, N., \& Ahn, H. (2015). Factors affecting adolescents' involvement in cyberbullying: What divides the $20 \%$ from the 80\%? Cyberpsychology, Behavior, and Social Networking, 18(7), 393-399. doi: 10.1089/cyber.2014.0362

Silva, E. (2009). Measuring skills for 21st-century learning. Phi Delta Kappan, 90(9), 630-634. doi: $10.1177 / 003172170909000905$

Sittichai, R., \& Smith, P. K. (2018). Bullying and cyberbullying in Thailand: Coping strategies and relation to age, gender, religion and victim status. Journal of New Approaches in Educational Research, 7(1), 24-30. doi: 10.7821/naer.2018.1.254

Small, D. (2016). Report to the legislature: Digital citizenship recommendations. Retrieved from Washington State Office of Superintendent of Public Instruction website: https://www.k12.wa.us/sites/default/files/public/ edtech/digitalcitmedialit/pubdocs/2016-12-digitalcitizenship-legislativereport.pdf

Soronko Solutions. (n.d.). Tech needs girls. Retrieved from http://www.soronkosolutions.com/tng.html

Spearman, J., \& Watt, H. M. G. (2013). Perception shapes experience: The influence of actual and perceived classroom environment dimensions on girls' motivations for science. Learning Environments Research, 16(2), 217-238. doi: 10.1007/s10984-013-9129-7

Stoet, G., \& Geary, D. C. (2018). The gender-equality paradox in science, technology, engineering, and mathematics education. Psychological Science, 29(4), 581-593. doi: 10.1177/0956797617741719

Subrahmanyam, K., Reich, S. M., Waechter, N., \& Espinoza, G. (2008). Online and offline social networks: Use of social networking sites by emerging adults. Journal of Applied Developmental Psychology, 29(6), 420-433. doi: 10.1016/j.appdev.2008.07.003 
Sweet, M., Pearson, L., \& Dudgeon, P. (2013). @Indigenousx: A case study of community-led innovation in digital media. Media International Australia,149(1), 104-111. doi: 10.1177/1329878X1314900112

Sydell, L. (2017, August 10). Colleges have increased women computer science majors: What can Google learn? National Public Radio. Retrieved from https://www.npr.org/sections/ alltechconsidered/2017/08/10/542638758/colleges-have-increased-women-computer-science-majorswhat-can-google-learn

Tarablus, T., Heiman, T., \& Olenik-Shemesh, D. (2015). Cyber bullying among teenagers in Israel: An examination of cyber bullying, traditional bullying, and socioemotional functioning. Journal of Aggression, Maltreatment \& Trauma, 24(6), 707-720. doi: 10.1080/10926771.2015.1049763

Third, A., Bellerose, D., Dawkins, U., Keltie, E., \& Pihl, K. (2014). Children's rights in the digital age: A download from children around the world. Retrieved from United Nations Children's Fund website: https://www.unicef.org/ publications/index_76268.html

Third, A., Bellerose, D., Diniz De Oliveira, J., Lala, G., \& Theakstone, G. (2017). Young and online: Children's perspectives on life in the digital age (The state of the world's children 2017 companion report). Retrieved from Western Sydney University website: https://www.unicef.org/publications/files/Young_and_Online_ Children_perspectives_Dec_2017.pdf

Touretzky, D., Gardner-McCune, C., Breazeal, C., Martin, F., \& Seehorn, D. (2020). A year in K-12 Al education. Al Magazine, 40(4), 88-90. doi: 10.1609/aimag.v40i4.5289

Touretzky, D. S., Gardner-McCune, C., Martin, F., \& Seehorn, D. (2019). K-12 guidelines for artificial intelligence: What students should know [PDF file]. Retrieved from https://github.com/touretzkyds/ai4k12/wiki

Trends in International Mathematics and Science Study and Progress in International Reading Literacy Study. (2015). TIMSS 2015 encyclopedia: Education policy and curriculum in mathematics and science. Retrieved from http://timssandpirls.bc.edu/timss2015/encyclopedia/

Tyner, K. R. (1998). Literacy in a digital world: Teaching and learning in the age of information. Mahwah, NJ: Erlbaum.

UC Berkeley Human Rights Center Research Team. (2019). Memorandum on artificial intelligence and child rights [PDF file]. Retrieved from https://www.unicef.org/innovation/media/10501/file/Memorandum\%20on\%20 Artificial\%20Intelligence\%20and\%20Child\%20Rights.pdf

United Nations Children's Fund [UNICEF]. (2017). The state of the world's children 2017: Children in a digital world. Retrieved from https://www.unicef.org/publications/index_101992.html

United Nations Children's Fund [UNICEF]. (2019a). Workshop report: Al and child rights policy [PDF file]. Office of Global Insight and Policy. Retrieved from https://ec.europa.eu/jrc/communities/sites/jrccties/files/ai_ and_child_rights_workshop_report_june_2019_sept23_3.pdf

United Nations Children's Fund [UNICEF]. (2019b, August 27). Developing policy guidance for Al and child rights. Retrieved from https://www.unicef.org/innovation/stories/developing-policy-guidance-ai-and-child-rights

United Nations Children's Fund [UNICEF] Office of Research - Innocenti. (2019). Growing up in a connected world [PDF file]. Retrieved from https://www.unicef-irc.org/publications/pdf/GKO\%20Summary\%20Report.pdf

United Nations Educational, Scientific and Cultural Organization [UNESCO]. (2016). A policy review: Building digital citizenship in Asia-Pacific through safe, effective and responsible use of ICT. Retrieved from https://unesdoc.unesco.org/ark:/48223/pf0000246813 
United Nations Educational, Scientific and Cultural Organization [UNESCO]. (2017). Cracking the code: Girls' and women's education in science, technology, engineering and mathematics (STEM). Retrieved from https://unesdoc.unesco.org/ark:/48223/pf0000253479

United Nations Educational, Scientific and Cultural Organization [UNESCO]. (2019a). Artificial intelligence for sustainable development: Synthesis report. Mobile Learning Week 2019. Retrieved from https://unesdoc.unesco.org/ark:/48223/pf0000370308

United Nations Educational, Scientific and Cultural Organization [UNESCO]. (2019b). Beijing Consensus on artificial intelligence (Al) and education. Retrieved from https://unesdoc.unesco.org/ark:/48223/pf0000368303

University of North Carolina Center for Health Equity Research. (n.d.). MAPSCorps nash \& edgecombe. Retrieved from https://cher.unc.edu/mapscorpsnc/

U.S. Bureau of Labor Statistics. (2019, September 4). Occupational outlook handbook: Computer and information technology occupations. Retrieved from https://www.bls.gov/ooh/computer-and-informationtechnology/home.htm

Valdivia, A., Brossi, L., Cabalin, C., \& Pinto, D. (2019). Alfabetizaciones y prácticas digitales desde agencias juveniles. Desafíos para la educación en Chile. Revista de Investigación Educacional Latinoamericana, 56(2), 1-17. Retrieved from http://pensamientoeducativo.uc.cl/index.php/pel/article/view/1109/2121

van der Hof, S. (2016). I agree, or do I? A rights-based analysis of the law on children's consent in the digital world. Wisconsin International Law Journal, 34(2), 409-445. Retrieved from https://hosted.law.wisc.edu/ wordpress/wilj/

van Deursen, A. J. A. M. (2010). Internet skills: Vital assets in an information society (Doctoral thesis). Retrieved from University of Twente website: https://research.utwente.nl/en/publications/internet-skills-vital-assetsin-an-information-society-2

van Deursen, A. J. A. M., Helsper, E. J., \& Eynon, R. (2014). Measuring digital skills. From digital skills to tangible outcomes. Project report. Retrieved from Oxford Internet Institute website: https://www.oii.ox.ac.uk/ research/projects/measures-and-models-of-internet-use/?publications

van Dijk, J. A. G. M., \& van Deursen, A. J. A. M. (2014). Digital skills: Unlocking the information society. New York, NY: Palgrave Macmillan.

Vega, V., \& Robb, M. B. (2019). The Common Sense census: Inside the 21st-century classroom. Retrieved from Common Sense website: https://www.commonsensemedia.org/research/the-common-sense-censusinside-the-21st-century-classroom-2019

von Hebel, M. (2009). You hold the keys to lifelong learning. In M. von Hebel, P. Kloosterman, \& D. Markovic (Eds.), Youthpass: Making the most of your learning (pp. 19-24). Retrieved from Youthpass website: https://www.youthpass.eu/en/help/guide/

Vuorikari, R., Punie, Y., Carretero, S., \& Van den Brande, L. (2016). DigComp 2.0: The digital competence framework for citizens. Update phase 1: The conceptual reference model. Retrieved from Publications Office of the European Union website: https://op.europa.eu/en/publication-detail/-/publication/bc52328b-294e-11e6b616-01aa75ed71a1/language-en/format-PDF/source-114913595

Wajcman, J., \& Lobb, L. A. P. (2007). The gender relations of software work in Vietnam. Gender, Technology, and Development, 11(1), 1-26. doi: 10.1177/097185240601100101 
Walrave, M., \& Heirman, W. (2011). Cyberbullying: Predicting victimisation and perpetration. Children \& Society, 25(1), 59-72. doi: 10.1111/j.1099-0860.2009.00260.x

Washington Office of Superintendent of Public Instruction. (n.d.). Digital citizenship \& media literacy. Retrieved from https://www.k12.wa.us/policy-funding/school-technology/internet-safety-policy/digital-citizenshipmedia-literacy

Watkins, S. C., Lombana-Bermudez, A., Cho, A., Vickery, J. R., Shaw, V., \& Weinzimmer, L. (2018). The digital edge: How Black and Latino youth navigate digital inequality. New York, NY: New York University Press.

Williams, A. L., \& Merten, M. J. (2008). A review of online social networking profiles by adolescents: Implications for future research and intervention. Adolescence, 43(170), 253-274. Retrieved from https://www.journals. elsevier.com/journal-of-adolescence/

Wittman, L. (2019, August 17). Digital citizenship support for schools. Retrieved from New South Wales Department of Education website: https://education.nsw.gov.au/teaching-and-learning/professionallearning/scan/past-issues/vol-31--2012/vol-31-no--2

World Bank. (2016). World development report 2016: Digital dividends. Retrieved from https://www.worldbank. org/en/publication/wdr2016

World Economic Forum [WEF]. (2015). New vision for education: Unlocking the potential of technology. Retrieved from http://www3.weforum.org/docs/WEFUSA_NewVisionforEducation_Report2015.pdf

World Economic Forum [WEF]. (2018). The global gender gap report 2018. Retrieved from http://reports. weforum. org/global-gender-gap-report-2018/the-global-gender-gap-index-2018/

World Economic Forum [WEF]. (2019). Generation Al: Establishing global standards for children and Al. Retrieved from https://www.weforum.org/reports/generation-ai-establishing-global-standards-for-children-and-ai

Ybarra, M. L., boyd, d., Korchmaros, J. D., \& Oppenheim, J. K. (2012). Defining and measuring cyberbullying within the larger context of bullying victimization. Journal of Adolescent Health, 51(1), 53-58. doi: 10.1016/j.jadohealth.2011.12.031

Xenos, M., Vromen, A., \& Loader, B. D. (2014). The great equalizer? Patterns of social media use and youth political engagement in three advanced democracies. Information, Communication \& Society, 17(2), 151167. doi: 10.1080/1369118X.2013.871318 


\section{APPENDIX $A^{45}$}

This Appendix A includes the full list of 35 frameworks we examined on digital citizenship, and related concepts (e.g., digital literacy, 21st century skills). To view a visualization of these frameworks in the context of our 17 areas of life connected to the digital world (that comprise our "digital citizenship+ (plus)" framework), please see part III, section 3 of this paper. In this appendix, you may find the following information for each stakeholder: 1) Framework author, 2) Author sector(s), 3) Headquarters, 4) Framework title, 5) Term(s) used (e.g., "digital citizenship," "online safety"), 6) Year updated, 7) Point(s) of contact or general inquiries email, and 8) Link to the referred source.

\begin{tabular}{|c|c|c|c|c|c|c|c|c|}
\hline \# & $\begin{array}{l}\text { Framework } \\
\text { Author }\end{array}$ & $\begin{array}{l}\text { Author } \\
\text { Sector(s) }\end{array}$ & $\begin{array}{l}\text { Head- } \\
\text { quarters }\end{array}$ & $\begin{array}{c}\text { Framework } \\
\text { Title }\end{array}$ & $\begin{array}{l}\text { Term(s) } \\
\text { Used }\end{array}$ & $\begin{array}{c}\text { Year } \\
\text { Updated }\end{array}$ & $\begin{array}{l}\text { Point(s) } \\
\text { of Contact } \\
\text { or General } \\
\text { Inquiries Email }\end{array}$ & $\begin{array}{l}\text { Link to } \\
\text { Referred } \\
\text { Source }\end{array}$ \\
\hline 1 & $\begin{array}{l}\text { Child } \\
\text { Exploitation } \\
\text { and Online } \\
\text { Protection } \\
\text { Command }\end{array}$ & Government & $\begin{array}{l}\text { London, } \\
\text { U.K. }\end{array}$ & ThinkUKnow & $\begin{array}{l}\text { Online } \\
\text { safety }\end{array}$ & 2019 & $\begin{array}{c}\text { communica- } \\
\text { tion@nca.gov. } \\
\text { uk }\end{array}$ & $\begin{array}{l}\text { Source } \\
\text { (ages 11-13 } \\
\text { and 14t) }\end{array}$ \\
\hline 2 & $\begin{array}{l}\text { Common } \\
\text { Sense, Project } \\
\text { Zero }\end{array}$ & $\begin{array}{l}\text { Non- } \\
\text { governmental } \\
\text { organization } \\
\text { (NGO), } \\
\text { Academia }\end{array}$ & $\begin{array}{l}\text { San } \\
\text { Francisco, } \\
\text { CA, U.S., and } \\
\text { Cambridge, } \\
\text { MA, U.S., } \\
\text { respectively }\end{array}$ & $\begin{array}{l}\text { Digital } \\
\text { Citizenship } \\
\text { Curriculum }\end{array}$ & $\begin{array}{c}\text { Digital } \\
\text { citizenship }\end{array}$ & 2019 & $\begin{array}{c}\text { Kelly Mendoza, } \\
\text { Carrie James, } \\
\text { and Emily } \\
\text { Weinstein }\end{array}$ & $\begin{array}{l}\text { Source } \\
\text { (Grades } \\
6-12 \text { ) }\end{array}$ \\
\hline 3 & $\begin{array}{l}\text { Convergence } \\
\text { Design Lab }\end{array}$ & Academia & $\begin{array}{c}\text { Chicago, IL, } \\
\text { U.S. }\end{array}$ & $\begin{array}{c}\text { The } 3 \text { C's } \\
\text { of Connect, } \\
\text { Consume, } \\
\text { Create, and } \\
\text { Six Pillars of } \\
\text { Instructional } \\
\text { Design }\end{array}$ & $\begin{array}{l}21 \text { st } \\
\text { century } \\
\text { skills }\end{array}$ & 2015 & Mindy Faber & Source \\
\hline 4 & $\begin{array}{c}\text { CyberSecurity } \\
\text { Malaysia }\end{array}$ & Government & $\begin{array}{l}\text { Selangor, } \\
\text { Malaysia }\end{array}$ & $\begin{array}{l}\text { CyberSAFE } \\
\text { Malaysia }\end{array}$ & $\begin{array}{l}\text { Cyber } \\
\text { safety }\end{array}$ & 2010 & $\begin{array}{c}\text { cybersafe@ } \\
\text { cybersecurity. } \\
\text { my }\end{array}$ & Source \\
\hline 5 & DQ Institute & NGO & Singapore & $\begin{array}{c}\text { Digital } \\
\text { Intelligence } \\
\text { (DQ) } \\
\text { Framework }\end{array}$ & $\begin{array}{c}\text { Digital } \\
\text { citizenship, } \\
\text { Digital } \\
\text { creativity, } \\
\text { Digital } \\
\text { competi- } \\
\text { tiveness }\end{array}$ & 2019 & $\begin{array}{c}\text { contact@DQin- } \\
\text { stitute.org }\end{array}$ & Source \\
\hline 6 & Enlaces & Government & $\begin{array}{l}\text { Santiago, } \\
\text { Chile }\end{array}$ & $\begin{array}{l}\text { Rules for } \\
\text { Digital } \\
\text { Citizenship } \\
\text { and a Safe } \\
\text { Internet }\end{array}$ & $\begin{array}{l}\text { Digital } \\
\text { citizenship, } \\
\text { Internet } \\
\text { safety }\end{array}$ & 2016 & $\begin{array}{l}\text { internetsegu- } \\
\text { ra@fct.pt }\end{array}$ & Source \\
\hline
\end{tabular}

${ }^{45}$ N.B.: For Perma.cc links in this Appendix A, to access full site functionality (e.g., to be redirected to secondary links and view embedded videos), please click "View the live page" in the top right corner. 


\begin{tabular}{|c|c|c|c|c|c|c|c|c|}
\hline$\#$ & $\begin{array}{c}\text { Framework } \\
\text { Author }\end{array}$ & $\begin{array}{l}\text { Author } \\
\text { Sector(s) }\end{array}$ & $\begin{array}{l}\text { Head- } \\
\text { quarters }\end{array}$ & $\begin{array}{l}\text { Framework } \\
\text { Title }\end{array}$ & $\begin{array}{l}\text { Term(s) } \\
\text { Used }\end{array}$ & $\begin{array}{c}\text { Year } \\
\text { Updated }\end{array}$ & $\begin{array}{c}\text { Point(s) } \\
\text { of Contact } \\
\text { or General } \\
\text { Inquiries Email }\end{array}$ & $\begin{array}{l}\text { Link to } \\
\text { Referred } \\
\text { Source }\end{array}$ \\
\hline 7 & $\begin{array}{l}\text { EU Kids } \\
\text { Online }\end{array}$ & Academia & $\begin{array}{l}\text { London, } \\
\text { U.K. }\end{array}$ & $\begin{array}{c}\text { Digital } \\
\text { Citizenship }\end{array}$ & $\begin{array}{c}\text { Digital } \\
\text { citizenship }\end{array}$ & 2017 & $\begin{array}{l}\text { Tijana Milose- } \\
\text { vic, Elisabeth } \\
\text { Staksrud, David } \\
\text { Šmahel, and } \\
\text { Sonia Living- } \\
\text { stone }\end{array}$ & Source \\
\hline 8 & $\begin{array}{l}\text { European } \\
\text { Commission }\end{array}$ & Government & $\begin{array}{l}\text { Brussels, } \\
\text { Belgium }\end{array}$ & $\begin{array}{l}\text { DigComp } \\
\text { 2.1: Digital } \\
\text { Competence } \\
\text { Framework } \\
\text { for Citizens }\end{array}$ & $\begin{array}{c}\text { Digital } \\
\text { competence }\end{array}$ & 2017 & $\begin{array}{c}\text { Stephanie } \\
\text { Carretero, } \\
\text { Riina Vuorikari, } \\
\text { and Yves Punie }\end{array}$ & Source \\
\hline 9 & $\begin{array}{l}\text { Global Digital } \\
\text { Citizen } \\
\text { Foundation } \\
\text { (GDCF) }\end{array}$ & NGO & $\begin{array}{l}\text { Vancouver, } \\
\text { British } \\
\text { Columbia, } \\
\text { Canada }\end{array}$ & $\begin{array}{l}\text { The Essential } \\
\text { Fluencies }\end{array}$ & $\begin{array}{c}\text { Global } \\
\text { digital } \\
\text { citizenship }\end{array}$ & 2017 & $\begin{array}{l}\text { Lee Watanabe } \\
\text { Crockett }\end{array}$ & Source \\
\hline 10 & $\begin{array}{l}\text { Good Play } \\
\text { Project and } \\
\text { Project } \\
\text { New Media } \\
\text { Literacies }\end{array}$ & Academia & $\begin{array}{c}\text { Cambridge, } \\
\text { MA, U.S., } \\
\text { and Los } \\
\text { Angeles, } \\
\text { CA, U.S., } \\
\text { respectively }\end{array}$ & $\begin{array}{l}\text { Our Space } \\
\text { Curriculum }\end{array}$ & $\begin{array}{l}\text { New media } \\
\text { literacies, } \\
\text { Ethical } \\
\text { thinking } \\
\text { skills }\end{array}$ & 2011 & $\begin{array}{c}\text { Howard } \\
\text { Gardner, Henry } \\
\text { Jenkins }\end{array}$ & Source \\
\hline 11 & Hobbs, Renee & Academia & $\begin{array}{l}\text { Kingston, } \\
\text { RI, U.S. }\end{array}$ & $\begin{array}{l}\text { Digital } \\
\text { and Media } \\
\text { Literacy }\end{array}$ & $\begin{array}{c}\text { Digital } \\
\text { and media } \\
\text { literacy }\end{array}$ & 2010 & Renee Hobbs & Source \\
\hline 12 & $\begin{array}{l}\text { International } \\
\text { Computer } \\
\text { Driving } \\
\text { License (ICDL) } \\
\text { Foundation }\end{array}$ & NGO & $\begin{array}{c}\text { Primary site } \\
\text { dependent } \\
\text { upon } \\
\text { regional } \\
\text { focus }\end{array}$ & $\begin{array}{l}\text { International } \\
\text { Computer } \\
\text { Driving } \\
\text { License }\end{array}$ & $\begin{array}{l}\text { Computer } \\
\text { skills }\end{array}$ & 2019 & $\begin{array}{l}\text { General inquiry } \\
\text { form. Contact } \\
\text { email will } \\
\text { depend upon } \\
\text { regional focus }\end{array}$ & Source \\
\hline 13 & $\begin{array}{l}\text { International } \\
\text { Society for } \\
\text { Technology } \\
\text { in Education } \\
\text { (ISTE) }\end{array}$ & NGO & $\begin{array}{l}\text { Arlington, } \\
\text { VA, U.S. }\end{array}$ & $\begin{array}{l}\text { ISTE } \\
\text { Standards for } \\
\text { Students }\end{array}$ & $\begin{array}{l}\text { Digital } \\
\text { citizen }\end{array}$ & 2016 & $\begin{array}{l}\text { standards@ } \\
\text { iste.org }\end{array}$ & Source \\
\hline 14 & $\begin{array}{l}\text { Jones, Lisa } \\
\text { and Mitchell, } \\
\text { Kimberly }\end{array}$ & Academia & $\begin{array}{l}\text { Durham, } \\
\text { NH, U.S. }\end{array}$ & $\begin{array}{c}\text { Digital } \\
\text { Citizenship }\end{array}$ & $\begin{array}{c}\text { Digital } \\
\text { citizenship }\end{array}$ & 2016 & $\begin{array}{l}\text { Lisa Jones, } \\
\text { Kimberly } \\
\text { Mitchell }\end{array}$ & Source \\
\hline
\end{tabular}




\begin{tabular}{|c|c|c|c|c|c|c|c|c|}
\hline$\#$ & $\begin{array}{l}\text { Framework } \\
\text { Author }\end{array}$ & $\begin{array}{l}\text { Author } \\
\text { Sector(s) }\end{array}$ & $\begin{array}{l}\text { Head- } \\
\text { quarters }\end{array}$ & $\begin{array}{c}\text { Framework } \\
\text { Title }\end{array}$ & $\begin{array}{l}\text { Term(s) } \\
\text { Used }\end{array}$ & $\begin{array}{c}\text { Year } \\
\text { Updated }\end{array}$ & $\begin{array}{c}\text { Point(s) } \\
\text { of Contact } \\
\text { or General } \\
\text { Inquiries } \\
\text { Email } \\
\end{array}$ & $\begin{array}{l}\text { Link to } \\
\text { Referred } \\
\text { Source }\end{array}$ \\
\hline 15 & $\begin{array}{l}\text { Lindsay, Julie } \\
\text { and Davis, } \\
\text { Vicki }\end{array}$ & Academia & $\begin{array}{l}\text { New South } \\
\text { Wales, } \\
\text { Australia, } \\
\text { and Albany, } \\
\text { Georgia, } \\
\text { U.S. } \\
\text { respectively }\end{array}$ & $\begin{array}{l}\text { Enlightened } \\
\text { Digital } \\
\text { Citizenship }\end{array}$ & $\begin{array}{c}\text { Digital } \\
\text { citizenship }\end{array}$ & 2013 & $\begin{array}{c}\text { Julie } \\
\text { Lindsay, } \\
\text { Vicki Davis }\end{array}$ & Source \\
\hline 16 & $\begin{array}{l}\text { Malaysian } \\
\text { Communi- } \\
\text { cations and } \\
\text { Multimedia } \\
\text { Commission }\end{array}$ & Government & $\begin{array}{l}\text { Cyberjaya, } \\
\text { Malaysia }\end{array}$ & $\begin{array}{l}\text { Klik Dengan } \\
\text { Bijak }\end{array}$ & $\begin{array}{l}\text { Internet } \\
\text { safety }\end{array}$ & 2014 & $\begin{array}{l}\text { kdb@cmc. } \\
\text { gov.my }\end{array}$ & Source \\
\hline 17 & $\begin{array}{l}\text { Means and } \\
\text { Measures } \\
\text { of Human } \\
\text { Achievement } \\
\text { (MHA) Labs }\end{array}$ & NGO & $\begin{array}{l}\text { Chicago, IL, } \\
\text { U.S. }\end{array}$ & $\begin{array}{l}\text { The Building } \\
\text { Blocks }\end{array}$ & $\begin{array}{l}21 \text { st } \\
\text { century } \\
\text { skills }\end{array}$ & 2013 & Leslie Beller & Source \\
\hline 18 & MediaSmarts & NGO & $\begin{array}{l}\text { Ottawa, } \\
\text { Ontario, } \\
\text { Canada }\end{array}$ & $\begin{array}{c}\text { Digital and } \\
\text { Media } \\
\text { Literacy } \\
\text { Fundamentals }\end{array}$ & $\begin{array}{c}\text { Digital } \\
\text { literacy, } \\
\text { Media } \\
\text { literacy }\end{array}$ & 2019 & $\begin{array}{l}\text { Matthew } \\
\text { Johnson }\end{array}$ & Source \\
\hline 19 & $\begin{array}{l}\text { Media Literacy } \\
\text { Council }\end{array}$ & NGO & Singapore & $\begin{array}{l}\text { Be Safe, Be } \\
\text { Smart, and } \\
\text { Be Kind }\end{array}$ & $\begin{array}{c}\text { Media } \\
\text { literacy, } \\
\text { cyber } \\
\text { wellness }\end{array}$ & 2019 & $\begin{array}{c}\text { info@ } \\
\text { medialiter- } \\
\text { acycouncil. } \\
\text { sg }\end{array}$ & Source \\
\hline 20 & $\begin{array}{l}\text { Media Literacy } \\
\text { Now }\end{array}$ & NGO & $\begin{array}{c}\text { Watertown, } \\
\text { MA, U.S. }\end{array}$ & $\begin{array}{l}\text { Media } \\
\text { Literacy }\end{array}$ & $\begin{array}{c}\text { Media } \\
\text { literacy, } \\
\text { digital } \\
\text { citizenship }\end{array}$ & 2016 & Erin McNeill & Source \\
\hline 21 & $\begin{array}{c}\text { Mossberger, } \\
\text { Karen; Tolbert, } \\
\text { Caroline; } \\
\text { and McNeal, } \\
\text { Ramona }\end{array}$ & Academia & $\begin{array}{c}\text { Phoenix, } \\
\text { AZ, U.S.; } \\
\text { Iowa City, } \\
\text { IA, U.S.; and } \\
\text { Cedar Falls, } \\
\text { IA, U.S. } \\
\text { respectively }\end{array}$ & $\begin{array}{c}\text { Digital } \\
\text { Citizenship }\end{array}$ & $\begin{array}{c}\text { Digital } \\
\text { citizenship }\end{array}$ & 2007 & $\begin{array}{l}\text { Karen } \\
\text { Mossberg- } \\
\text { er, Caroline } \\
\text { Tolbert, and } \\
\text { Ramona } \\
\text { McNeal }\end{array}$ & Source \\
\hline 22 & $\begin{array}{l}\text { National } \\
\text { Association for } \\
\text { Media Literacy } \\
\text { Education } \\
\text { (NAMLE) }\end{array}$ & NGO & $\begin{array}{l}\text { New York, } \\
\text { NY, U.S. }\end{array}$ & $\begin{array}{l}\text { Core } \\
\text { Principles } \\
\text { of Media } \\
\text { Literacy } \\
\text { Education }\end{array}$ & $\begin{array}{l}\text { Media } \\
\text { literacy }\end{array}$ & 2007 & $\begin{array}{c}\text { Michelle } \\
\text { Ciulla Lipkin }\end{array}$ & Source \\
\hline
\end{tabular}




\begin{tabular}{|c|c|c|c|c|c|c|c|c|}
\hline \# & $\begin{array}{l}\text { Framework } \\
\text { Author }\end{array}$ & $\begin{array}{l}\text { Author } \\
\text { Sector(s) }\end{array}$ & $\begin{array}{l}\text { Head- } \\
\text { quarters }\end{array}$ & $\begin{array}{l}\text { Framework } \\
\text { Title }\end{array}$ & $\begin{array}{l}\text { Term(s) } \\
\text { Used }\end{array}$ & $\begin{array}{c}\text { Year } \\
\text { Updated }\end{array}$ & $\begin{array}{c}\text { Point(s) } \\
\text { of Contact } \\
\text { or General } \\
\text { Inquiries } \\
\text { Email }\end{array}$ & $\begin{array}{l}\text { Link to } \\
\text { Referred } \\
\text { Source }\end{array}$ \\
\hline 23 & $\begin{array}{l}\text { National } \\
\text { Coalition for } \\
\text { Core Arts } \\
\text { Standards } \\
\text { (NCCAS) }\end{array}$ & NGO & U.S.-wide & $\begin{array}{l}\text { National } \\
\text { Core Arts } \\
\text { Standards - } \\
\text { Media Arts }\end{array}$ & Media arts & 2014 & Dain Olsen & Source \\
\hline 24 & Netsafe & NGO & $\begin{array}{l}\text { Auckland, } \\
\text { New } \\
\text { Zealand }\end{array}$ & $\begin{array}{c}\text { Defining } \\
\text { Digital } \\
\text { Citizenship in } \\
\text { New Zealand } \\
\text { Education }\end{array}$ & $\begin{array}{c}\text { Digital } \\
\text { citizenship }\end{array}$ & 2018 & $\begin{array}{c}\text { Neil } \\
\text { Melhuish }\end{array}$ & Source \\
\hline 25 & $\begin{array}{c}\text { New South } \\
\text { Wales (NSW) } \\
\text { Department of } \\
\text { Education }\end{array}$ & Government & $\begin{array}{l}\text { Sydney, } \\
\text { New South } \\
\text { Wales, } \\
\text { Australia }\end{array}$ & $\begin{array}{c}\text { Digital } \\
\text { Citizenship }\end{array}$ & $\begin{array}{c}\text { Digital } \\
\text { citizenship }\end{array}$ & 2019 & $\begin{array}{c}\text { DoEinfo@ } \\
\text { det.nsw. } \\
\text { edu.au }\end{array}$ & Source \\
\hline 26 & $\begin{array}{c}\text { PantallasAmi- } \\
\text { gas }\end{array}$ & NGO & $\begin{array}{l}\text { Bilbao, } \\
\text { Spain }\end{array}$ & $\begin{array}{c}\text { Digital } \\
\text { Citizenship }\end{array}$ & $\begin{array}{c}\text { Digital } \\
\text { citizenship }\end{array}$ & 2019 & $\begin{array}{l}\text { Jorges } \\
\text { Flores } \\
\text { Fernandez }\end{array}$ & $\begin{array}{l}\text { Source (All } \\
\text { sub-head- } \\
\text { ings under } \\
\text { "Ciudadanía } \\
\text { Digital" } \\
\text { ("Digital Cit- } \\
\text { izenship")) }\end{array}$ \\
\hline 27 & $\begin{array}{l}\text { Partnership for } \\
\text { 21st Century } \\
\text { Learning (P21) }\end{array}$ & NGO & $\begin{array}{l}\text { Columbus, } \\
\text { Ohio, U.S. }\end{array}$ & $\begin{array}{c}\text { Framework } \\
\text { for } 21 \text { st } \\
\text { Century } \\
\text { Learning }\end{array}$ & $\begin{array}{l}21 \text { st } \\
\text { century } \\
\text { skills }\end{array}$ & 2019 & $\begin{array}{l}\text { thellman@ } \\
\text { battellefork- } \\
\text { ids.org }\end{array}$ & Source \\
\hline 28 & Ribble, Mike & Academia & $\begin{array}{l}\text { Topeka, } \\
\text { Kansas, } \\
\text { U.S. }\end{array}$ & $\begin{array}{c}\text { Nine } \\
\text { Elements } \\
\text { of Digital } \\
\text { Citizenship } \\
\text { and S3 } \\
\text { (Safe, Savvy, } \\
\text { and Social) } \\
\text { Framework }\end{array}$ & $\begin{array}{c}\text { Digital } \\
\text { citizenship }\end{array}$ & 2019 & Mike Ribble & Source \\
\hline 29 & $\begin{array}{c}\text { Singapore } \\
\text { Ministry of } \\
\text { Education } \\
(\mathrm{MoE})\end{array}$ & Government & Singapore & $\begin{array}{l}\text { MoE's Cyber } \\
\text { Wellness } \\
\text { Framework }\end{array}$ & $\begin{array}{c}\text { Cyber } \\
\text { wellness }\end{array}$ & 2018 & $\begin{array}{l}\text { contact@ } \\
\text { moe.gov.sg }\end{array}$ & Source \\
\hline 30 & $\begin{array}{l}\text { Spy Hop } \\
\text { Productions }\end{array}$ & NGO & $\begin{array}{l}\text { Salt Lake } \\
\text { City, Utah }\end{array}$ & Spy Hop Way & $\begin{array}{c}\text { Digital } \\
\text { media arts }\end{array}$ & 2019 & $\begin{array}{l}\text { Kasandra } \\
\text { VerBrugg- } \\
\quad \text { hen }\end{array}$ & Source \\
\hline
\end{tabular}




\begin{tabular}{|c|c|c|c|c|c|c|c|c|}
\hline$\#$ & $\begin{array}{c}\text { Framework } \\
\text { Author }\end{array}$ & $\begin{array}{c}\text { Author } \\
\text { Sector(s) }\end{array}$ & $\begin{array}{l}\text { Head- } \\
\text { quarters }\end{array}$ & $\begin{array}{c}\text { Framework } \\
\text { Title }\end{array}$ & $\begin{array}{l}\text { Term(s) } \\
\text { Used }\end{array}$ & $\begin{array}{c}\text { Year } \\
\text { Updated }\end{array}$ & $\begin{array}{l}\text { Point(s) } \\
\text { of Contact } \\
\text { or General } \\
\text { Inquiries } \\
\text { Email }\end{array}$ & $\begin{array}{l}\text { Link to } \\
\text { Referred } \\
\text { Source }\end{array}$ \\
\hline 31 & $\begin{array}{c}\text { United Nations } \\
\text { Children's Fund } \\
\text { (UNICEF) }\end{array}$ & $\begin{array}{l}\text { International } \\
\text { organization }\end{array}$ & $\begin{array}{c}\text { New York, } \\
\text { NY, U.S. }\end{array}$ & $\begin{array}{c}\text { Digital } \\
\text { citizenship }\end{array}$ & $\begin{array}{c}\text { Digital } \\
\text { citizenship, } \\
\text { Digital } \\
\text { literacy }\end{array}$ & 2017 & $\begin{array}{l}\text { Jasmina } \\
\text { Byrne }\end{array}$ & Source \\
\hline 32 & $\begin{array}{l}\text { United Nations } \\
\text { Educational, } \\
\text { Scientific } \\
\text { and Cultural } \\
\text { Organization } \\
\text { (UNESCO) }\end{array}$ & $\begin{array}{l}\text { International } \\
\text { organization }\end{array}$ & $\begin{array}{l}\text { Paris, } \\
\text { France }\end{array}$ & $\begin{array}{l}\text { Media and } \\
\text { Information } \\
\text { Literacy }\end{array}$ & $\begin{array}{c}\text { Media and } \\
\text { information } \\
\text { literacy }\end{array}$ & 2011 & $\begin{array}{l}\text { Alton } \\
\text { Grizzle } \\
\text { (under } \\
\text { "Contact") }\end{array}$ & Source \\
\hline 33 & $\begin{array}{c}\text { Washington } \\
\text { State } \\
\text { Legislature }\end{array}$ & Government & $\begin{array}{l}\text { Olympia, } \\
\text { Washing- } \\
\text { ton, U.S. }\end{array}$ & $\begin{array}{c}\text { Substitute } \\
\text { Senate } \\
\text { Bill } 6273 \text { - } \\
\text { Washington } \\
\text { State } \\
\text { Legislature }\end{array}$ & $\begin{array}{c}\text { Digital } \\
\text { citizenship, } \\
\text { media } \\
\text { literacy, } \\
\text { Internet } \\
\text { safety }\end{array}$ & 2016 & $\begin{array}{l}\text { Dennis } \\
\text { Small } \\
\text { (under } \\
\text { "Contact In- } \\
\text { formation") }\end{array}$ & Source \\
\hline 34 & World Bank & $\begin{array}{l}\text { International } \\
\text { organization }\end{array}$ & $\begin{array}{l}\text { Washing- } \\
\text { ton, D.C., } \\
\text { U.S. }\end{array}$ & $\begin{array}{c}\text { Digital } \\
\text { Engagement } \\
\text { Evaluation }\end{array}$ & $\begin{array}{c}\text { Digital } \\
\text { citizen en- } \\
\text { gagement }\end{array}$ & 2016 & $\begin{array}{l}\text { Tiago } \\
\text { Peixoto }\end{array}$ & Source \\
\hline 35 & $\begin{array}{c}\text { World } \\
\text { Economic } \\
\text { Forum (WEF) }\end{array}$ & $\begin{array}{l}\text { International } \\
\text { organization }\end{array}$ & $\begin{array}{c}\text { Cologny- } \\
\text { Geneva, } \\
\text { Switzerland }\end{array}$ & $\begin{array}{l}\text { 21st-Century } \\
\text { Skills }\end{array}$ & $\begin{array}{l}\text { 21st- } \\
\text { century } \\
\text { skills }\end{array}$ & 2015 & $\begin{array}{c}\text { contact@ } \\
\text { weforum. } \\
\text { org }\end{array}$ & Source \\
\hline
\end{tabular}




\section{APPENDIX B}

This Appendix B provides the initial, full list of 40 areas of life connected to the digital world our YaM team developed - in the context of our framework mapping (see part III, section 1 of this paper) - in collaboration with Berkman Klein Center fellows, staff, and summer interns. We ultimately reduced this list to 17 areas of life, provided in part III, section 2 (our "digital citizenship+ (plus)" framework).

1. Digital Divide: Acknowledgment of the digital divide in terms of Internet access, basic digital literacy, and frequency and intensity of Internet use, and the implications of this divide with respect to inclusion and inequality.

2. Connectivity: Knowing how to connect to and access the Internet, individually or collectively (e.g., mesh technologies, wi-fi sharing).

3. Information Literacy: The ability to locate, evaluate (the quality of), and effectively use information from online sources.

4. Media and Digital Literacy: The ability to engage in an array of activities needed for full participation in our media-saturated, information-rich society, including the capacity to analyze media messages; engage in participatory action; create content online; and locate and share information in a responsible way.

5. Attention Economy: The understanding that Internet use happens within an environment where one's attention is a currency and commodity. This area also includes the skills needed to consume and distribute information in a more efficient way, and the ability to produce influential content.

6. Storytelling: The ability to tell stories (combining digital and physical resources) in an engaging way.

7. Online Broadcasting: The ability to create systematic but decentralized communication channels to spread content under the one-to-many model, live or pre-recorded.

8. Influence Capacity: The capacity to produce and distribute content with the support of digital tools to maximize one's potential influence.

9. Data: Understanding how companies (e.g., Facebook, Google) collect and analyze one's data, and understanding data analytics tools and methods. Part of data encompasses the understanding of big data (i.e., understanding the positive and negative implications of massive data gathering, centralization, and analysis).

10. Artificial Intelligence and Algorithms: Understanding of the Al systems one encounters, the algorithms involved in the platforms one interacts with, and the ethical conversations happening around the development of these technologies.

11. Identity Building: The knowledge and tools to use digital technologies to explore elements of one's own identity, examine how one's identity is shared and shaped by others, and the capacity to leverage these technologies to freely express one's identity.

12. Belonging and Affiliation: The ability to create or join online or offline communities of interest using digital technologies.

13. Agency: The process of developing the knowledge, skills, and motivation to pursue one's goals and/or solve personal or collective problems by taking action and responsibility.

14. Purpose: The understanding of how to use digital tools to work towards fulfilling one's personal purpose(s). 
15. Leadership: Using digital technologies to organize groups of people around a common goal, communicate and manage tasks effectively, and establish and promote trust.

16. Healthy Relationships: The ability to engage in healthy relationships with others (both romantic- and friendship-based relationships), in-person and through digital platforms, by creating and maintaining 1) effective communication patterns, and 2) respect for each other.

17. Digital Contributions: The motivation to engage in active contributions to digital spaces (i.e., "Leave Your Mark").

18. Digital Wellness: Understanding how to protect one's physical and psychological well-being in an online world (e.g., guarding against Internet addiction, and repetitive stress syndrome).

19. Privacy: The knowledge and skills to handle personal information shared online with discretion, and the ability to protect the privacy of both self and peers.

20. Digital Footprint: The capacity to manage one's digital reputation responsibly, and the awareness of both the short- and long-term effects of one's digital footprint.

21. Offline Social Awareness: The ability to appropriately interpret situations and maintain interpersonal abilities when interacting with others face-to-face while in the presence of digital technologies.

22. Law and Regulation: Knowledge of the legal frameworks surrounding the Internet and other digital tools (e.g., copyright, fair use).

23. Digital Rights and Responsibilities: Knowledge of the rights and responsibilities involved in the use of digital technologies (e.g., reporting instances of abuse, acknowledgement of copyright).

24. Freedom of Expression: An understanding of concepts such as illegitimate surveillance, filtering, and censorship, and how to interact with these issues.

25. Netiquette: Digital good manners or observance of informal codes of conduct to make the Internet inclusive, usable, useful, amicable, and peaceful.

26. Safety: The knowledge and ability needed to counteract the risks that digital tools present to protect one's physical and mental integrity.

27. Security: The knowledge and ability needed to protect the integrity of one's information, IT systems, and digital assets.

28. Activism, Advocacy, and Organizing: Using digital technologies to advance a collective cause. This encompasses the capacity to create public narratives that are capable of mobilizing support around specific themes (e.g., LGBTQ rights, peace building, addressing hate speech).

29. Collective Action: Gathering community support/materials online for a project or cause (e.g., crowdsourcing, crowdfunding, volunteering).

30. Digital Tools for Rights: The use of digital technologies to actively protect fundamental human rights (e.g., freedom of expression).

31. Cultural/global Competence: Awareness of cultural nuances, and regional differences that exist in other parts of the world, and the ability to empathize and work well online with others from various cultures/ backgrounds. 
32. Power Relationships: Understanding power relationships/structures in society and how digital technologies are capable of counteracting or changing these (e.g., access to knowledge, social mobility).

33. Social Entrepreneurship and Innovation (Public Problem-solving): Use of digital technologies to foster entrepreneurship to solve local problems.

34. Sharing of Informal Expertise: Awareness of one's informal expertise in a specific topic and the skills to share that expertise in a digital space (e.g., video tutorials).

35. Digital Economy: Knowing how to navigate the digital economy as either a consumer or producer.

36. Civic Engagement: Knowing how to participate and/or take action to promote the quality of life in one's community, from micro to macro levels.

37. E-government: The ability to access and use online services and information provided by the government.

38. Politics and Democratic Behavior: The ability to engage in democratic behaviors using digital technologies (e.g., online voting).

39. Online Participation Skills: The awareness and use of digital tools to convey opinions and requests to the government, or voice one's opinion in general online collective spaces (e.g., participatory budgeting, online petitions).

40. Internet Governance: Knowledge of the institutions, models, and infrastructures that govern the Internet. 


\section{APPENDIX C}

This Appendix C provides a subset of photos from our team's exercise with Berkman Klein fellows, staff, and summer interns around grouping proposed areas of life connected to the digital world under overarching umbrella headings (such as "the engaged Internet," "the interpersonal Internet," etc.), with images grouped by Berkman Klein community member. This exercise was conducted in the context of our framework mapping (see part III, section 1 of this paper).

Exercise instructions:

1. Look over the 40 terms and definitions related to digital citizenship.

2. Divide the terms into approximately five groups (ideally of similar size), each based on a common theme or characteristic, and name the groups.

3. For each of your thematic groups, rank the terms you have placed within it from most to least important.

4. Glue these ranked lists to your poster board/sheet of paper and label the groups.

\section{Person \#1 - YaM Research Assistant}


Organizing

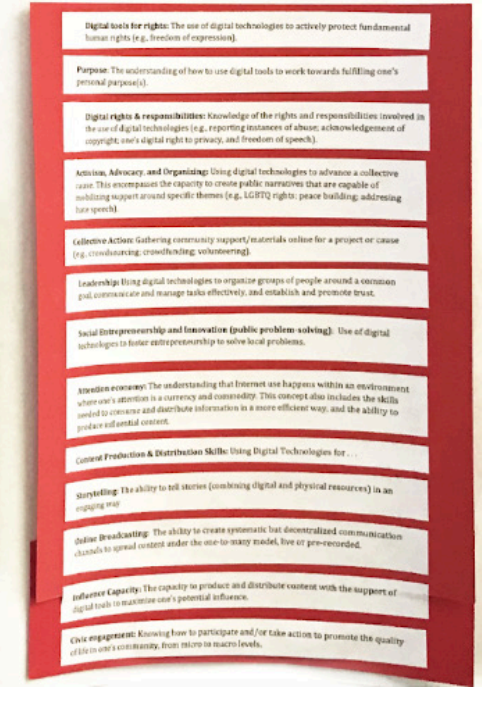




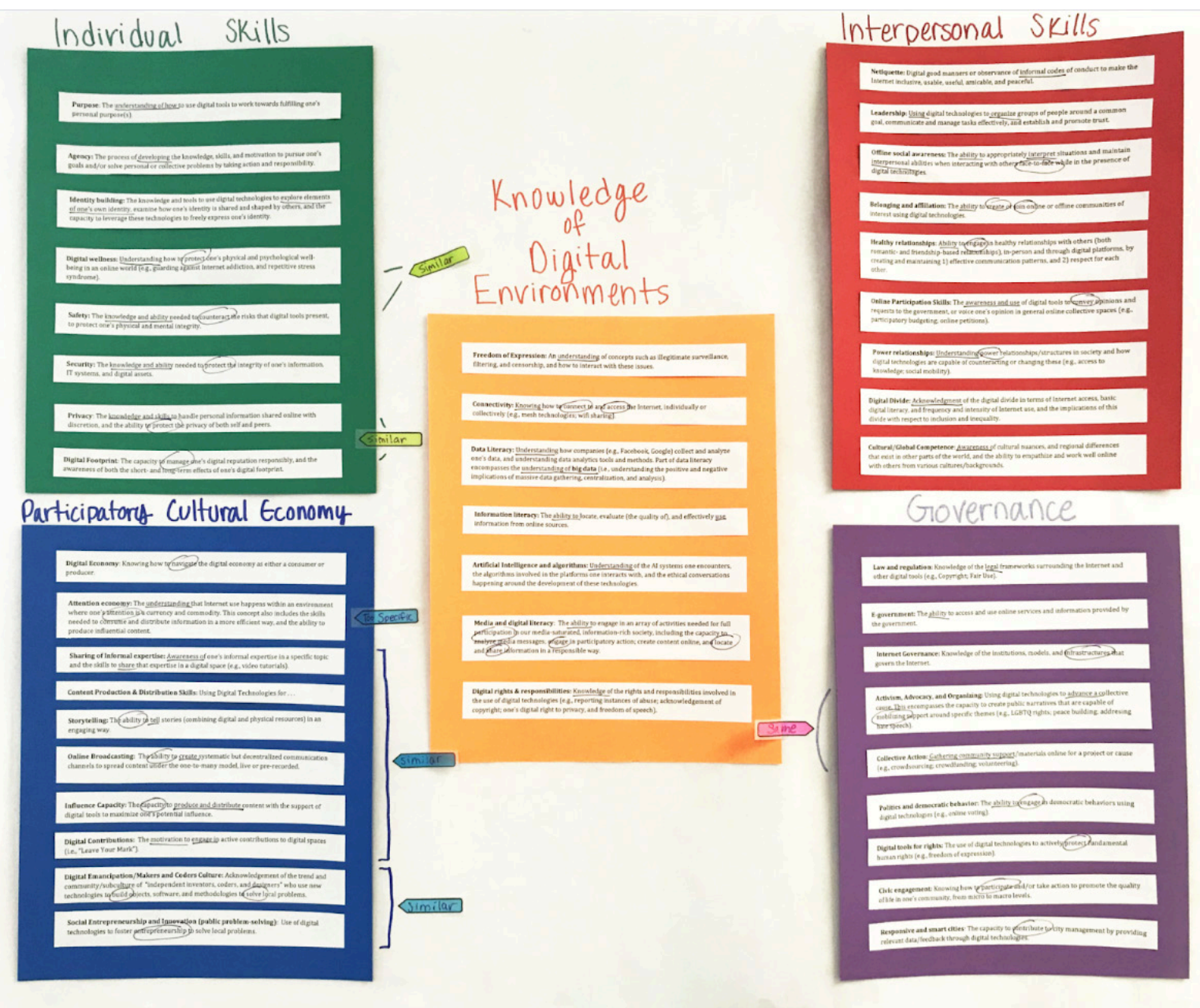




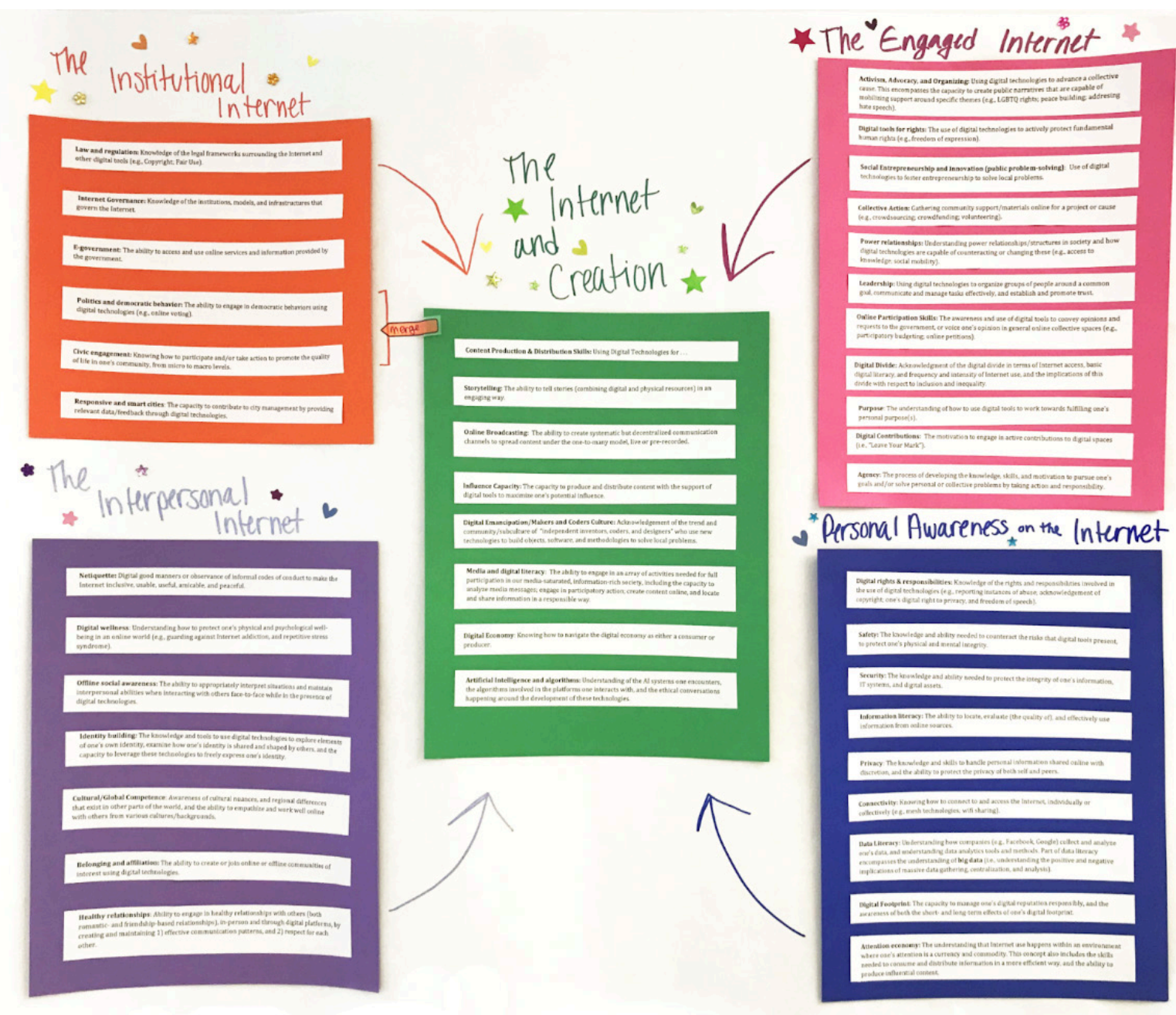




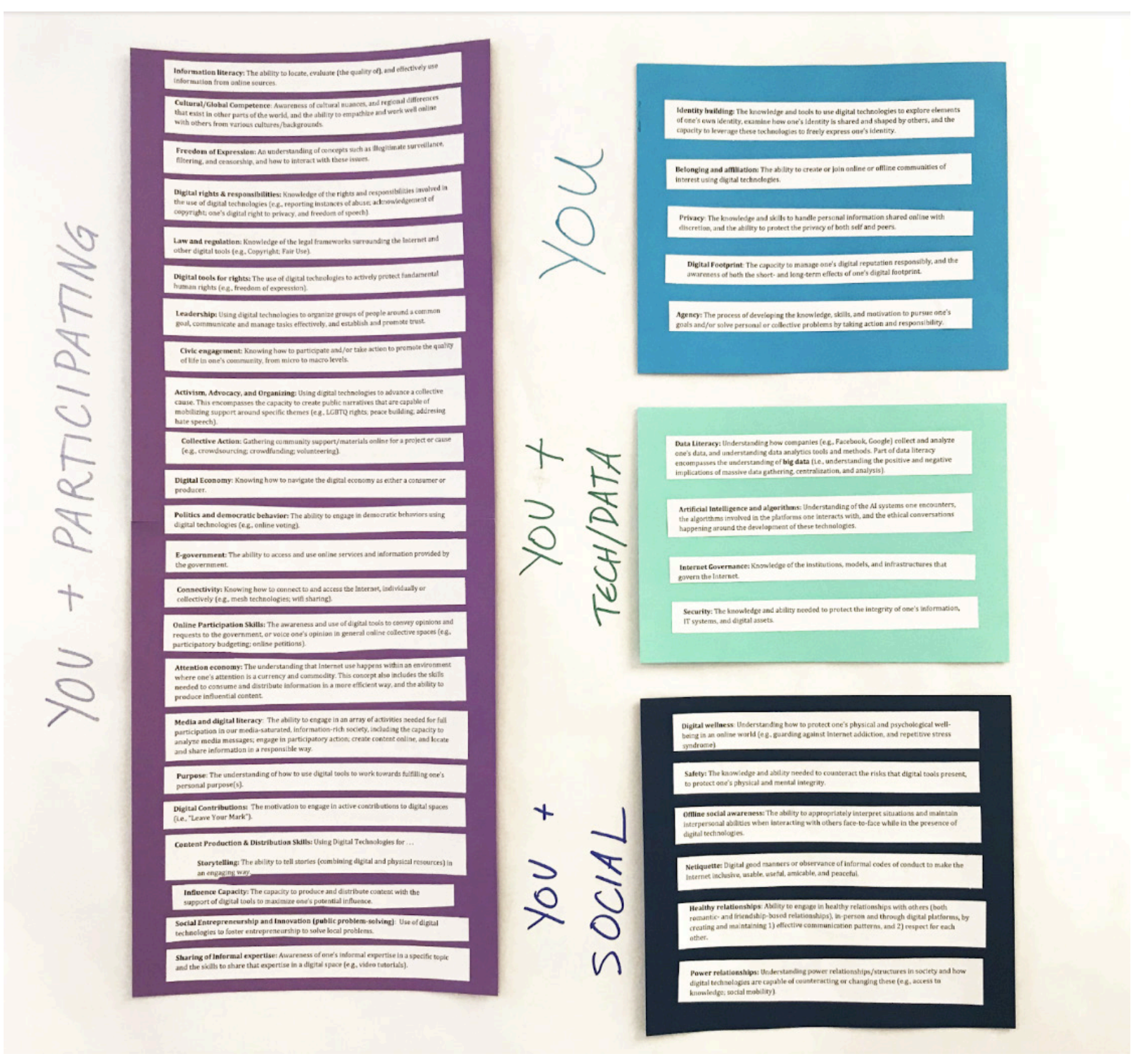




\section{APPENDIX D}

\section{Table 2}

K-12 Grades And Approximate Corresponding Ages In U.S. Education

\begin{tabular}{|c|c|c|c|}
\hline Educational Level & School type & Grade & $\begin{array}{l}\text { Age } \\
\text { (approx.) }\end{array}$ \\
\hline \multirow[t]{6}{*}{ Primary Education } & \multirow[t]{6}{*}{ Elementary School } & Kindergarten & $5-6$ \\
\hline & & 1 & $6-7$ \\
\hline & & 2 & $7-8$ \\
\hline & & 3 & $8-9$ \\
\hline & & 4 & $9-10$ \\
\hline & & 5 & $10-11$ \\
\hline \multirow[t]{7}{*}{ Secondary Education } & \multirow[t]{3}{*}{ Middle (Junior High) School } & 6 & $11-12$ \\
\hline & & 7 & $12-13$ \\
\hline & & 8 & $13-14$ \\
\hline & \multirow[t]{4}{*}{ High School } & 9 & $14-15$ \\
\hline & & 10 & $15-16$ \\
\hline & & 11 & $16-17$ \\
\hline & & 12 & $17-18$ \\
\hline \multirow{5}{*}{$\begin{array}{l}\text { Post-secondary (Tertiary) } \\
\text { Education }\end{array}$} & \multirow[t]{4}{*}{ College/Undergraduate[i] } & Freshman & $18-19$ \\
\hline & & Sophomore & $19-20$ \\
\hline & & Junior & $20-21$ \\
\hline & & Senior & $21-22$ \\
\hline & $\begin{array}{l}\text { Graduate or Professional } \\
\text { School[ii] }\end{array}$ & (Varies) & $22+$ \\
\hline
\end{tabular}

Primary and secondary education are compulsory, and are referred to collectively as "K-12 [K through 12] education;" after this, ages typically become more variable.

[i] In the U.S. context, college is a noun referring to the institution, either a stand-alone institution or as a constituent of a larger university, but is also used as an adjective as in "college education," "college degree," and "college students." Undergraduate refers to the student, but may also be used as an adjective in "undergraduate education," "undergraduate degree," and "undergraduate institution." Despite formal redundancy, the phrase "undergraduate students" is also common usage. The typical undergraduate degree is the four-year bachelor's degree, but some institutions such as community colleges and junior colleges award the two-year associate's degree, considered the equivalent of the first two years of a bachelor's degree course. Note that in the United States, unlike many other countries, a professional degree (mainly, the four-year M.D. medical degree and the three-year J.D. legal degree) is an advanced degree obtained after the undergraduate degree. Master's degree programs are also not typically offered as part of college education, and require a separate application process and admission with a bachelor's degree as a prerequisite.

[ii] High school grades are numbered, but the terms freshman, sophomore, junior, and senior are also frequently used. If educational level is not clear in context, these terms will be proceeded by "high school" or "college," as in "high school sophomore" and "college sophomore"). 
